\title{
Predicción del inicio de la temporada de polinización del plátano de sombra en la Comunidad de Madrid y en la ciudad de Córdoba. Técnicas y resultados
}

\section{Nota técnica digital 1 de Biometeorología}

\author{
Coordinador: \\ José Luis Camacho Ruiz ${ }^{(1)}$ \\ Autores (por orden alfabético): \\ Inmaculada Cadenas Cortina (2) \\ José Luis Camacho Ruiz (1) \\ Darío Cano Espadas (3) \\ Patricia Cervigón Morales (4) \\ Adela Montserrat Gutiérrez Bustillo ${ }^{(5)}$ \\ Javier Subiza Garrido-Lestache ${ }^{(6)}$
}

(1) Dirección de Planificación, Estrategia y Desarrollo Comercial (DPEDC), AEMET

(2) Departamento de Desarrollo y Aplicaciones (DDA), Dirección de Producción e Infraestructuras (DPI), AEMET

(3) Delegación Territorial en Madrid, AEMET

(4) Red Palinológica de la Comunidad de Madrid (PALINOCAM), Consejería de Sanidad

(5) Red PALINOCAM, Universidad Complutense de Madrid (UCM)

(6) Red PALINOCAM, Clínica Subiza 


\section{Agradecimientos}

Este trabajo ha sido posible en el marco del convenio de cooperación entre la Consejería de Sanidad de la Comunidad Autónoma de Madrid y la Agencia Estatal de Meteorología. Agradecemos la colaboración recibida tanto desde el Servicio de Sanidad Ambiental de dicha Consejería como de la Delegación Territorial de Madrid de AEMET así como el apoyo recibido por el último titular de la extinta Subdirección General de Climatología y Aplicaciones que propulsó de manera decidida la cooperación entre instituciones y el intercambio de información.

De manera muy destacada también queremos expresar nuestro agradecimiento a todos aquellos que con su esfuerzo logran que existan datos polínicos y meteorológicos día a día y en particular a la Dra. Carmen Galán de la Universidad de Córdoba que ha proporcionado los datos de polen de plátano de dicha ciudad.

(C) Ministerio de Medio Ambiente, y Medio Rural y Marino

Agencia Estatal de Meteorología

Madrid, 2009

Catálogo de Publicaciones de la Administración General del Estado:

https://cpage.mpr.gob.es/

NIPO: 784-09-018-5

https://doi.org/10.31978/784-09-018-5

Agencia Estatal de Meteorología (AEMET)

C/ Leonardo Prieto Castro, 8

28040 Madrid

http://www.aemet.es/

@Aemet_Esp

https://www.facebook.com/AgenciaEstataldeMeteorologia 


\section{Prólogo por Ana $M^{a}{ }^{a}$ Casals Carro, Delegada Territorial de AEMET en Madrid}

Esta Nota Técnica es el resultado de un trabajo interdisciplinar en el que cabe destacar la colaboración entre meteorólogos, biólogos y médicos, con un objetivo final muy concreto: mejorar la calidad de vida de las personas aquejadas por problemas de alergia. Esperamos que sea el inicio de una larga colaboración entre la meteorología y otras disciplinas, para incrementar la calidad de vida de la población y optimizar el sistema sanitario.

Con el fin de avanzar en el conocimiento de todos los aspectos ligados a la emisión de polen de plátano en primavera, poder así mejorar el actual sistema de vigilancia de dicho polen y optimizar los recursos del sistema sanitario, han colaborado AEMET, que ha aportado su banco de datos de variables meteorológicas para diferentes horas y distintos emplazamientos, y la Consejería de Salud de la Comunidad de Madrid, que ha proporcionado los recuentos de polen diarios de la red Palinocam (red de la comunidad de Madrid).

El objetivo de esta colaboración ha sido avanzar en el conocimiento de todos los aspectos ligados a la emisión del polen del plátano para poder predecir con antelación suficiente su aparición en la primavera. Las razones por la que se ha escogido esta especie son múltiples y variadas, en primer lugar porque hay datos de recogida de polen de plátano desde 1982. El plátano es un árbol urbano, por tanto se riega y la aparición del polen, debido al riego, solamente se correlaciona con la variable temperatura.

Sería deseable que este trabajo se ampliara con el estudio de la incidencia en la calidad de vida de los pacientes con alergia a este tipo de polen, una vez que éstos dispongan de antemano de la información sobre cuándo se va a producir su aparición.

Una vez que la información meteorológica está disponible para la toma de decisiones, parece aconsejable implicar a los Ayuntamientos para que colaboren en su difusión a la población y para que la eduquen en la interpretación de los datos ofrecidos, preferentemente haciendo uso de Internet. Esto no es óbice para que dicha información no pudiera aparecer también en otras páginas públicas, como la de la propia AEMET en sus espacios dedicados a calidad del aire y a los efectos de la meteorología sobre la salud.

Es lógico pensar que a este estudio le seguirán otros sobre el polen de olivos y de gramíneas, tema mucho más complicado ya que, además de la temperatura, intervienen otros factores en correlación con la aparición del polen, como son, viento, advección térmica y lluvia. Se abre, por tanto, un camino de estudios y desarrollos que permitirán poner a disposición del usuario productos de fácil acceso y de gran utilidad a la hora de planificar sus actividades y de aumentar su calidad de vida. Las predicciones estacionales se podrán utilizar en el futuro para adelantar a los pacientes esta predicción un mes. 
Finalmente, resulta obligado, a la vista del resultado de la presente iniciativa, recomendar al máximo la promoción de este tipo de colaboraciones interdisciplinares relacionadas con la meteorología y su aplicación a la mejora de la calidad de vida, en cumplimiento con la misión asignada a la Agencia Estatal de Meteorología. 


\section{ÍNDICE}

\section{INTRODUCCIÓN. OBJETIVOS. DATOS UTILIZADOS}

\section{GENERALIDADES DEL TIPO POLÍNICO PLATANUS}

2.1. Platanus Hispanica Miller ex Münchh: caracteres botánicos

2.2. Aerobiología de Platanus en España

2.3. Aerobiología de Platanus en Madrid

2.4. Observaciones fenológicas (años 2008-2009)

\section{ASPECTOS MÉDICOS}

3.1. Polinosis por platanus hispánica

3.2. Alérgenos y reactividad cruzada

4. ASPECTOS TÉCNICOS E INSTITUCIONALES DE LA VIGILANCIA DEL POLEN EN LA ATMÓSFERA DE MADRID. RED PALINOCAM

4.1. Introducción

4.2. La Red Palinológica de la Comunidad de Madrid y la Red Española de Aerobiología: RED PALINOCAM Y REA

4.2.1. Funcionamiento de la REA

5. RELACIÓN ENTRE PARÁMETROS METEOROLÓGICOS Y EL INICIO DE LA TEMPORADA DE POLINIZACIÓN

5.1. Determinación de la cantidad diaria umbral para determinar el inicio de la temporada

5.2. Relación estadística entre calor acumulado y fecha de inicio

5.3. Estudios series PalinoCAM. 1994.2007

5.4. Evaluación de los modelos de predicción según umbrales. Resultados

6. METODO DE PREDICCIÓN. EJEMPLO DE MARZO 2008 y 2009

6.1. Descripción del método

6.2. Aplicación a los años 2008 y 2009

6.3. Conclusión

7. DESCRIPCION DEL MÉTODO DE PRONÓSTICO DE TEMPERATURAS MÁXIMAS Y MÍNIMAS

7.1. Introducción al sistema de predicción por conjuntos (EPS)

7.2. Temperaturas máximas y mínimas a partir del EPS 
8. EVALUACIÓN DEL MÉTODO PARA OTROS OBSERVATORIOS DE LA COMUNIDAD DE MADRID Y PARA CÓRDOBA

8.1 Estaciones próximas a Madrid

8.2 El caso de Aranjuez

8.3 Cambios en umbral: el caso de Córdoba

9. CONCLUSIONES Y PROPUESTA DE ESQUEMA DE OPERACIÓN 


\section{INTRODUCCIÓN. OBJETIVOS. DATOS UTILIZADOS}

\section{José Luis Camacho. AEMET}

El plátano de sombra es una especie de árbol frecuente en las ciudades españolas, en jardines o en calles, debido a su porte y capacidad para proporcionar sombra, En la comunidad de Madrid está ampliamente extendido destacando sus alineaciones en las grandes avenidas de la capital o en la ciudad de Aranjuez. Información más detallada sobre la biología de este árbol tan común se proporciona en el capítulo 2.

Sin embargo, y tal y como ocurre con otros árboles o arbustos ornamentales, su polen ocasiona reacciones alérgicas a un segmento notable de la población. Estas reacciones alérgicas frente a la presencia de dicho polen en la atmósfera van desde la rinitis, estornudos, enrojecimiento y picazón de la piel hasta, finalmente, dificultades respiratorias que pueden llegar a manifestarse como episodios de asma con necesidad de hospitalización del paciente. Las cifras de impacto de dicho polen en la población varían según los diferentes estudios y los lugares como se verá en el capítulo 3. En particular, se mencionan estudios médicos realizados sobre pacientes en la Comunidad de Madrid que indican que cantidades relativamente pequeñas de polen pueden ocasionar síntomas de alergia en los pacientes.

Además, las cantidades diarias de polen de plátano en el aire experimentan un aumento muy grande en su fase inicial y en muy poco días. Los aspectos estadísticos de la distribución de las cantidades diarias de dicho polen y su relación con factores meteorológicos se tratan en el capítulo 5.

Las cantidades diarias de polen en la comunidad de Madrid son monitorizadas mediante una red de estaciones en las que se encuentran captadores que son gestionados diariamente por una red de colaboradores coordinados por la Red PalinoCAM. La descripción de los métodos, los aspectos institucionales a nivel de Comunidad de Madrid, de España y de Europa así como la información que proporciona al público se trata con detalle en el capítulo 4.

El objetivo de este trabajo es avanzar en el conocimiento interdisciplinar de todos los aspectos ligados a la emisión de polen de plátano en una determinada época del año para poder mejorar el actual sistema de vigilancia y pronóstico de dicho polen, en especial, el inicio de la temporada de polinización. Dicho conocimiento, expresado en estas páginas puede proporcionar a los gestores del sistema sanitario, información útil para optimizar sus recursos y para aliviar las consecuencias sobre el segmento de población que sufre de alergia a este polen. La descripción de los avances realizados para lograr un pronóstico de la fecha de inicio de la temporada de polen de plátano para la ciudad de Madrid y alrededores con la suficiente antelación se hace en el capítulo 6.

Los aspectos técnicos del método de predicción de las temperaturas máximas y mínimas basado en la Predicción por Conjuntos del Centro Europeo de Predicción del Tiempo a Plazo Medio se describen en el capítulo 7. La extensión de los pronósticos a otras áreas de la Comunidad de Madrid o a la ciudad de Córdoba y las particularidades o los problemas encontrados se describen en el capítulo 8. Finalmente, las conclusiones y una propuesta de método operacional para realizar dicho pronóstico se escriben en el capítulo 9. 
La temporada de polinización del plátano depende de las características geográficas y meteorológicas del lugar. En el sur de la Península, se inicia antes. Exceptuando la sierra, en la Comunidad de Madrid, se puede considerar genéricamente marzo como el mes de inicio aunque en algunos años se ha retrasado a abril.

Se han construido una base de datos mediante hojas de cálculo Excel a partir de las series de datos meteorológicos de Madrid-Retiro (periodo 1980 a 2007), Cuatro Vientos, Getafe Base Aérea, Torrejón Base Aérea, Barajas Aeropuerto (periodo 19932008). A esto hay que añadir la serie de datos meteorológicos del aeropuerto de Córdoba entre 1993 y 2008. Las variables meteorológicas consideradas han sido temperaturas extremas y medias diarias, precipitación diaria, insolación diaria, recorrido de viento diario, humedad relativa a las 00, 07, 13 y 18 horas. Esta información procede del Banco de Datos de AEMET. La información aportada por la Consejería de Salud de la Comunidad de Madrid consiste en las series de datos de recuentos de polen diarios de la Red Palinocam entre 1997 y 2007. Las estaciones están situadas en, Alcalá de Henares, Alcobendas, Getafe, Facultad de Farmacia (Ciudad Universitaria), General Pardiñas (Madrid), Leganés, Aranjuez y Coslada 


\section{GENERALIDADES DEL TIPO POLÍNICO PLATANUS}

\section{Dr. A. M. Gutiérrez Bustillo. Profesora Titular de Botánica. Departamento de Biología Vegetal II. Facultad de Farmacia. Universidad Complutense de Madrid.}

Al tipo polínico Plátanus se adjudican los granos de polen producidos por las distintas especies del género que incluye unas 6-7 especies de grandes árboles caducifolios, que viven en las zonas de clima templado del hemisferio norte. En nuestras ciudades, la especie más frecuente es Platanus hispanica Miller ex Münchh "plátano de paseo o plátano de sombra", profusamente cultivado en parques, jardines y formando alineaciones en paseos y carreteras. No se conoce en estado espontáneo, pero puede aparecer asilvestrado en sotos y riberas, sobre suelos frescos y fértiles. Otros nombres vulgares: cat.: plàtan; eusk.: platano arrunta, alboa; gall.: pradeiro

\subsection{Platanus hispanica Miller ex MÜnChH: CaRaCteres botánicos}

Porte: Árbol caducifolio, muy robusto, que puede sobrepasar los $30 \mathrm{~m}$ de altura. Tronco grueso y recto, fácil de reconocer por su aspecto, con grandes manchas de color blanquecino o amarillento, originadas por el desprendimiento de placas de la corteza. Hojas: alternas, palmeadas con 3-5(7) lóbulos ovado-triangulares, que llegan hasta casi la mitad de la lámina. Margen entero o con dientes irregulares y gruesos. Inflorescencias: unisexuales, globosas y agrupadas sobre largos pedúnculos. Las masculinas, más pequeñas y de color verde amarillento, se desarrollan algo antes que las femeninas, que aparecen al mismo tiempo que las hojas, son mayores y de color verderojizo. Flores: Unisexuales pequeñas y poco vistosas, con cáliz y corola de piezas pequeñas, escamosas, las masculinas con 3-8 estambres de filamentos muy cortos y las femeninas con 3-9 carpelos envueltos en la base por un penacho de pelos y rematados por un estilo largo y rojizo.

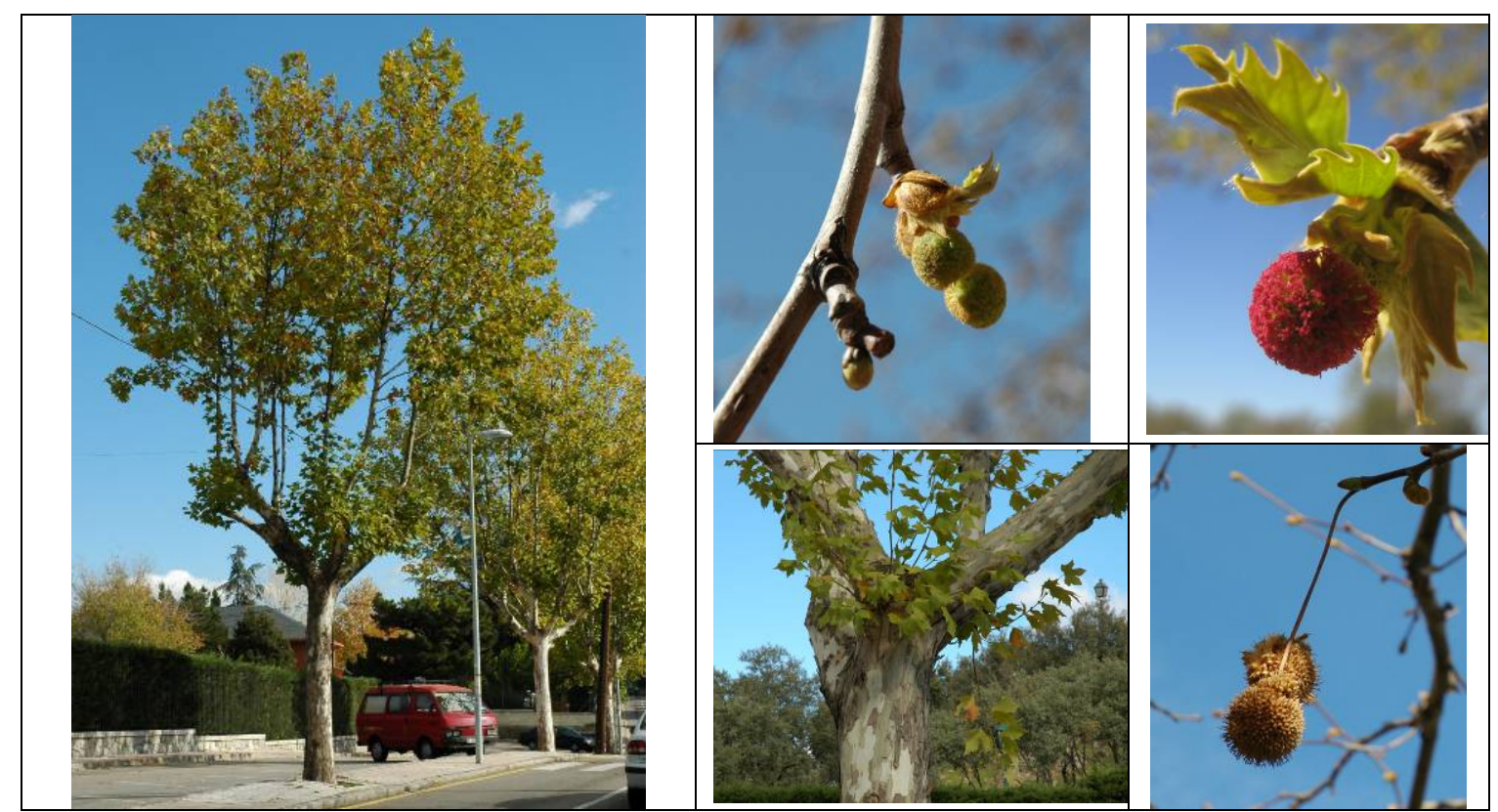

Figura 2.1.1. Platanus hispanica Miller ex Münchh. Porte del árbol; grupos de inflorescencias masculinas; inflorescencias femeninas rojizas; aspecto de la corteza; cabezuelas de frutos maduros. 
Frutos: son aquenios coriáceos, claviformes, con pelos rígidos, de color pardo en su base, que maduran al final del verano o en otoño; aparecen reunidos en cabezuelas esféricas, que pueden permanecer en el árbol hasta la primavera siguiente. Distribución y ecología: Los plátanos de sombra o de paseo son árboles originarios del mediterráneo oriental, sudeste de Europa y oeste de Asia. Muy cultivados en Europa occidental y comunes en casi toda España, excepto en zonas muy secas o de clima muy frío. Presentes desde muy antiguo en numerosas ciudades españolas, son frecuente en parques, plazas, calles y paseos y alineaciones a lo largo de las carreteras. Toleran bien las podas drásticas y la contaminación atmosférica urbana.

Morfología polínica: el polen es isopolar, radiosimétrico, oblato-esferoidal en vista ecuatorial, subcircular a subtriangular en vista polar, planaperturado. De tamaño pequeño, el eje mayor mide de 17 a 22 micras. Trizonocolpado, colpos anchos con la membrana apertural granulada. La exina de aproximadamente 2 micras de grosor, reticulada, con lúmenes pequeños e irregulares y muros de superficie granulosa.

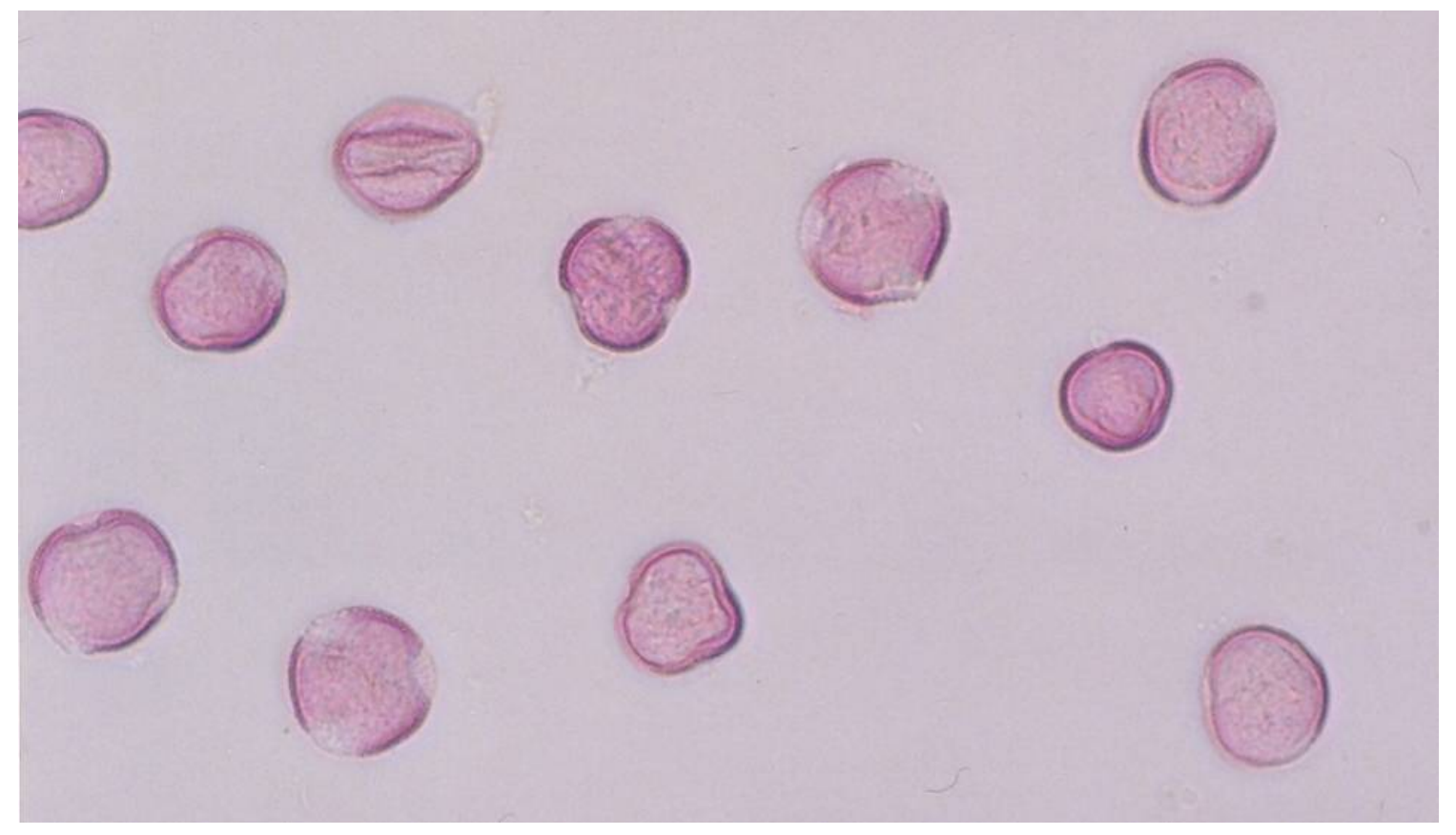

Figura 2.1.2. Aspecto de una preparación de granos de polen de Platanus, teñida con fucsina, al Microscopio Óptico (M.O.).

\section{Polinización y dispersión:}

Florece en la segunda quincena de marzo o la primera de abril. De polinización anemófila y elevada producción polínica, estimada en $21 \times 10^{6}$ granos de polen por inflorescencia (TORMO \& al., 1996).

\section{2 Aerobiología de Platanus en España}

El polen de Platanus está presente en la atmósfera de toda España durante un periodo muy corto, que generalmente comprende el mes de marzo y la primera quincena de abril. Algunos años puede hacer acto de presencia en los últimos días de febrero, y en ciudades como Barcelona su época de presencia atmosférica se alarga hasta mayo, junio o incluso más. La información aerobiológica a nivel nacional y regional (Díaz de la 
Guardia et al., 2000; Gabarra et al., 2002), pone de manifiesto grandes diferencias en la incidencia de este tipo polínico, así en Barcelona, Madrid y Sevilla, es el tipo polínico mayoritario o casi, mientras que en Almería, Cartagena, Cádiz, Málaga, Oviedo, las cantidades son tan bajas, que simplemente nos indican su presencia en la época correspondiente.

El periodo de máxima incidencia atmosférica del polen de Platanus es de unos pocos días, ya que su periodo floración también es corto. Por ello no suele haber más de diez días al año con concentraciones superiores a 100 granos $/ \mathrm{m}^{3}$. Las concentraciones medias diarias pueden alcanzar cifras muy elevadas, superándose en muchas ocasiones los 1000 granos de polen $/ \mathrm{m}^{3}$ de aire.

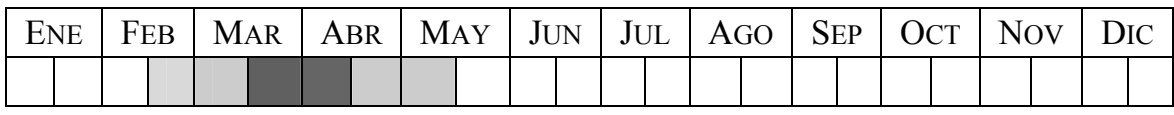

Fig. 2.2.1. Periodo de presencia atmosférica de Platanus en España.

\begin{tabular}{|c|c|c|c|c|c|}
\hline Comunidad & Localidad & Años & Promedio & Máximo & Mínimo \\
\hline \multirow[t]{8}{*}{ Andalucía } & Sevilla & $1995-2001$ & 12542 & 23078 & 3448 \\
\hline & Málaga & $1995-2001$ & 376 & 546 & 271 \\
\hline & Jaén & $1995-2001$ & 1207 & 2888 & 250 \\
\hline & Huelva & $1995-2001$ & 421 & 779 & 112 \\
\hline & Granada & 1995-2001 & 1543 & 2000 & 1055 \\
\hline & Córdoba & $1995-2001$ & 6816 & 10951 & 1332 \\
\hline & Cádiz & $2000-2001$ & 111 & 151 & 71 \\
\hline & Almería & $1998-2001$ & 96 & 195 & 35 \\
\hline Valencia & Burjassot & 1998-2001 & 582 & 816 & 87 \\
\hline Murcia & Cartagena & $1995-2001$ & 175 & 359 & 69 \\
\hline \multirow[t]{2}{*}{ Extremadura } & Cáceres & 1996-2001 & 1131 & 1546 & 427 \\
\hline & Badajoz & $1995-2000$ & 807 & 1092 & 425 \\
\hline Castilla-La Mancha & Ciudad Real & $1997-2001$ & 3346 & 6015 & 1529 \\
\hline Madrid & Ciudad Universitaria & $1995-2001$ & 15321 & 28196 & 4892 \\
\hline \multirow[t]{4}{*}{ Cataluña } & Tarragona & $1997-2001$ & 1444 & 1691 & 1310 \\
\hline & Lérida & $1997-2001$ & 1501 & 1943 & 909 \\
\hline & Gerona & 1997-2001 & 3027 & 4828 & 1514 \\
\hline & Barcelona & $1995-2001$ & 22946 & 25785 & 15818 \\
\hline Aragón & Zaragoza & 1995-2001 & 4283 & 6620 & 1616 \\
\hline Castilla y León & León & 1995-2001 & 1174 & 2527 & 97 \\
\hline Asturias & Oviedo & 1998-2001 & 687 & 1774 & 14 \\
\hline \multirow[t]{5}{*}{ Galicia } & Vigo & $1995-2001$ & 626 & 1356 & 191 \\
\hline & Orense & 1995-2001 & 1086 & 2225 & 203 \\
\hline & Lugo & 1999-2001 & 30 & 49 & 13 \\
\hline & Santiago de Compostela & 1995-2001 & 935 & 2445 & 198 \\
\hline & La Coruña & 1999-2001 & 39 & 49 & 22 \\
\hline
\end{tabular}

Tabla 2.2.2. Datos aerobiológicos de Platanus en España. Estaciones, años considerados y valores promedio, máximo y mínimo del total anual de polen en ese periodo. Elaborada a partir de los datos publicados en los Boletines de la Red Española de Aerobiología, REA vols. 3-7. 


\section{3. Aerobiología de Platanus en Madrid}

A partir de la información aerobiológica generada por la RED PALINOCAM hemos elaborado una serie de tablas y gráficas (incluidas en el anexo), que nos informan sobre la dinámica atmosférica del tipo polínico Platanus en la región de Madrid.

En la Comunidad de Madrid, el polen de Platanus puede estar presente en la atmósfera, en concentraciones significativas, durante el periodo comprendido entre el 5 de marzo y el 30 de abril.

Si consideramos las concentraciones medias diarias (granos de polen $/ \mathrm{m}^{3}$ de aire) y el polen total anual (PTA, total granos de polen/año)) observamos grandes diferencias espaciales (estaciones de muestreo) e interanuales. Considerando los valores mínimo, máximo y promedio del PTA para todo el periodo (1994-2008) podemos separar las estaciones en tres grupos (Incidencia alta, media o baja).

\begin{tabular}{|l|r|r|r|r|}
\hline Incidencia ALTA & PTA min.-PTA max. & Promedio & $\%$ & [ ] min.-max. \\
\hline Alcalá de Henares & $1731-53273$ & 22811 & 35,30 & $320-12917$ \\
\hline Ciudad Universitaria & $912-28196$ & 10536 & 23,37 & $156-4936$ \\
\hline Barrio de Salamanca & $1702-17400$ & 9426 & 22,81 & $75-4265$ \\
\hline Aranjuez & $1395-22219$ & 9255 & 23,30 & $279-3757$ \\
\hline Incidencia MEDIA & & & & \\
\hline Getafe & $851-14550$ & 6356 & 18,90 & $103-2043$ \\
\hline Leganés & $681-8210$ & 3457 & 14,59 & $142-1285$ \\
\hline Incidencia BAJA & & & & \\
\hline Coslada & $184-3901$ & 1744 & 3,99 & $28-708$ \\
\hline Alcobendas & $212-5953$ & 1576 & 4,06 & $23-1246$ \\
\hline Villalba & $52-1490$ & 519 & 1,38 & $9-233$ \\
\hline
\end{tabular}

Tabla 2.3.1. Valores extremos y medios de los parámetros PTA, \% de representación y concentración ([ ] ) máxima anual.

En todas las estaciones del primer grupo el porcentaje del PTA de plátano (\%) sobre el total de polen anual -que se calcula sumando el PTA de todos los tipos polínicos presentes en el año- es muy alto, se trata por tanto del polen mayoritario en el espectro polínico de las mismas. Las concentraciones medias diarias alcanzan valores muy elevados, generalmente entre 10 y 40 días se superan los 30 granos de polen y de ellos, entre 5 y 25 días se superan los 100 granos de polen.

En el segundo grupo, con niveles atmosféricos más bajos de polen de plátano, se incluyen Getafe y Leganés, dos estaciones con un espectro polínico y una dinámica estacional bastante similares. En estas dos estaciones el porcentaje de representación del polen de Platanus menor que en el grupo anterior, alcanza valores similares al polen procedente de las cupresáceas (ciprés, arizónicas), que son por tanto, los dos tipos polínicos con mayor incidencia.

El tercer grupo corresponde a las estaciones de Coslada, Alcobendas y Villalba, con niveles bajos de polen de plátanos. Las concentraciones medias diarias también son mucho más bajas, con años en los que ningún día se han superado los 30 granos de polen y otros en que como máximo hay 20 días con concentraciones superiores a 30 granos. Los días con concentraciones superiores a 100 granos no suelen ser más de 15. 


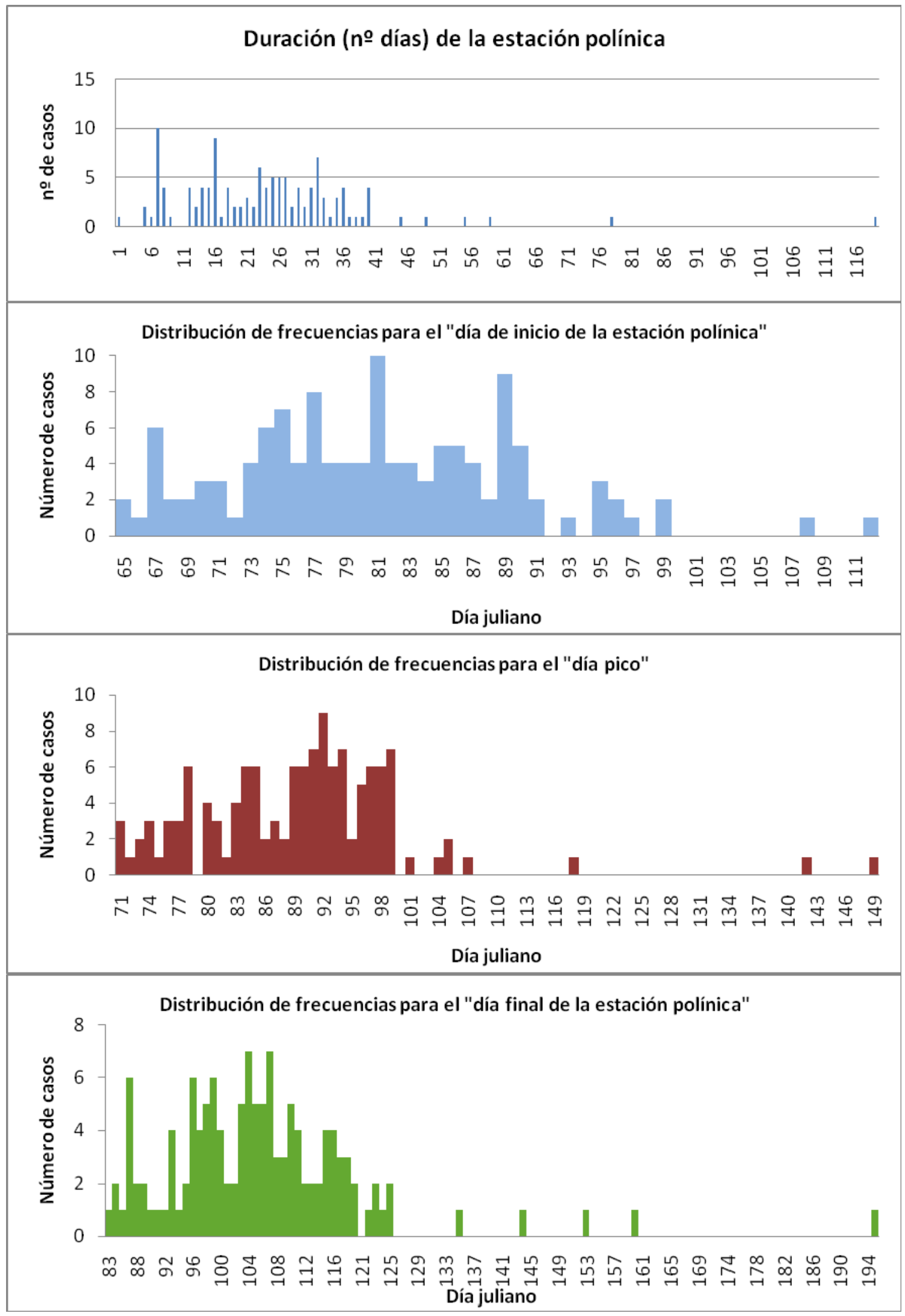

Fig. 2.3.1. Distribución de frecuencias de la duración total y las fechas de inicio, pico y final de la Estación Polínica, para todas las estaciones y años considerados alcanzando concentraciones medias diarias significativas, superiores a treinta granos $/ \mathrm{m}^{3}$ de aire, entre 10 y 40 días cada año, de los meses de marzo y abril. 
Hemos determinado la estación polínica de Platanus en la red, aplicando la concentración media diaria "umbral" de 30 granos de polen $/ \mathrm{m}^{3}$ de aire (Camacho \& al. 2008) para determinar el inicio y el final de la estación. La estación polínica del plátano, comparada con la de otros tipos polínicos atmosféricos de Madrid, es muy corta y transcurre casi siempre entre el 5 de marzo y el 30 de abril.

Los gráficos de la fig. 2.3.1 revelan que el inicio se produce generalmente entre el cinco y el treinta de marzo, el día pico entre el 12 de marzo y el 8 de abril y el final entre el 24 de marzo y el tres de mayo.

\subsection{OBSERVACIONES FENOLÓGICAS (AÑOS 2008-2009)}

La fenología proporciona datos sobre el ritmo periódico de fenómenos biológicos como la floración y la maduración del fruto, que dependen de la idiosincrasia propia de la especie y están relacionados con el clima local. En el caso de la floración de Platanus, solo hemos encontrado en la bibliografía información de carácter general -en las floras aparece como época de floración los meses de abril y mayo- mientras que en las publicaciones de aerobiología - con los datos de presencia atmosférica del polen en los últimos 15 años- se da como periodo de floración los meses de marzo y abril.

\begin{tabular}{|l|l|}
\hline Publicación & Época de floración \\
\hline Willkomm \& Lange (1870) & mayo \\
\hline Couthino, A. X. Pereira (1939) & abril-mayo \\
\hline $\begin{array}{l}\text { López González, G. \& Rocha Alfonso, M. } \\
\text { L.-1990- }\end{array}$ & abril-junio \\
\hline López Lillo, A. \& Mielgo, M. (2000) & abril-mayo \\
\hline Trigo, M. M. \& al. (2008) & marzo-abril \\
\hline
\end{tabular}

Tabla 2.4.1. Datos bibliográficos sobre floración de Platanus

Con objeto de obtener la información necesaria para poder mejorar la predicción del inicio de la estación polínica del plátano, hemos procedido a la observación directa del desarrollo de los botones florales en algunos árboles de Ciudad Universitaria, en los días previos el inicio de la floración, para conocer aproximadamente cuantos días tardan las inflorescencias masculinas en madurar y emitir el polen. Los resultados de los dos años de observaciones aparecen en la tabla 2.4.2. También hemos incluido en dicha tabla los datos sobre la estación polínica de Platanus en Ciudad Universitaria, aplicando la concentración media diaria "umbral" de 30 granos de polen $/ \mathrm{m}^{3}$ de aire (Camacho \& al. 2008) para determinar el inicio y el final de la estación. Los datos de la tabla evidencian que en 2009 las yemas florales tardaron en desarrollarse más días que en 2008: en 2008 apreciamos las primeras inflorescencias con flores abiertas el 15 de marzo y el inicio de la estación polínica, en Ciudad Universitaria, se produjo el 19 de marzo, tres días después. En 2009, no observamos flores abiertas hasta el 18 de marzo, pero el inicio de la estación polínica corresponde al 14 de marzo, cuatro días antes.

Para explicar estos pocos días de diferencia (tres-cuatro) entre la apertura de las flores y el inicio de la estación polínica, debemos referirnos a la escasez y precariedad de nuestras observaciones fenológicas, hechas sobre dos-tres pies de planta de la Ciudad Universitaria y sobre las yemas de las ramas más bajas. 


\begin{tabular}{|c|c|c|}
\hline Estado fenológico & 2008 & 2009 \\
\hline Yema de invierno & 28 febrero & 16 febrero \\
\hline Yema movida & 3 marzo & 19 febrero \\
\hline Se aprecian las inflorescencias $\hat{\partial}$ & 6 marzo & 2 marzo \\
\hline $\begin{array}{l}\text { Grupos de inflorescencias } \hat{\sigma} \\
\text { claramente apreciables }\end{array}$ & 13 marzo & 16 marzo \\
\hline Flores $\overbrace{}^{\lambda}$ abiertas & 15 marzo & 18 marzo \\
\hline Aparecen las inflorescencias $q$ & 18 marzo & 23 marzo \\
\hline Total días & 18 días & 35 días \\
\hline Estación polínica & & \\
\hline Inicio & 19 marzo & 14 marzo \\
\hline Final & 28 abril & 25 abril \\
\hline Total días & 40 días & 42 días \\
\hline
\end{tabular}

Tabla 2.4.2. Observaciones fenológicas y datos aerobiológicos de Platanus en Ciudad Universitaria (años 2008-2009). 


\section{REFERENCIAS BIBLIOGRÁFICAS}

Camacho, J. L., Cano, D., Cervigón, P., Gutiérrez, A. M. \& Subiza, J. -2008- Predicción de eventos extremos de polen alergénico en la Comunidad de Madrid. Inicio de la estación polínica del plátano de sombra. XXX Jornadas Científicas de la AME Zaragoza 5-7 mayo 2008. Agua y cambio climático http://www.ameweb.org/JORNADAS/4A Camacho.pdf

Couthino, A. X. Pereira -1939-Flora de Portugal. $2^{\text {a }}$ edición. Lisboa

Díaz de la Guardia C., Sabariego S., Alba F., Ruiz L., García Mozo H., Toro F. J., Valencia R., Rodríguez Rajo F. J., Guàrdia A. \& Cervigón P.-2000Aeropalynological study of the genus Platanus L. in the Iberian Peninsula. Polen 10: 93-101.

Gabarra E., Belmonte J. \& Canela, M.-2002-Aerobiological behaviour of Platanus L. pollen in Catalonia (North-East Spain). Aerobiologia 18:185-193.

López González, G. \& Rocha Alfonso, M. L.-1990-Platanaceae. In: Castroviejo, S. \& al. Flora Ibérica vol. II: 3-5. Servicio de Publicaciones del CSIC.

López Lillo, A. \& Mielgo, M.-2000-Árboles de Madrid, pg. 176. Ediciones MundiPrensa. ISBN: 84-7114-887-0.

Tormo R., Muñoz A., Silva I. and Gallardo F.: 1996, Pollen production in anemophilous trees. Grana 35, 38-46.

Trigo, M. M., Jato, V., Fernández, D. \& Galán, C. (Coord.)-2008-Atlas aeropalinológico de España. Red Española de Aerobiología. Secretariado de Publicaciones. Universidad de León, 177 pags. ISBN: 978-84-9773-403-5. Willkomm \& Lange-1870-Prodromus Florae Hispanica. 


\section{ASPECTOS MÉDICOS DE LA POLINOSIS POR PLATANUS}

\section{Javier Subiza. Director del Centro de Asma y Alergología Subiza}

La de las platanáceas es una pequeña familia que incluye únicamente el género Platanus, con unas 7(9) especies repartidas por las zonas templadas de América del Norte, sudeste de Europa, Himalaya e Indochina. Algunas especies suministran maderas de cierto interés comercial, pero su principal aplicación es como plantas ornamentales, sobre todo como árboles de paseo. Son angiospermas, es decir plantas con flores, pese a que en este casos eran muy poco vistosas, del grupo de las dicotiledóneas (subclase Magnoliidae), aquellas en las que el embrión, que en esta familia está bien diferenciado, tiene inicialmente dos hojas que se ven en la plantita que nace de la semilla. Las flores, que son unisexuales y van en inflorecencias separadas en el mismo pie de planta, se polinizan normalmente por medio del viento, lo que hace que la presencia de granos de polen en el aire sea normal en la época de floración (Fig. 3.1).

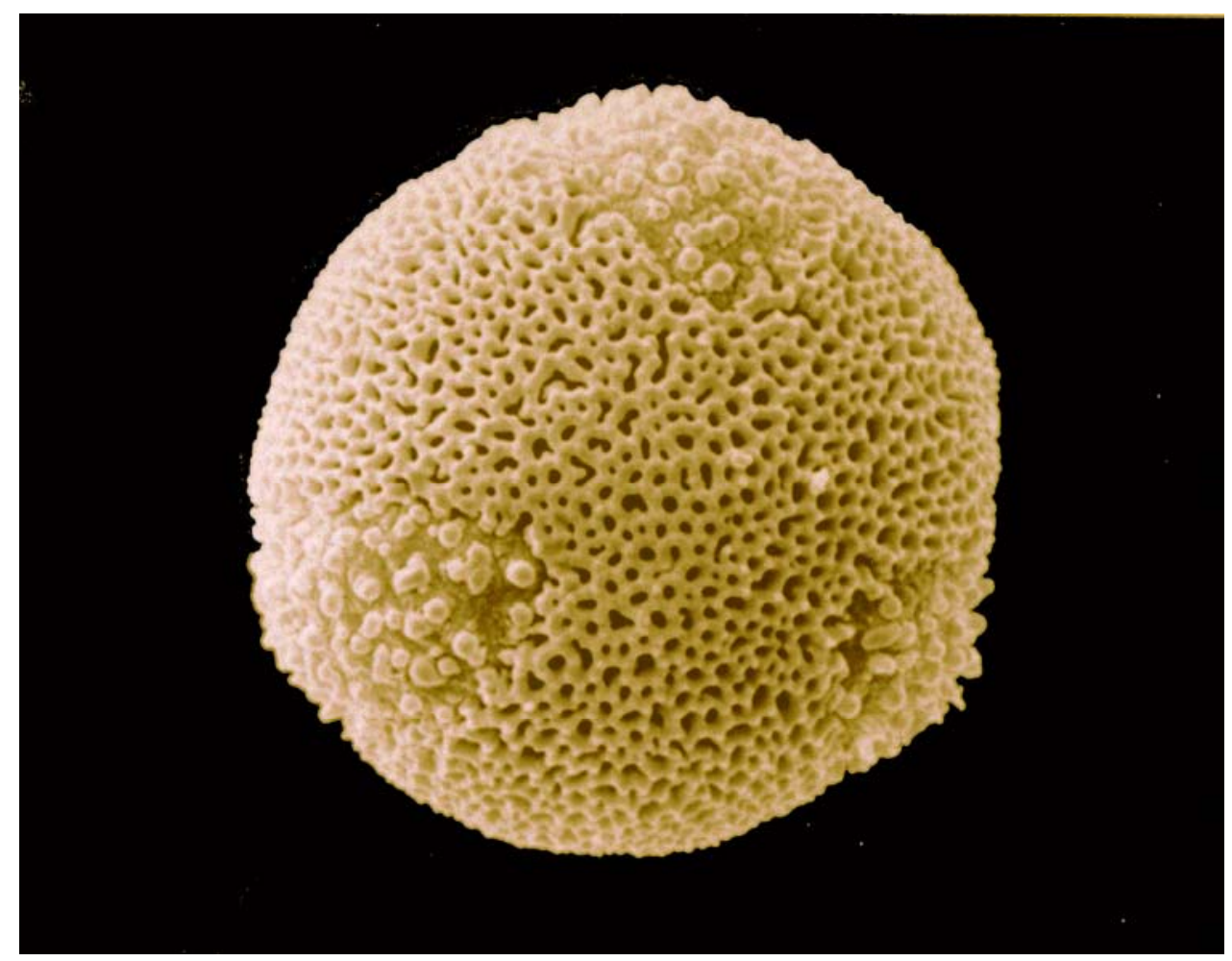

Fig. 3.1 Polen de Platanus visto mediante el microscopio electrónico.

Son árboles caducifolios que tienen hojas simples, casi siempre palmeadas, en disposición alterna, con largos pecíolos que se ahuecan e inflan en la base, rodeando a las yemas. Las flores son de dos sexos y nacen en inflorescencias esféricas largamente pedunculadas; las masculinas tienen 3-8 estambres, generalmente 4 ó 6 , y una envuelta doble con el mismo número de sépalos y pétalos libres; en las femeninas suelen faltar los pétalos y llevan en lugar de estambres 3-9 carpelos libres, en 2 ó 3 verticilos, cada uno con 1 ó 2 rudimentos seminales colgantes, ortótropos (derechos) o ligeramente hemianátropos (girados 180 en torno al punto por el que se unen al cabillo y soldados sólo de forma parcial a éste). El fruto es un aquenio en forma de cuña que lleva inferiormente un penacho de pelos revueltos que facilitan su diseminación por el viento; 
se agrupan de forma radial y apretada en infrutescencias esféricas a modo de bolas. Las semillas tienen un embrión recto, delgado y endosperma escaso, oleaginoso y con proteínas.

La familia tiene un solo género y una sola especie de importancia cultivada o asilvestrada en España, el Platanus común o de paseo, Platanus orientalis L. var. acerifolia Aiton [Platanus hispanica Mill. ex Münchh.; Platanus hybrida Brot.; Platanus acerifolia (Aiton) Willd.] Se trata de un árbol caducifolio, muy robusto, que puede alcanzar $35 \mathrm{~m}$ de altura, ampliamente cultivado en las ciudades y pueblos de la mayor parte de la Península, más raro en las zonas muy secas o de clima muy frío, así como en muchas de las regiones de clima templado del Globo. Se le puede ver también asilvestrado, sobre todo en los sotos y márgenes de cursos de agua, en suelos profundos y frescos, donde se ha naturalizado. Hay registros fósiles que demuestran que el Platanus fue en otros tiempos un componente habitual de muchos bosques de la Península, pero seguramente se extinguió durante las fases frías glaciares. Tolera muy bien la polución. Su clasificación es muy controvertida ya que durante mucho tiempo se afirmó que se trataba de un híbrido de Platanus orientalis (especie del sudeste de Europa y oeste de Asia, hasta el norte de Irán.) y de Platanus occidentalis L., una especie americana. Sin embargo parece haber evidencia de que se trata en realidad de una simple variedad de Platanus orientalis. La variedad acerifolia, que se ha considerado por muchos como una raza originada en los jardines europeos, parece proceder en último término de formas silvestres orientales (del Ponto y Lycia); formas semejantes existen también al parecer en Turquía (Anti Taurus). También se ofrecen para su cultivo en los viveros españoles la raza típica del Platanus oriental, de hojas más profundamente lobadas (con hendiduras que sobrepasan por lo general la mitad de la longitud de la lámina) y con 2-6(7) cabezuelas en un solo pedúnculo, la Platanus orientalis L. var. orientalis (Platanus oriental, Platanus de Levante, Platanus de oriente) y el Platanus de Virginia, la Platanus occidentalis L., del sudoeste de Norteamérica, que tiene las hojas subpentagonales, con 3-5 lóbulos muy poco profundos (las hendiduras no sobrepasan un tercio o un cuarto de la longitud de la lámina), cabezuelas generalmente solitarias, raramente en parejas, y frutillos truncados o redondeados en el ápice. Uno y otro se ven con relativa poca frecuencia. El Platanus florece en marzo o abril y madura los frutos a fines de verano o en el otoño. ${ }^{1-3}$

\section{Morfología del polen}

\section{Platanus:}

Forma: suboblado u oblado esferoidal

Tamaño: 16-25 $\mu \mathrm{m}$ (pequeñomediano)

Aperturas: trizonocolpado. Colpos cortos cubiertos de granulaciones que le dan un aspecto desflecado Exina: grosor medio, micro reticulada Intina: grosor medio

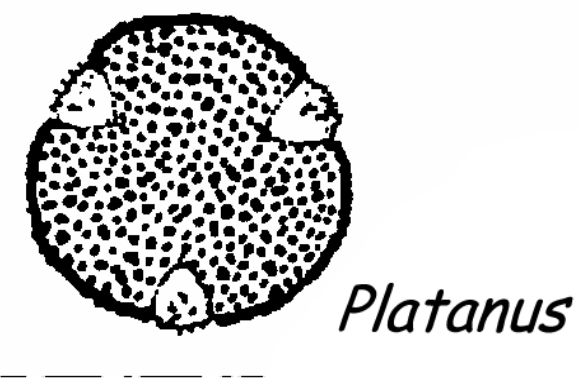




\subsection{Polinosis por Platanus hispanica}

La polinización del plátano de sombra (Fig. 3.2) se produce de forma brusca al comienzo de la primavera, en marzo-abril, pudiendo llegar a picos de mas de 2.500 granos $/ \mathrm{m}^{3}$ de aire como ocurrió en Barcelona ${ }^{2-3}$ o picos como el que se produjo en Madrid el 14 de marzo de 1997 con 4.265 granos $/ \mathrm{m}^{3}$ de aire. El Platanus como causa relevante de polinosis se describió en la década de los 90 en Madrid. ${ }^{4-5}$

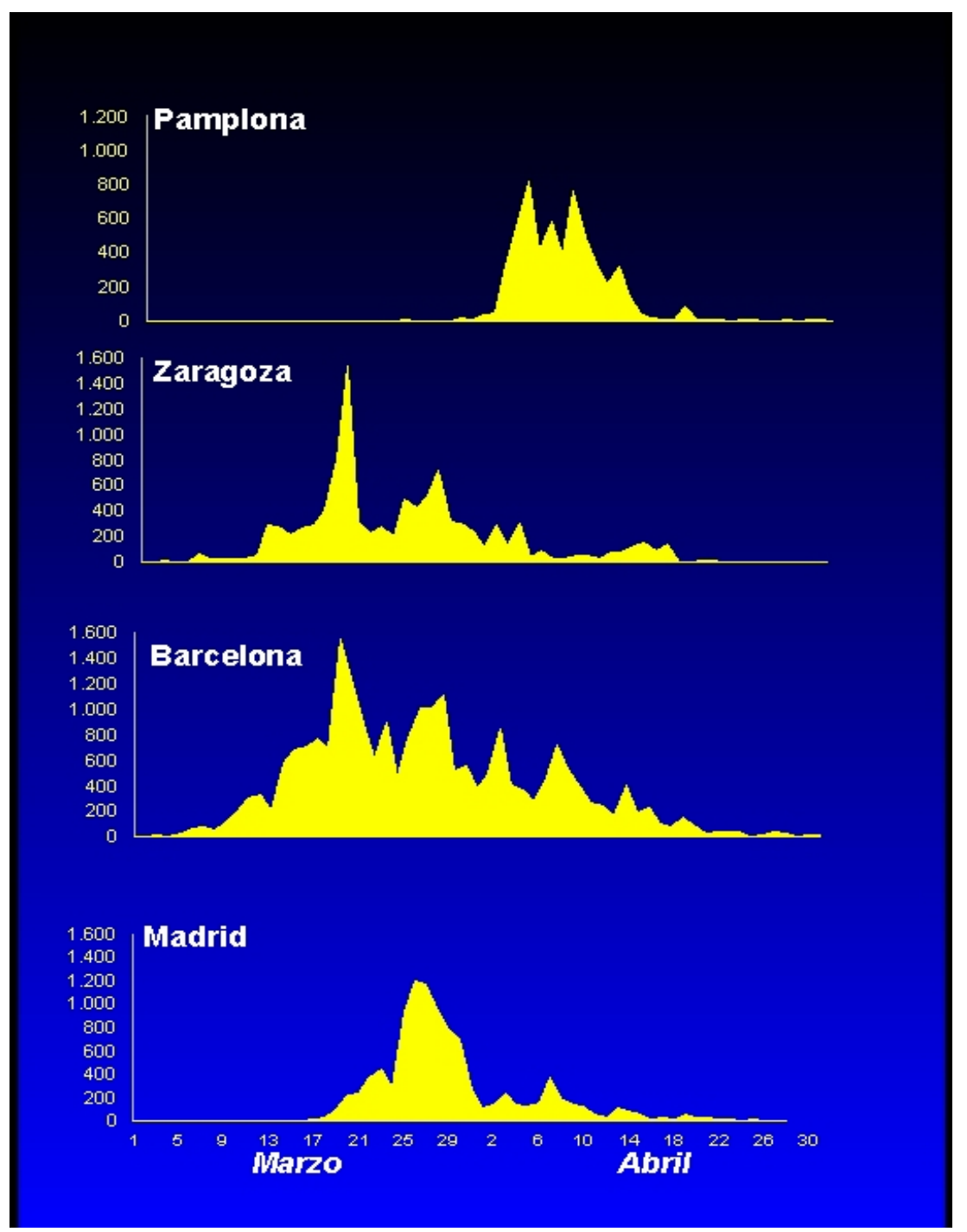

Fig.3.2. Recuentos atmosféricos de Platanus, expresado como granos $/ \mathrm{m}^{3}$ de aire (medias diarias). Datos Comité de Aerobiología de la SEAIC.

La sensibilización a polen de Platanus en Madrid ha sufrido grandes variaciones en cuanto a su prevalencia, pasando de unas PCP del 2\% en 1980 a unas PCP del 52\% en 1995. Esto se debe probablemente a un aumento en los recuentos de pólenes en estos años. ${ }^{6}$ En un estudio del Comité de Aerobiología de la SEAIC (2003) se encontró que la mayor prevalencia de sensibilizaciones a Platanus correspondía con las ciudades con mayores concentraciones de estos pólenes como Barcelona, Madrid y Zaragoza (Fig $3.3)$. 


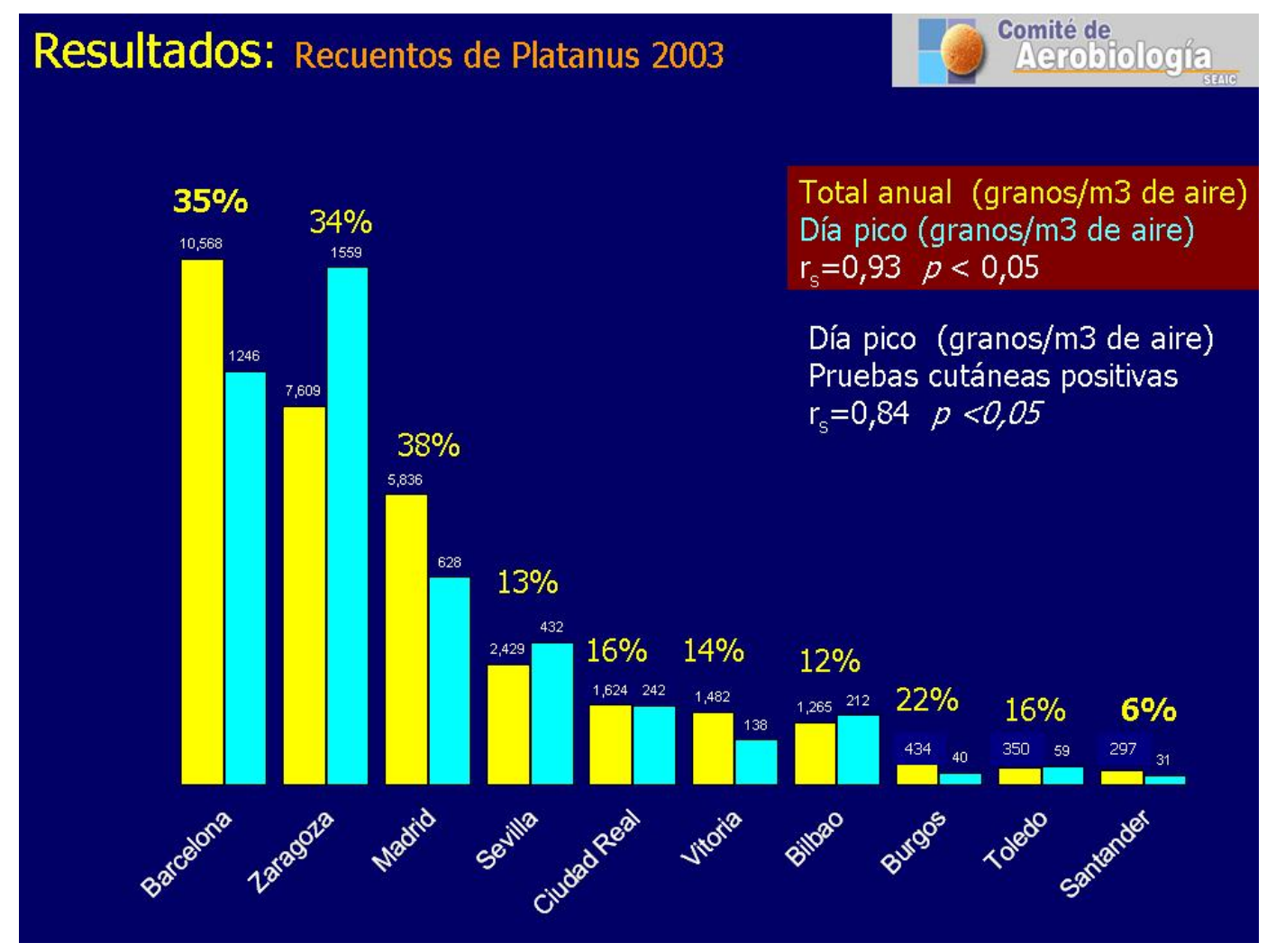

Fig 3.3. Recuentos de pólenes de Platanus en 2003, expresados como totales anuales (amarillo) [suma de los recuentos diarios de un año) y día pico (azul) (día del año con recuentos más altos], obsérvese la correlación significativa entre ambas variables. También se observa una correlación significativa entre los recuentos de pólenes y la prevalencia de sensibilización a Platanus entre los pacientes con polinosis de 11 ciudades. Datos facilitados por el Comité de Aerobiología de la Sociedad Española de Alergología.

Se ha descrito la sensibilización a Platanus, como un factor de riesgo significativo de padecer asma entre los pacientes con polinosis de Madrid debido probablemente a que se asocia con un mayor grado de atopia. Efectivamente la mayoría de los pacientes alérgicos al Platanus los son también a gramíneas y otros pólenes y se ha podido encontrar un significativa relación entre el número de PCP (grado de atopia) y la prevalencia de asma. ${ }^{5}$

Algunos pacientes en otoño, durante los meses de septiembre y octubre, refieren presentar síntomas. La explicación a este hecho se podría encontrar en la reflotación de polen adherido a las hojas durante la época de polinización y que se desprenden en el momento de su caída. ${ }^{2}$

Los síntomas mas frecuentes asociados a polinosis por Platanus son los debidos a la rinoconjuntivitis y asma que aparecen de forma brusca al comienzo de la primavera (Fig. 3.4). La mayor parte de los pacientes pertenecen al ámbito urbano. 


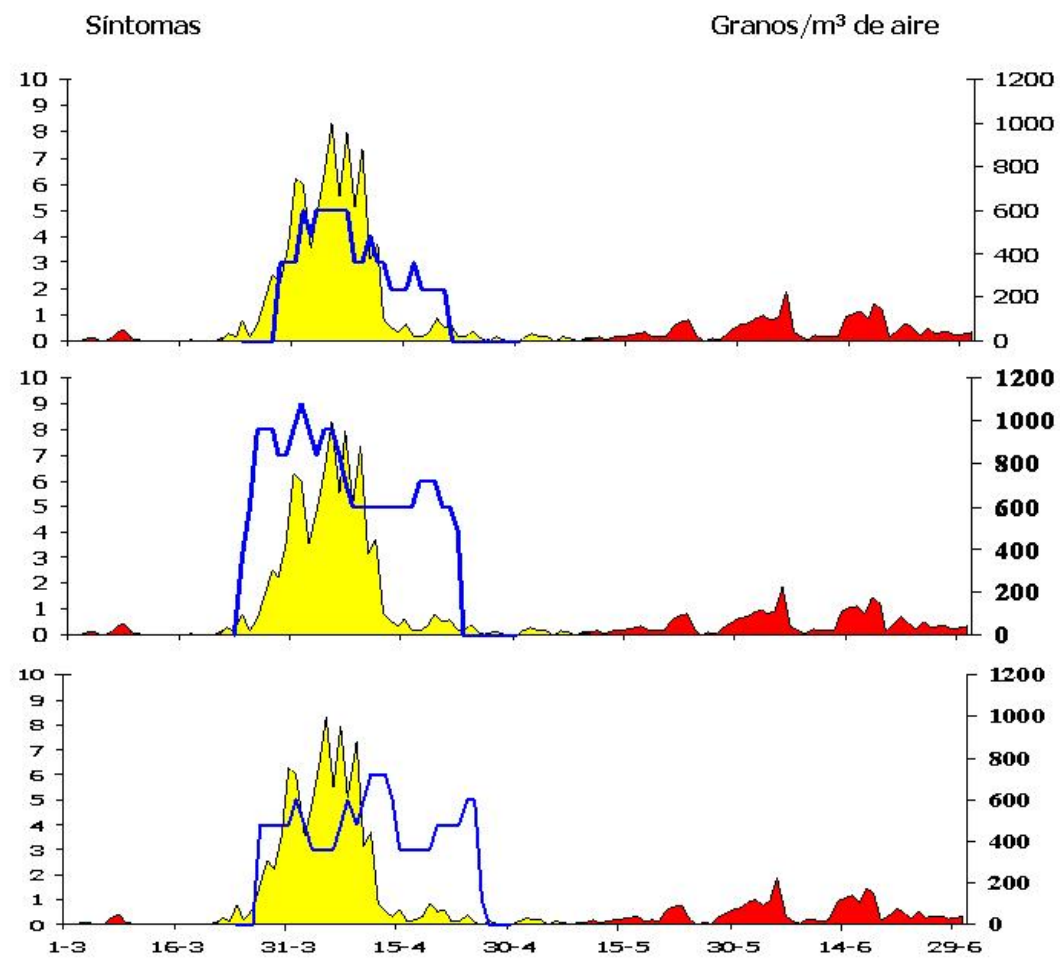

Fig. 3.4. Síntomas de asma (línea blanca) recogidos en sus cartillas de síntomas por 3 pacientes sensibilizados a Platanus. Obsérvese el comienzo brusco de los síntomas coincidiendo con el comienzo también muy brusco de los recuentos de Platanus en la atmósfera.

\subsection{AlÉRgENOS Y REACTIVIDAD CRUZADA}

En el momento actual se han caracterizado dos alérgenos mayores denominados Pla a 1 de $17 \mathrm{KDa}$ y Pla a 2 de $43 \mathrm{KDa}^{7-8}$ Otros alérgenos caracterizados son de la familia de las profilinas que es una proteína conocida como panalérgeno. Estas profilinas parecen estar implicadas en la reactividad cruzada entre algunos alimentos vegetales y el polen de Platanus. ${ }^{9}$

Este fenómeno consistiría en que una vez producida la IgE especifica frente al polen, por reactividad cruzada frente a estructuras alergénicas que están presentes en los alimentos de origen vegetal, se desarrolla secundariamente una alergia frente a estos alimentos. ${ }^{3}$ Entre estos alimentos se encuentran el melocotón, manzana, cereza, melón, kiwi, cacahuete, garbanzo, frutos secos (avellana, castaña, nuez) lechuga, judías verdes y maíz. ${ }^{3}$ En otros estudios: plátano, apio, cacahuete avellana. ${ }^{10}$

La alergia alimentaria debida a profilinas se suele manifestar como síndrome de alergia oral con síntomas circunscritos en la mucosa orofaringea ${ }^{3}$. Se ha descrito también reactividad cruzada entre pólenes de Platanus y gramíneas por RAST inhibición. ${ }^{5}$

En la actualidad la casi totalidad de los laboratorios existentes en nuestro país disponen de extracto de polen de Platanus acerifolia para inmunoterapia, estandarizado en unidades biológicas. 


\section{Definiciones y Abreviaturas}

PCP Pruebas cutáneas positivas

Día pico Máxima concentración media diaria del año

Total anual Suma de las concentraciones medias diarias de un año

\section{REFERENCIAS}

1 Kremer BP. Plátano (platanus hybrida). En: Árboles. Editorial Blume S.A. Barcelona 1990: 164-165.

2 Valero A.L, Rosell A. Amat P, Sancho J, Roig J, Piulats J, Malet. Hipersensibilidad a polen de Platanus acerifolia:detección de las fracciones alergénicas. Rev. Esp Alerg1 Inmunol Cli. 1999; 14: 220-226.

3 Enrique E, Cisteró - Bahima A, Bartolomé B, Alonso R, San Miguel- Moncin M. M, Bartra J, Martinez J. Platanus acerifolia pollinosis and food allergy. Allergy. 2002; 57:351-6.

4 Subiza J, Cabrera M, Valdivieso R. Et al. Seasonal asthma caused by airborne Platanus pollen. Clin Exp Allergy 1994; 24:1123-1129.

5 Varela S, Subiza J, Subiza JL, Rodríguez R, Garcia B, Jerez M, et al. Platanus pollen as an important cause of pollinosis. J Allergy Clin Immunol 1997; 100: 748- 754.

6 Subiza J, Jerez M, Gavilán M, et al. ¿Cuáles son los pólenes que producen polinosis epidémica en el medio urbano de Madrid? Rev Esp Alergol Inmunol Clin.1998; 13: 107-119.

7 Anfosso F, Soler M, Mallea M, Charpin J. Isolation and characterización in vitro of an allergen from plane-tree8Platanus acerifolia) pollen. Int Arch allergy Appl Immunol 1997: 54 481-486

8 Bartolomé B, Olive A, Vives R, Martínez J, Martínez A, Palacios R. Estudio y caracterización de los alergenos del polen de platanus acerifolia. Rev Esp Alerg Inmunol Clin 1996; 11: 211

9 Enrique E, Bartolomé B, San Miguel-Moncin M, M Alonso R, Bartra J, CisteroBahima A. Implicación de las profilinas en la reactividad cruzada entre alimentos y polen de platanus acerifolia. Alerol Inmunol cli 2001

10 Miralles JC, Caravaca F, Guillén F, Lombardero M, Negro JM. Cross-reactivity between Platanus pollen and vegetables. Allergy 2002; 57: 146- 149. 


\title{
4. ASPECTOS TÉCNICOS E INSTITUCIONALES DE LA VIGILANCIA DEL POLEN EN LA ATMÓSFERA DE MADRID. RED PALINOCAM
}

\author{
Patricia Cervigón Morales. Coordinadora de la Red Palinocam. Servicio de \\ Sanidad Ambiental. Consejería de Sanidad de la Comunidad de Madrid.
}

\subsection{INTRODUCCIÓN}

Los niveles de polen dependen de múltiples factores, entre los que destacan los relativos a la constitución y características de las masas vegetales, origen de la emisión del polen y los relativos a la dinámica atmosférica y factores meteorológicos, que determinan el modo de difusión del polen y por tanto los niveles de inmisión o concentración en un momento y lugar determinado a los que la población está expuesta. Desde el punto de vista de la Salud Pública interesa medir la exposición a la que está sometida la población.

La Red Palinológica de la Comunidad de Madrid, integrada por la Consejería de Sanidad (que la promueve y coordina), la Facultad de Farmacia de la Universidad Complutense de Madrid (que ejerce la dirección técnica), los Ayuntamientos de Alcalá de Henares, Alcobendas, Aranjuez Coslada, Getafe, Las Rozas Leganés, y Madrid, el Centro de Asma y Alergia y el Centro de Salud Pública del área 6 en Collado Villalba a, es un importante sistema de vigilancia e información de niveles de polen en la atmósfera que está en funcionamiento desde 1993 con el impulso y supervisión de la Comisión de Asma del Programa Regional de Vigilancia y Control del Asma de Madrid y el Comité de Expertos de la misma.

Este entramado institucional toma cuerpo con la creación de un Comité de Expertos mediante la Resolución 19/1994, de 4 de marzo (Boletín Oficial de la Comunidad de Madrid de 10/3/94), cuya composición se define mediante Resolución de 29 de noviembre de 1994 (BOCM de 7/12/94) y se modifica mediante Resolución 11163/98, de 12 de junio (BOCM de 6/7/98) y mediante Resolución 13/2000, de 21 de enero (BOCM de 2/2/00). El comité de expertos está coordinado desde el Servicio de Sanidad Ambiental, bajo la Dirección Técnica de la Facultad de Farmacia de la Universidad Complutense y está integrado por representantes de cada una de las instituciones involucradas. El marco jurídico se completa con acuerdos firmados por los Ayuntamientos con la Consejería de Sanidad y con el Convenio de Colaboración firmado con la Facultad de Farmacia de la Universidad Complutense de Madrid. La última modificación de la composición del Comité de Expertos se publica en el Boletín Oficial de la Comunidad de Madrid con fecha 18 de agosto de 2004 (BOCM 18/08/04).

Desde 1993 funciona en la Comunidad esta Red Palinológica en la Comunidad, compuesta por once captadores, tres de los cuales están situados en el municipio de Madrid (Centro, Ciudad Universitaria, Barrio de Salamanca) y ocho están en otros municipios de la Comunidad de Madrid, concretamente en Alcalá de Henares, Alcobendas, Aranjuez, Collado Villalba, Coslada, Getafe, Las Rozas y Leganés, cuyos responsables constituyen un Comité de Expertos cuya coordinación se realiza desde la 
Consejería de Sanidad, con la dirección técnica de la Facultad de Farmacia de la Universidad Complutense.

La Red Palinocam lleva 15 años vigilando e informando sobre la concentración de polen en el aire. En todo este tiempo se ha ido evolucionando en el conocimiento del contenido aerobiológico de la región, periodos de polinización, plantas polinizadoras más frecuentes etc. Todo el trabajo realizado ha sido posible gracias a la estrecha colaboración con los laboratorios municipales, en virtud a los convenios suscritos entre la Comunidad de Madrid y los distintos ayuntamientos a lo largo de estos quince años, la colaboración desinteresada del Ayuntamiento de Madrid y de la Clínica de Asma y Alergia, y la participación de la Facultad de Farmacia, desde donde se ejerce la Dirección Técnica de la Red.

Desde cada uno de estos puntos donde hay captadores de polen se envían los datos al Servicio de Sanidad Ambiental, centro coordinador, que elabora los informes correspondientes. El objetivo fundamental de la Red es proveer de información de los niveles de polen presentes en la atmósfera de la Comunidad de Madrid tanto a las personas que sufren procesos alérgicos como a los profesionales involucrados en sus cuidados.

En el marco de la Vigilancia de riesgos ambientales y la Salud Pública, recoge la información recogida de los 11 captadores; Los datos de polen, su serie histórica y el pronóstico meteorológico permiten formular diariamente predicciones de niveles de polen, de gran interés para alérgicos y sanitarios, gracias a que durante el primer semestre las lecturas de las muestras aerobiológicas se realiza todos los días, además se elaboran boletines de información durante todo el año. La Red Palinológica de la Comunidad de Madrid ofrece información, mediante la actualización en Internet y en la Operadora Automática de telefonía:

- Información diaria de enero a junio

- Información semanal durante todo el año.

- Predicción diaria de niveles de polen en los periodos de máxima polinización de: Cupresáceas, Plátano, Gramíneas y Olivo.

Toda la información está disponible en:

- Internet: www.madrid.org/polen

- Operadora automática 902545900

- E-mail: isp.polen@salud.madrid.org

\subsection{La Red Palinológica de la CoMunidad de MAdRid y la Red Española de AEROBIOLOGÍA: RED PALINOCAM Y REA}

La RED PALINOCAM, está integrada en la Rea desde sus comienzos; comenzó suministrando los datos de la Facultad de Farmacia de la Universidad Complutense, pero se ha ido ampliando en los últimos años, y en la actualidad son cuatro los captadores de los que se envían datos de Madrid: Alcalá de Henares, Aranjuez, Collado Villalba y Facultad de Farmacia. 
En España, desde principios de los 80, diversos grupos de investigadores han desarrollado trabajos de aerobiología. En 1992 se planteó una federación de estos grupos y se constituyó la Red Española de Aerobiología, REA, con el objetivo de coordinar los distintos grupos de trabajo, crear una base común de datos aerobiológicos para su difusión a los colectivos interesados y contribuir, con la información generada, a la red europea EAN-EPI (European Allergy Network-European Pollen Information), con sede en la Universidad de Viena, Austria.

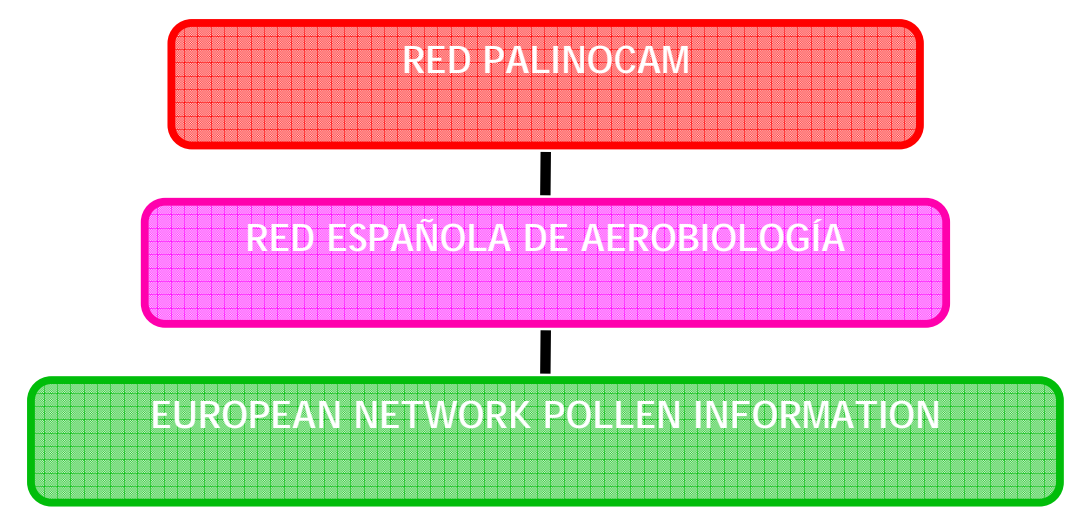

Figura 4.1. Estructura de las redes de vigilancia de polen a nivel de Comunidad Autónoma, Estado y Europa.

\subsubsection{Funcionamiento de la REA}

Cada uno de los grupos de trabajo integrados en la REA se gestiona independientemente, pero sigue un protocolo metodológico de trabajo estandarizado y envía semanalmente sus resultados a la base de datos nacional ubicada en la Universidad de Córdoba. En el Centro Coordinador se actualiza tanto el Banco polínico nacional como el europeo y se genera la información y previsión polínica para ser transmitida a través de los distintos medios de comunicación.

La base metodológica está orientada a obtener resultados totalmente comparables en todas las localidades estudiadas. Por ello, se ha acordado el uso de captadores basados en el sistema Hirst (modelos comerciales Burkard y Lanzoni), se ha estandarizado el método de muestreo, el sistema de recuento y la obtención de los resultados en todos los centros.

La cobertura geográfica de la REA pretende abarcar la mayor parte del territorio de la España Continental. En la última década han ubicado Unidades de Monitorización Aerobiológico en buena parte del territorio nacional. Las localidades muestreadas integradas en la REA y su localización geográfica pueden observarse en el mapa que se adjunta. El último captador se ha ubicado en las Islas Baleares, concretamente en Palma de Mallorca en el mes de Agosto de 2003.

En el transcurso de los años se ha ampliado notablemente la red de localidades de muestreo. El interés de la REA es conseguir que los principales núcleos de población, así como las diferentes unidades biogeográficas y bioclimáticas existentes en España, 
cuenten con Unidades de Monitorización Aerobiológico. En la actualidad, la REA cuenta con información enviada desde 49 puntos en toda la Península y Baleares.

La base de datos de polen de la Red Europea de Aeroalérgenos se emplea para unificar los datos de más de 400 estaciones de muestreo de toda Europa; científicos, en su mayoría aerobiólogos, emplean estos datos para calcular las estadísticas, tendencias y distribución del polen. Esta página sirve de lugar de intercambio de datos de polen de todas las estaciones europeas.

La Asociación Panamericana es una asamblea pluridisciplinar, donde científicos y expertos, comparten intereses comunes en el conocimiento de las fuentes, dispersión y deposición de las partículas biológicas aerovagantes. La organización se constituyó oficialmente en 1989, en el II Simposium Canadiense en Aerobiología (I Panamericano). La PAAA es una organización asociada a la Asociación Internacional de Aerobiología y actúa como representante de la IAA en América. Siendo la IAA, la asociación Internacional de Aerobiología, la que engloba todas las asociaciones nacionales del mundo

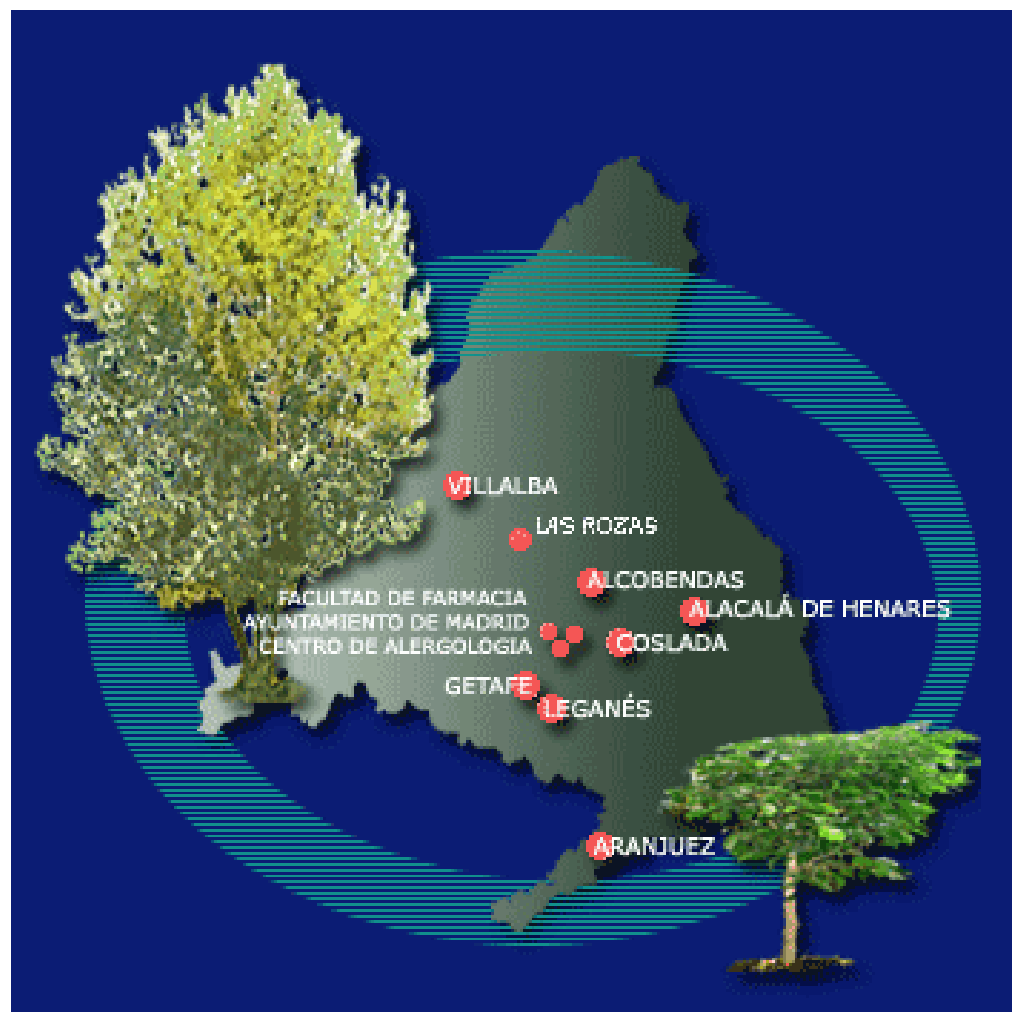

Figura 4.2. Red Palinológica de la Comunidad de Madrid. 


\title{
5. RELACIÓN ENTRE PARÁMETROS METEOROLÓGICOS Y EL INICIO DE LA TEMPORADA DE POLINIZACIÓN
}

\author{
José Luis Camacho. AEMET
}

Las cantidades diarias de polen muestran una elevada variabilidad diaria, mensual y anual. En particular, el estudio de los totales anuales es muy ilustrativo de los problemas que hay que afrontar para su tratamiento estadístico. En la serie de Madrid-General Pardiñas entre 1979 y 2006 se aprecia como en la década de los 90 se registraron grandes cantidades de polen anuales. Sin embargo, esta variabilidad se puede explicar por el aumento en las plantaciones con motivos ornamentales y en las podas sistemáticas e intensas en algunos años. Como el volumen total de polen que un árbol puede poner en el aire depende de la cantidad de ramas y de su edad, estas labores de jardinería modulan el total recogido en un observatorio. Además, el posible suministro adicional de agua mediante riego, hace que las relaciones estadísticas con la pluviometría de la zona sean poco fiables.

Por ello, se abandonó la idea de realizar predicción de la cantidad total de polen en función de variables meteorológicas y se pensó en reducir el problema estadístico a un ajuste de fechas de inicio a partir de una determinación y ajuste de valores umbrales para la cantidad de polen y para las variables meteorológicas.

\subsection{DETERMINACIÓN DE LA CANTIDAD DIARIA UMBRAL PARA DETERMINAR EL INICIO DE LA TEMPORADA}

Se analiza en primer lugar el problema de la determinación del umbral diario que determinaría la fecha de inicio de la temporada. En muchos estudios sobre pólenes, se utiliza el valor del día en que se alcanza el 2\% (o el 5\%) del total anual acumulado. Una discusión sobre estos valores se pueden encontrar en Laadi et al. 2003. Este método tiene el inconveniente de que es necesario esperar a fin de año para conocer el valor de la fecha de inicio de la estación por lo que no es útil para montar un sistema de predicción. Adicionalmente, y como hemos establecido antes, la cantidad de polen depende del número de árboles y de su estado, por ello, el umbral del $2 \%$ o del $5 \%$ en Madrid corresponde a valores próximos al centenar de granos $/ \mathrm{m}^{3}$ o ampliamente superiores.

Un simple vistazo a las gráficas de valores diarios de polen en la época de inicio muestra como se pasa de manera muy brusca de muy pocos granos a muchas decenas o centenares en periodos de 2 a 4 días. Una muestra de este hecho de puede observar en la figura 5.1 para los años 1994-95 y 96 de la serie Madrid-General Pardiñas. 1994 es un ejemplo de inicio relativamente temprano, 1995 de año normal comenzando alrededor del día 19 de marzo (San José en el calendario católico) y 1996 es un ejemplo de año tardío. Obsérvese las grandes variaciones posteriores. Estas no ofrecen interés desde el punto de vista médico ya que la inmensa mayoría de los alérgicos persisten en sus síntomas bastantes días después de exponerse al fenómeno. 


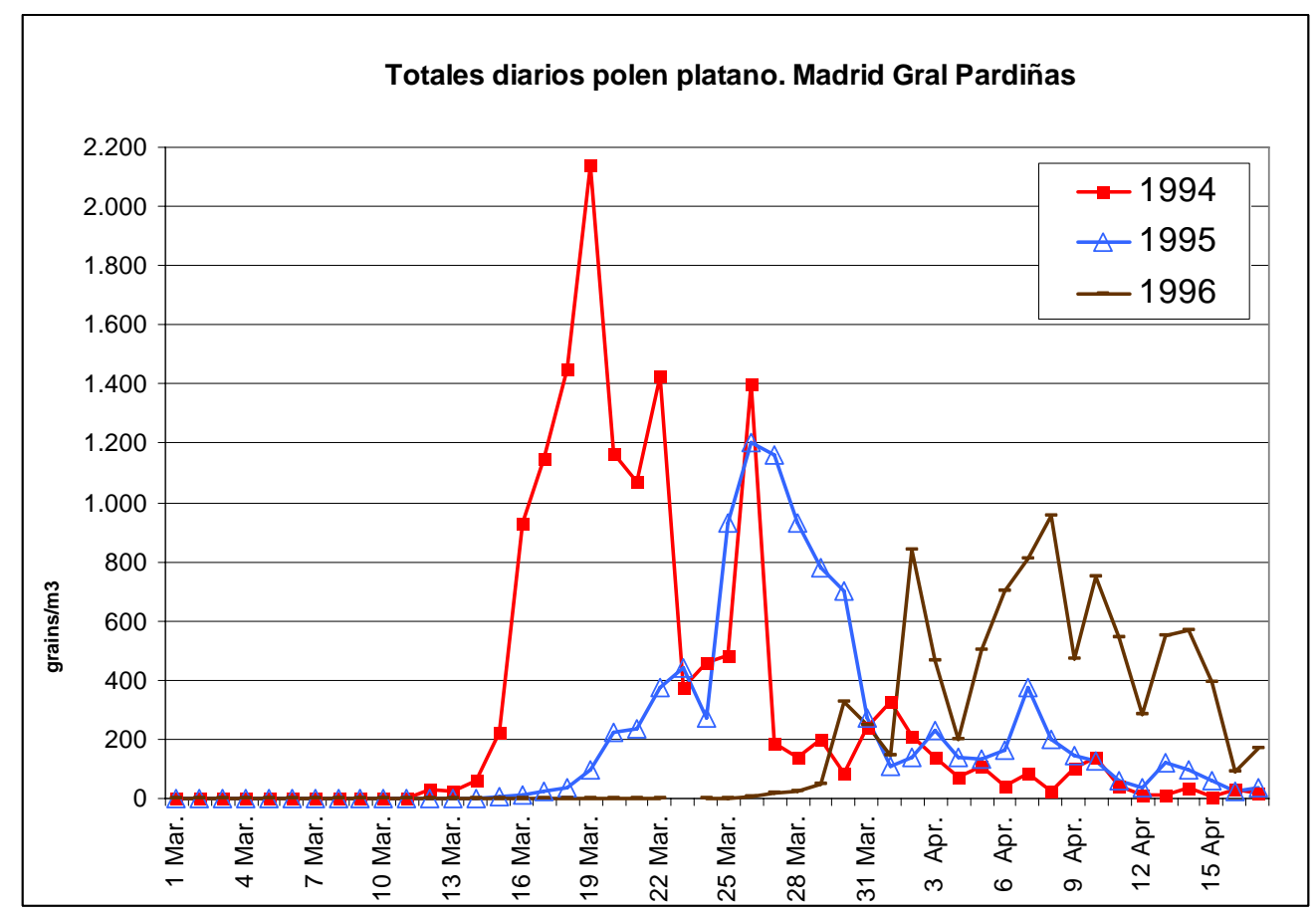

Fig. 5.1. Evolución diaria del polen de plátano en los registros de Madrid-General Pardiñas para 1994, 95 у 96.

Tal y como se ha comentado en el apartado de aspectos médicos, se sabe que valores de muy pocas decenas de granos producen importantes síntomas en muchos pacientes sensibles a este tipo de polen. Para ajustar la fecha de inicio de la temporada de polinización (ITP) según el umbral de cantidad de polen según criterios estadísticos y médicos se realizaron una serie de pruebas que están descritas en uno de los artículos previos a esta Nota Técnica (Camacho et al, 2008 a). Como resultado se seleccionó el umbral de 30 granos $/ \mathrm{m}^{3}$ para evitar falsos comienzos de la temporada y para asegurar que los pacientes muestren efectos alérgicos a esas concentraciones.

Hemos representado en la figura 5.2, el día de ITP entre 1980 y 2006 para diferentes umbrales. Entre 1980 y 2000 parece existir una tendencia hacia el adelanto de la ITP ocasionada sobre todo por el inicio temprano en 1997,98 y 2000. Sin embargo, entre 2001 y 2006 hay un retroceso aparente. Ello nos lleva a ser prudentes en cuanto a extraer conclusiones sobre tendencias en fechas de floración u otros parámetros fenológicos en relación con el cambio climático si no se dispone de una serie suficientemente larga. Sacar conclusiones sobre tendencias en periodos de dos décadas reflejaría factores inherentes a la variabilidad climática natural que, a corto plazo, pueden ser mayores que las tendencias a un plazo mayor. 


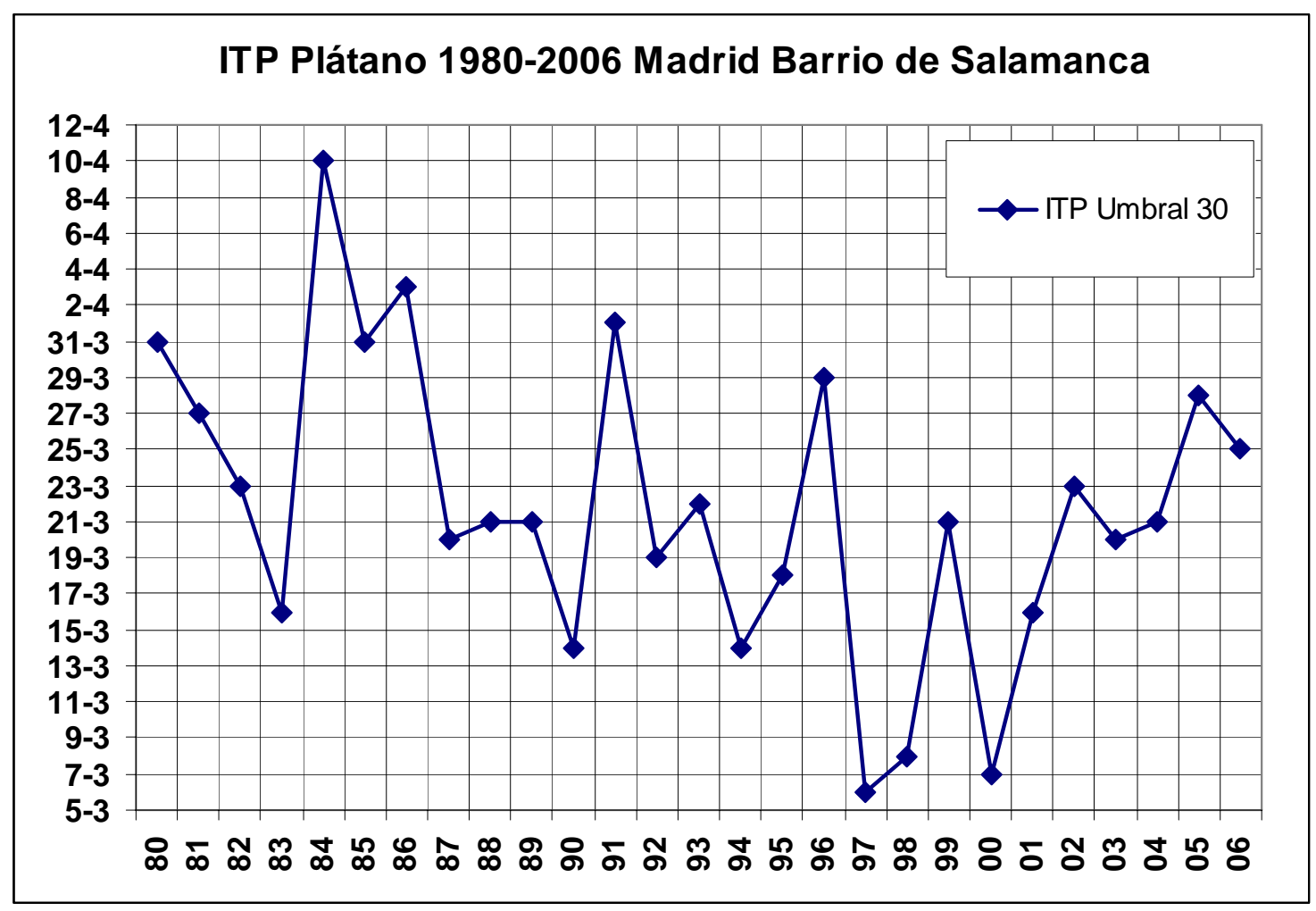

Fig. 5.2. Fecha de inicio de la polinización del plátano según registros de Madrid-General Pardiñas. Umbrales de 10, 30 y 50 granos $/ \mathrm{m}^{3}$.

\subsection{Relación estadística entre calor acumulado y fecha de inicio.}

Una vez fijada el valor umbral para el ITP, en este apartado estudiaremos las relaciones estadísticas entre esa fecha y variables meteorológicas. Inicialmente, se trabajó con los datos meteorológicos de Madrid Retiro entre 1980 y 2006. Según diferentes fuentes, el inicio de la fecha de polinización en los árboles depende en gran medida de la acumulación de calor a lo largo de las semanas precedentes, (Weryszko-Chmielewska et al, 2006). (García-Mozo et. al, 2002 y 2006)

Para descartar factores, se ha considerado posibles relaciones estadísticas entre el ITP y las temperaturas extremas, la precipitación, la insolación, el recorrido del viento y la humedad relativa. En el caso de las temperaturas extremas, la precipitación y la insolación se han construido valores acumulados para ver el efecto que podían tener sobre la fecha de ITP.

No se han encontrado relaciones estadísticas claras entre ningún factor excepto los relativos a las temperaturas. Las relaciones estadísticas más claras encontradas para Madrid lo son con magnitudes que tengan en cuenta la acumulación de temperatura sobre un umbral determinado. Para Madrid-Retiro, se han calculando la acumulación de grados días de las medias sobre 10 grados y la acumulación de grados días de las máximas sobre 15 grados. La primera magnitud es muy utilizada en aplicaciones agrícolas, apareciendo en el Boletín Agrometeorológico de AEMET. La segunda se ha incluido tras examen detenido de las curvas de evolución de temperatura y del contenido de polen para la serie entera, en donde se pudo apreciar la influencia de los 
periodos sostenidos de temperaturas calurosas en el mes de marzo. Dicho calor ha sido cuantificado, de manera arbitraria, en el umbral de 15 grados para las máximas.

Como se ha apreciado que periodos de buena insolación y de temperaturas máximas agradables no eran suficientes para iniciar la polinización sino que era preciso que las mínimas TAMBIEN fueran suaves, después de ver el comportamiento por separado de ambos índices, se decidió ensayar el promedio de ambos para cada día. Es decir, se calcula como índice de predicción el promedio de acumulación A dicho índice le vamos a denominar Promedio de Acumulación de Calor (PAC) de ahora en adelante.

Tomando las fechas en las que se sobrepasa el umbral de 30 granos $/ \mathrm{m} 3$ en cada año y calculando la acumulación de grados día para las máximas (AcumGrx) y las medias (AcumGrMd) sobre los umbrales antes indicados desde el 1 de enero de cada año y la acumulación de horas de sol desde la misma fecha (Insolacum), obtenemos los valores promediados siguientes para la serie 1980-2006 de Madrid-Retiro:

\begin{tabular}{ccc} 
AcumGrMd $\left({ }^{\circ} \mathrm{C}\right)$ & AcumGrx $\left({ }^{\circ} \mathrm{C}\right)$ & Insolacum (horas) \\
\hline 47,4 & 53,5 & 450,4
\end{tabular}

El valor del PAC correspondiente a los valores obtenidos sería de 50,4. Utilizando, por razones prácticas un valor ajustado al grado entero de 50 grados como valor umbral, realizando una clasificación de la fecha en el valor del PAC de Madrid Retiro está comprendido por primera vez entre 45 y 55 grados más próximo a este valor, en clases de tres días a contar desde el 1 de enero, obtendremos valores de lo que denominamos "classdiagr". Por otra parte, clasificando asimismo en clases de tres días la fecha en la que la serie de recuentos de polen de plátanos Madrid-General Pardiñas pasa del umbral $30 \mathrm{granos} / \mathrm{m}^{3}$, se obtiene un ajuste lineal entre las clases obtenidas de las fechas de ambos eventos. La clasificación del día en que por primera vez el PAC tiene un valor entre 45 y 55 grados le llamamos "clasedial". La ventaja de esta clasificación es que es fácilmente realizable por un sistema automático ya que incluye un intervalo de error de 5 grados sobre el valor umbral Otra clasificación es posible, aunque requiere intervención manual y es la de la fecha en que el valor es más próximo a 50 grados. A esta clasificación le llamaremos "Clasediaclose"

Utilizando el conjunto completo de años entre 1980 y 2006 obtenemos varias relaciones lineales, según el criterio seguido. La representación gráfica de dicha relación se tiene en al figura 5.4

$$
\begin{gathered}
\text { Clasediapol }=12,099+0,561 * \text { Clasedia } 1 \\
\text { Clasediapol }=12,102+0,554 * \text { Clasediaclose }
\end{gathered}
$$

Ambas relaciones son estadísticamente significativas para un nivel de confianza del $99 \%$, explicando el $69 \%$ de la variabilidad de la clase de Clasediapol y con un coeficiente de correlación de 0,833 y 0,832 respectivamente. El error estándar de la primera relación es de 1,6 clases y el error absoluto medio de 1,3. La representación gráfica de este ajuste se muestra en la figura 5.3. 


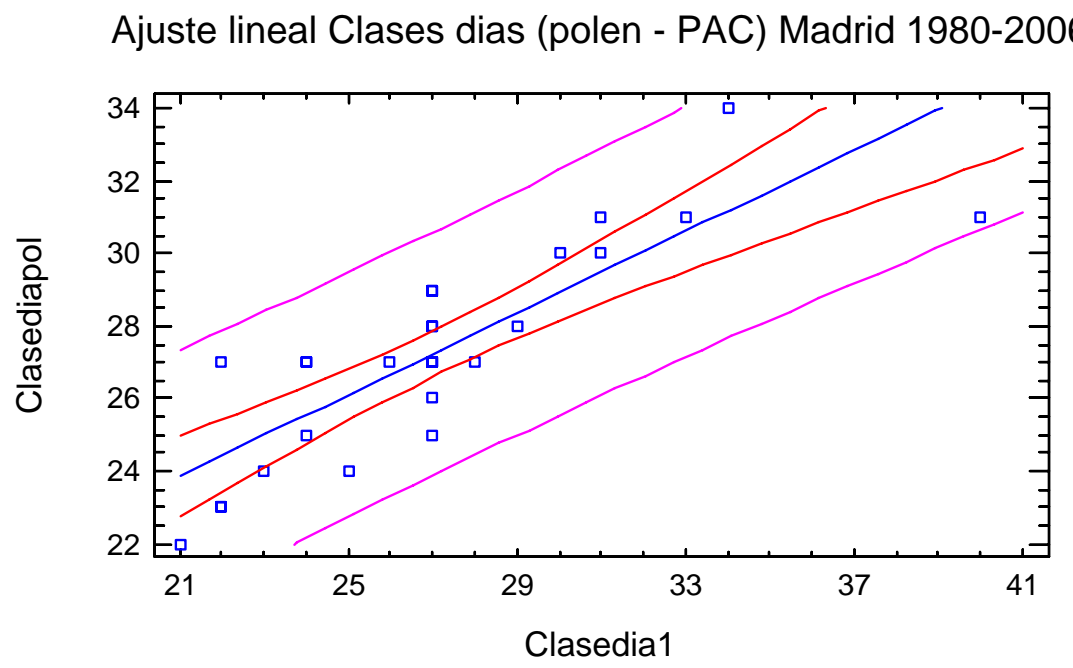

Fig. 5.3. Ajuste lineal entre la clase de día de inicio de la polinización del polen de plátano (umbral $=30$ granos $/ \mathrm{m}^{3}$ ) en el observatorio de Madrid General Pardiñas y el día en que la acumulación de grados día del PAC de Madrid Retiro se encuentra por primera vez entre $45 \mathrm{y}$ 55 grados día. Periodo estudiado: 1980-2006.

Un análisis de los puntos más influyentes muestran como el año 1986 condiciona dicha relación. Tras eliminarlo, el siguiente año que muestra un comportamiento más singular es el año 1987. Ambos puntos se encuentran en los márgenes del diagrama de dispersión, por lo que no afectan. Eliminando ambos años de la serie, para el resto obtenemos las siguientes relaciones lineales:

$$
\begin{aligned}
& \text { Clasediapol }=6,16667+0,783333 * \text { Clasedia } 1 \\
& \text { Clasediapol }=6,67011+0,755527 * \text { Clasediaclose }
\end{aligned}
$$

Ambas relaciones son estadísticamente significativas para un nivel de confianza del $99 \%$, explicando el 84 y el $82 \%$ de la variabilidad de la clase de Clasediapol y con un coeficiente de correlación de 0,915 y 0,907 respectivamente. El error estándar de la primera relación es de 1,2 clases y el error absoluto medio de 0,9 . Si empleamos pues esta relación para predicción utilizaremos un factor de tolerancia de $+/-1$ clase para evaluar nuestros pronósticos. En la figura 5.4 se representa esta relación excluyendo 1986 y 1987. Se puede concluir que la relación estadística entre el PAC y la fecha de inicio de la temporada de polinización es muy fuerte. 


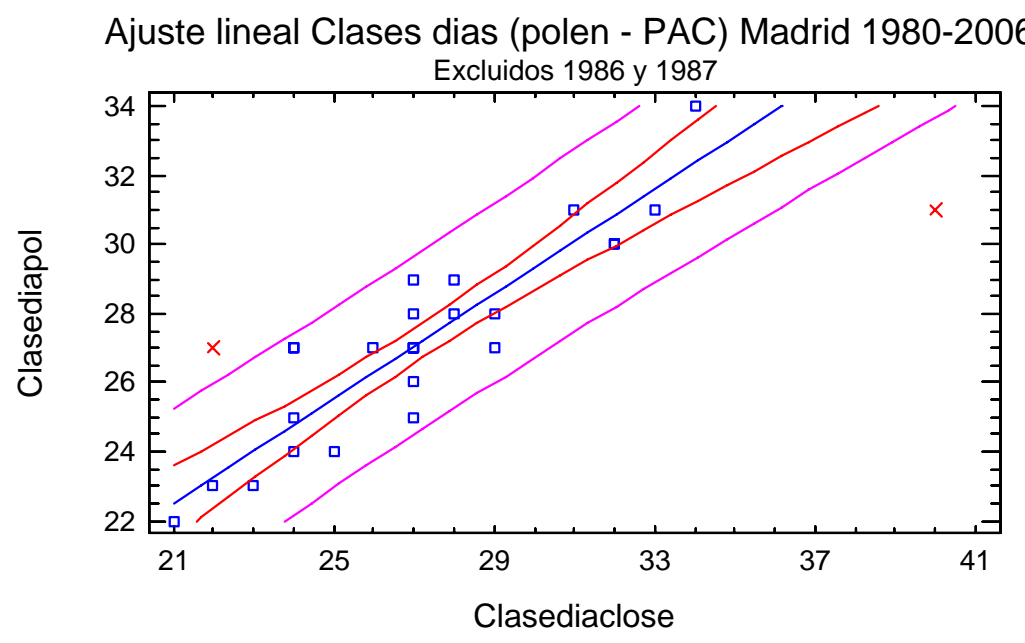

Fig. 5.4. Ajuste lineal entre la clase de días de inicio de la polinización del polen de plátano (umbral $=30$ granos $/ \mathrm{m}^{3}$ ) en el observatorio de Madrid General Pardiñas y el día en que la acumulación de grados día del PAC de Madrid Retiro se encuentra por primera vez entre $45 \mathrm{y}$ 55 grados día. Periodo estudiado: 1980-2006. La equis roja de la derecha corresponde al año 1986 y la equis roja de la izquierda a 1987.

Hay que citar otros procedimientos como el de García-Mozo et al. 2002 en el que se utiliza un método un poco más sofisticado teniendo en cuenta la variación diaria simulada mediante un modelo de onda diurna sinusoidal y que se aplica a árboles del género Quercus con fechas de inicio de la polinización similares a la del plátano. El ajuste de umbrales de acumulación y la cantidad de acumulación sobre ese umbral se ajustan entre ambos y para cada observatorio. En nuestro método, partimos de la base de que la zona de Madrid tiene un comportamiento climático único y que el árbol solo responderá a partir de acumulaciones de calor claras, por lo que se parte de umbrales fijos para máximas y medias que están en la parte alta de los utilizados en el trabajo de García-Mozo.

Nuestra impresión para el plátano es que solo es necesario computar los periodos sostenidos de calor y que, la utilización de un umbral alto, muestra mediante la representación gráfica del PAC, la interrupción en el proceso de desarrollo de las flores mejor que otros procedimientos.

Por último, se procedió a realizar un fichero con las condiciones de temperatura y lluvias observadas cada año desde finales de febrero hasta la fecha en la que se produjo el inicio de la temporada de polinización y que sirve como tabla auxiliar para ayudar a la predicción del inicio de la temporada

\subsection{ESTUDIOS SERIES PALINOCAM. 1994.2007}

En este apartado se analiza el comportamiento estadístico de las series diarias de polen de plátano entre marzo y abril (los únicos meses en que se miden cantidades significativas) para 6 estaciones de la Comunidad de Madrid pertenecientes a la red PalinoCAM. 
Se consideraron las series de Aranjuez (AR), Alcobendas (AL), Getafe (GT), Leganés (LG), Ciudad Universitaria (CU), General Pardiñas (GP). Las series de Coslada y Alcalá no se tuvieron inicialmente en cuenta por recomendación de los gestores de la red. En un caso por la poca presencia de plátanos en Coslada y en la otra por que el captador está situado en medio de ellos.

Se calcula el resultado de realizar correlaciones cruzadas por rangos de Speaman entre ellos que muestra que la relación más fuerte se produce entre Getafe y General Pardiñas con 0,87 . En cambio, la serie de Leganés es la que muestra menor correlación. Este hecho podría explicarse debido a que la población de plátanos en los alrededores ha ido evolucionando mucho en el periodo de tiempo considerado.

$\begin{array}{lcccccc} & \text { AR } & \text { AL } & \text { GT } & \text { LG } & \text { CU } & \text { GP } \\ \text { AR } & 1,00 & 0,77 & 0,83 & 0,64 & 0,81 & 0,84 \\ \text { AL } & 0,77 & 1,00 & 0,76 & 0,60 & 0,78 & 0,75 \\ \text { GT } & 0,83 & 0,76 & 1,00 & 0,73 & 0,80 & 0,87 \\ \text { LG } & 0,64 & 0,60 & 0,73 & 1,00 & 0,61 & 0,75 \\ \text { CU } & 0,81 & 0,78 & 0,80 & 0,61 & 1,00 & 0,85 \\ \text { GP } & 0,84 & 0,75 & 0,87 & 0,75 & 0,85 & 1,00\end{array}$

Tabla 5.1. Correlación de rangos de Spearman para los valores diarios de total de polen de plátano en marzo y abril de las estaciones de Aranjuez (AR), Alcobendas (AL), Getafe (GT), Leganés (LG), Ciudad Universitaria (CU), General Pardiñas (GP). Periodo 1994-2006.

Observatorio por observatorio, se ve que la mejor correlación de la serie de Aranjuez es con General Pardiñas (con Getafe también es muy buena), la de Alcobendas es con Ciudad Universitaria, la de Getafe es con General Pardiñas, la de Leganés es también con General Pardiñas, Ciudad Universitaria también con General Pardiñas y esta última tiene su mejor correlación con Getafe.

Hemos utilizado este tipo de correlación en vez de la de Pearson por que es más robusto frente a la existencia de valores que se separan mucho de la media como es el caso de los altos valores de polen de plátano que se producen en algunos días. Todos los pares de valores muestran correlación significativa a un nivel de confianza igual o superior al $95 \%$.

Hay que destacar como resumen, la significativa relación entre las series de recuentos de polen de plátano de Getafe y la de General Pardiñas, siendo mejor la relación entre estas que entre esta última y Ciudad Universitaria. Como también tiene relación apreciable con Alcobendas, hay que concluir que el comportamiento de la serie de General Pardiñas puede ser un buen resumen de lo que sucede en la ciudad y sus alrededores.

Por otra parte hay que destacar la relación entre Aranjuez y Ciudad Universitaria que probablemente se explique por que ambos observatorios están en un clima similar en las zonas bajas de los valles y menos afectados por núcleos urbanos. Hay que recordar que la Ciudad Universitaria conecta con las grandes zonas boscosas de la casa de Campo y el monte del Pardo. 


\subsection{EVALUACIÓN DE LOS MODELOS DE PREDICCIÓN SEGÚN UMBRALES. RESULTADOS}

Por último, mostraremos los resultados de dos tipos diferentes de modelos estadísticos de pronóstico del inicio de la temporada de polinización del plátano en Madrid. Antes de ello, daremos cuenta de un ensayo realizado para mostrar las posibilidades de realizar una alerta a fecha 1 de marzo de la posibilidad de que venga avanzada la temporada de polinización del plátano. Se calculó a fecha 28 de febrero, el valor acumulado del PAC del observatorio Madrid Retiro y se comparó con las fechas de inicio de la temporada en Madrid General Pardiñas. El resultado aparece en la tabla 5.2

$\begin{array}{cccccc}\text { AÑO } & \text { Grados } & \text { Fecha inicio } & \text { AÑO } & \text { Grados } & \text { Fecha inicio } \\ 1986 & 0,7 & \text { 03-abr } & 1985 & 9,7 & 31-\text { mar } \\ 2006 & 0,8 & 25-\mathrm{mar} & 1989 & 10,2 & 21-\mathrm{mar} \\ 2005 & 1,4 & 28-\mathrm{mar} & 1987 & 10,5 & 20-\mathrm{mar} \\ 1996 & 1,9 & 29-\mathrm{mar} & 1981 & 10,9 & 27-\mathrm{mar} \\ 1993 & 2,0 & 22-\mathrm{mar} & 1980 & 11,6 & 31-\mathrm{mar} \\ 1991 & 2,4 & 02-\mathrm{abr} & 2002 & 11,7 & 23-\mathrm{mar} \\ 1988 & 3,5 & 21-\mathrm{mar} & 1983 & 12,5 & 16-\mathrm{mar} \\ 1994 & 3,9 & 14-\mathrm{mar} & 1995 & 15,3 & 18-\mathrm{mar} \\ 1992 & 5,0 & 19-\mathrm{mar} & 1999 & 15,9 & 21-\mathrm{mar} \\ 1984 & 6,0 & 10-\mathrm{abr} & 2004 & 21,9 & 21-\mathrm{mar} \\ 2003 & 6,3 & 20-\mathrm{mar} & 1998 & 27,1 & 08-\mathrm{mar} \\ 1982 & 6,8 & 23-\mathrm{mar} & 1997 & 28,0 & 06-\mathrm{mar} \\ 2001 & 9,4 & 16-\mathrm{mar} & 2000 & 31,8 & 07-\mathrm{mar} \\ & & & 1990 & 38,7 & 14-\mathrm{mar}\end{array}$

Tabla 5. 2. Clasificación de la fecha de inicio de la estación polínica del plátano, en relación al calor acumulado desde el 1 de enero hasta finales de febrero. Series Madrid General Pardiñas y Madrid Retiro. Años 1980-2006.

Se puede observar como los cuatro años en que comenzó antes, tienen los mayores valores previos de acumulación de calor a fecha 28 de febrero. Parece lícito suponer que si los valores de acumulación observados en el futuro, están en ese rango de valores, se podrás presuponer que ese año, habrá un inicio temprano de la estación de polinización.

Teniendo en cuenta la serie larga de polen de Madrid-General Pardiñas y la serie de temperaturas de Madrid-Retiro bajo los criterios de agregación en clases expresados en el párrafo 5.2, el pronóstico de la clase de día (agrupaciones de 3 en 3 días) con error de $+/-1$ clase, mediante la fórmula 1 (incluyendo los años 86 y 87) obtiene los resultados que se expresan en la tabla 5.3. Juliano calor indica el día en que se sobrepasa el umbral de acumulación de calor. Juliano polen, el día en que se sobrepasa el umbral de 30 granos $/ \mathrm{m}^{3}$ de concentración media diaria de polen de plátano.

Se observa el importante error cometido en el pronóstico en 1986 y 1987, ambos errores son de signos opuestos lo que podría indicar que estamos ante alguna singularidad importante no recogida por el modelo y que requiere un estudio especial tanto de la calidad del dato de polen como de la situación meteorológica. Si no se consideraran ambos años, los indicadores de habilidad para predicción subirían. 


\begin{tabular}{|c|c|c|c|c|c|c|}
\hline Ã̃̃ & Juliano calor & $\begin{array}{c}\text { Juliano } \\
\text { polen }\end{array}$ & Aciertos & $\begin{array}{c}\text { Falsas } \\
\text { Alarmas }\end{array}$ & Retrasos & Dif días \\
\hline 1980 & 92 & 91 & 1 & 0 & 0 & 1 \\
\hline 1981 & 82 & 86 & 1 & 0 & 0 & -4 \\
\hline 1982 & 81 & 82 & 1 & 0 & 0 & -1 \\
\hline 1983 & 72 & 75 & 1 & 0 & 0 & -3 \\
\hline 1984 & 100 & 101 & 1 & 0 & 0 & -1 \\
\hline 1985 & 97 & 90 & 0 & 0 & 1 & 7 \\
\hline 1986 & 120 & 93 & 0 & 0 & 1 & 27 \\
\hline 1987 & 67 & 79 & 0 & 1 & 0 & -12 \\
\hline 1988 & 81 & 81 & 1 & 0 & 0 & 0 \\
\hline 1989 & 71 & 80 & 0 & 1 & 0 & -9 \\
\hline 1990 & 70 & 72 & 1 & 0 & 0 & -2 \\
\hline 1991 & 98 & 92 & 0 & 0 & 1 & 6 \\
\hline 1992 & 78 & 79 & 1 & 0 & 0 & -1 \\
\hline 1993 & 86 & 81 & 0 & 0 & 1 & 5 \\
\hline 1994 & 74 & 71 & 1 & 0 & 0 & 3 \\
\hline 1995 & 81 & 77 & 1 & 0 & 0 & 4 \\
\hline 1996 & 96 & 89 & 0 & 0 & 1 & 7 \\
\hline 1997 & 63 & 64 & 1 & 0 & 0 & -1 \\
\hline 1998 & 66 & 67 & 1 & 0 & 0 & -1 \\
\hline 1999 & 80 & 80 & 1 & 0 & 0 & 0 \\
\hline 2000 & 67 & 67 & 1 & 0 & 0 & 0 \\
\hline 2001 & 81 & 75 & 0 & 0 & 1 & 6 \\
\hline 2002 & 81 & 82 & 1 & 0 & 0 & -1 \\
\hline 2003 & 72 & 79 & 0 & 1 & 0 & -7 \\
\hline 2004 & 80 & 81 & 1 & 0 & 0 & -1 \\
\hline 2005 & 80 & 87 & 0 & 1 & 0 & -7 \\
\hline 2006 & 86 & 84 & 1 & 0 & 0 & 2 \\
\hline \multicolumn{3}{|c|}{ Prob de Detección } & \multicolumn{2}{|c|}{ POD } & \multicolumn{2}{|r|}{0,63} \\
\hline \multicolumn{2}{|c|}{ Falsa Alarma } & & \multicolumn{2}{|c|}{ FAR } & \multicolumn{2}{|r|}{0,15} \\
\hline \multicolumn{2}{|c|}{ Predice tarde } & & \multicolumn{2}{|c|}{ Miss (\%) } & & 0,22 \\
\hline
\end{tabular}

Tabla 5.3. Evaluación del pronóstico de clase ( 3 días) para día de inicio de la temporada del polinización del plátano en la zona central de la ciudad de Madrid (clases de 3 días). Se permite un error de +/- 1 clase. Series temporales entre 1980 y 2006.

Para obtener representatividad espacial sobre Madrid y sus poblaciones circundantes, se optó por realizar un promediado de los valores de grados día acumulados para los cinco observatorios meteorológicos y también realizar un promediado de datos de polen acumulados para los observatorios de Madrid-General Pardiñas, Madrid-Ciudad Universitaria y Getafe. Los días en que se superan los umbrales de 50 grados día por un lado y de 30 granos $/ \mathrm{m}^{3}$ acumulados se pueden ver en la Tabla 5.5. Si permitimos un error de $+/-2$ días y utilizamos dicho valor de acumulación de temperatura como predictor, los resultados y la evaluación del pronóstico se encuentran también en dicha tabla. En esta tabla y en la anterior hay que tener en cuenta que el fenómeno SIEMPRE se produce, por lo que no tiene sentido utilizar algunos indicadores como el Índice Crítico de Acierto (CSI).

El resultado es similar al del otro método empleado, con una probabilidad de detección de la fecha de inicio relativamente elevada. Teniendo en cuenta que el valor 
climatológico del inicio de la estación sería el día 79 (20 de marzo), se observa que de los 9 aciertos, en siete de ellos la fecha prevista difiere en más de dos días de dicho valor, otorgando valor a dicha predicción sobre la mera climatología. De los 5 fallos, solo en un caso, el valor climatológico hubiera sido acertado.

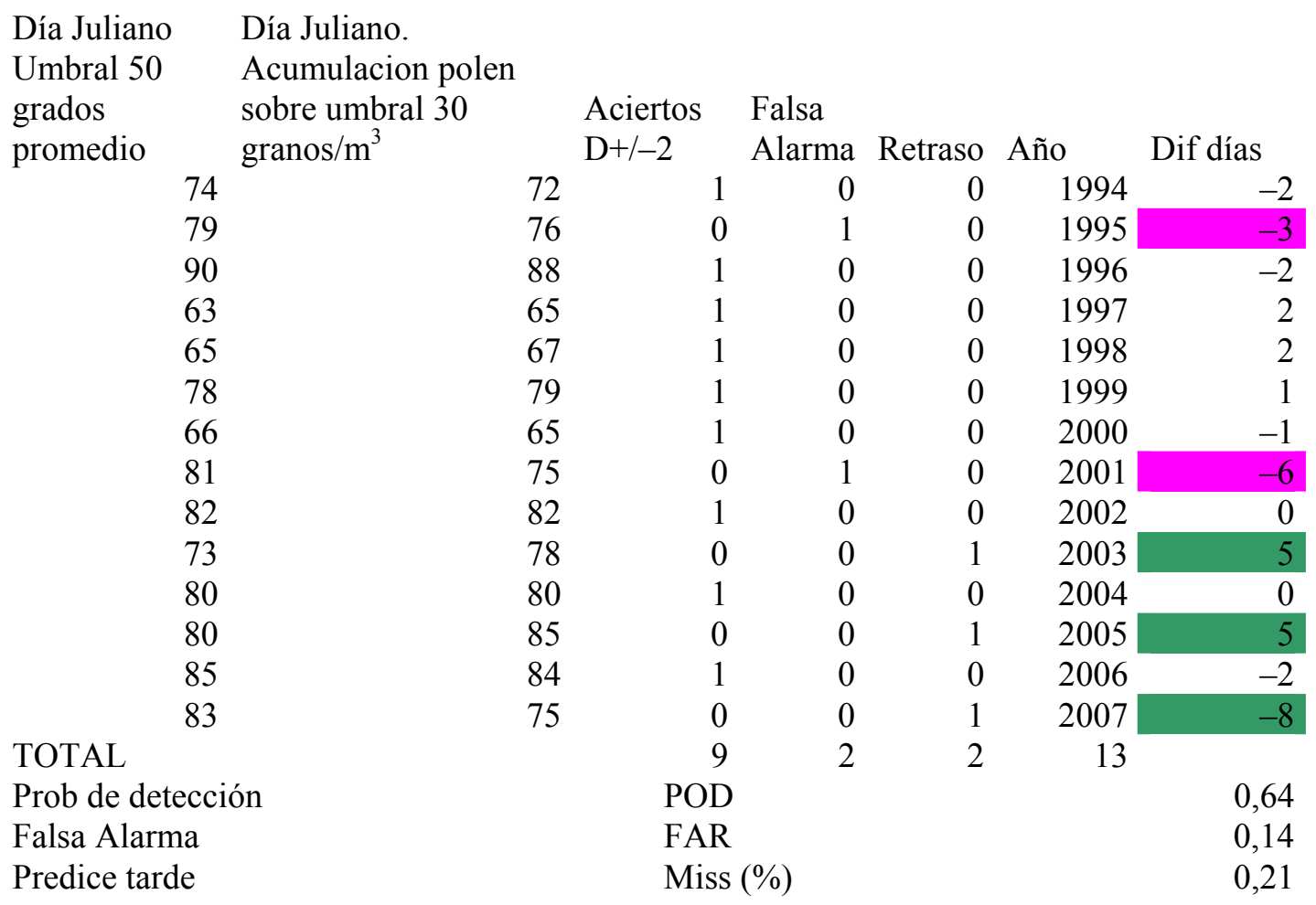

Tabla 5.5. Evaluación del pronóstico de día de inicio de la estación polínica del plátano en Madrid ciudad y periferia a partir de los promedios de acumulación de calor se cinco observatorios de Madrid y periferia. Se permite error de $+/-2$ días. Series temporales entre 1994 y 2007.

\section{REFERENCIAS Y BIBLIOGRAFÍA}

Alcázar, P., P. Cariñanos, C. De Castro, F. Guerra, C. Moreno, E. Domínguez-Vilches, C. Galán. Airborne plane-tree (Platanus hispanica) pollen distribution in the city of Córdoba, South-western Spain, and possible implications on pollen allergy. J. Invest Allergol Clin Immunol 2004; Vol. 14(3): 238-243.

Camacho, J.L, D. Cano, P. Cervigón, A.M. Gutiérrez, Javier Subiza. Predicción de eventos extremos de pólenes alergénicos en la Comunidad de Madrid. Inicio de la temporada de polinización del plátano de sombra. XXX Jornadas Científicas de la AME. Zaragoza, 5-7 mayo 2008.

García-Mozo H., C. Galán, V. Jato, J. Belmonte, C. Díaz de la Guardia, D. Fernández, M. Gutiérrez, M.J. Aira, J.M. Roure, L. Ruiz, M.M. Trigo, E. Domínguez-Vilches. Quercus pollen season dynamics in the Iberian Peninsula. Response to meteorological parameters and possible consequences of climate change. Ann Agric Environ Med 2006, 13, 209-224. 
García-Mozo, H., C. Galán, M.J. Aira, J. Belmonte, C. Díaz de la Guardia, D. Fernández, A.M. Gutierrez , F.J. Rodríguez, M.M. Trigo, E. Domínguez-Vilches. "Modelling start of oak pollen season in different climatic zones in Spain" Agricultural and Forest Meteorology, 110 (2002) 247-257.

Laadi, M., Michel Thibaudon, Jean-Pierre Besancenot. "Two statistical approaches to forecasting the start and duration of the pollen season of Ambrosia in the area of Lyon (France)”. Int. J. Biometeorol (2003), 48. 65-75.

Subiza, J, M. Jerez, M.J. Gavilán, S. Varela, R. Rodríguez, M.J. Narganes, J.A. Jiménez, J. Tejada Cazorla, C. Fernández Pérez, M. Cabrera y E. Subiza ¿Cuáles son los pólenes que producen polinosis epidémica en el medio urbano de Madrid? Rev. Esp. Alergol Inmunol Clín, Abril 1998 Vol. 13, Núm. 2, pp. 107-119.

Varela, S., J. Subiza, J.L. Subiza, R. Rodríguez, B. García, M. Jerez, J.A. Jiménez, R. Panzani. Platanus pollen as an important cause of pollinosis. J. Allergy Clin. Immunol. 1997, 6:748-754.

Weryszko-Chmielewska, E., M. Puc, K. Piotrowska. Effect of Meteorological Factors on Betula, Fraxinus and Quercus Pollen Concentrations in the Atmosphere of Lublin and Szczecin, Poland. Ann Agric Environ Med 2006, 13, 243-249. 


\section{MÉTODO DE PREDICCIÓN. EJEMPLO DE MARZO 2008 y 2009}

\section{Darío Cano. AEMET}

El objetivo es generar un producto de predicción en la Delegación en Madrid de AEMET para la predicción de la aparición del polen de plátano que pueda ser utilizado como ayuda para una alerta sanitaria. Hemos realizado dos experimentos en el año 2008 y 2009 con objeto de evaluar la disposición técnica de la Delegación para elaborar este producto de manera casi automática para la provincia de Madrid. El producto empieza a elaborarse y emitirse a partir del 1 de Enero. El "predictor" es el índice PAC que da cuenta de la cantidad de calor acumulado.

\subsection{DESCRIPCIÓN DEL MÉTODO}

Una rutina informática extrae de la "matriz de predicción" para municipios de España, elaborada en la AEMET a partir de las predicciones del modelo ECMWF con la técnica EPS, los valores de temperaturas extremas y precipitación prevista en los municipios elegidos. Se extraen, también, de la base de datos climatológica, los valores observados en los mismos puntos el día anterior. Por correo electrónico se reciben los datos de polen de la red PALINOCAM y una serie de fotografías de emplazamientos elegidos con un comentario botánico, que dan cuenta del desarrollo de la flor.

Se elabora un producto gráfico que integra esta información y se envía por e-mail a los simulados usuarios. El procedimiento es sencillo y no requiere de desarrollos informáticos complejos, aunque todavía el producto final se elabora de forma manual.

Se han hecho pruebas para la elección de los umbrales: en cada estación concreta, en medias ponderadas de distintas estaciones, etc. De momento, el producto que hemos simulado en operación ha sido con un umbral de $50^{\circ}$ para el PAC de la estación del Retiro como "predictor" del inicio de la polinización en cualquier estación de la red PALINOCAM en Madrid.

Se ha ensayado también el uso de las observaciones meteorológicas cercanas al medidor de Polen, de manera que cada umbral del índice PAC esté referido a la serie de observación elegida por cercanía, pero no parece que se mejoren mucho más las predicciones.

Como resultado adicional se ha obtenido una base de datos, en la que se integran los datos meteorológicos y de polen, con todos los años disponibles. Intentamos hacer una predicción mediante el método de "análogos", buscando años de comportamiento similar al año que es objeto de la predicción. Aunque los resultados no son todavía muy determinantes la base de datos gráfica es de gran interés, creemos, para comprender y profundizar en el estudio.

Hay que señalar que la precipitación no parece tener relación determinante con la fecha de aparición. Este hecho puede justificarse por tratarse de una especie cultivada con aporte de agua por riego. 

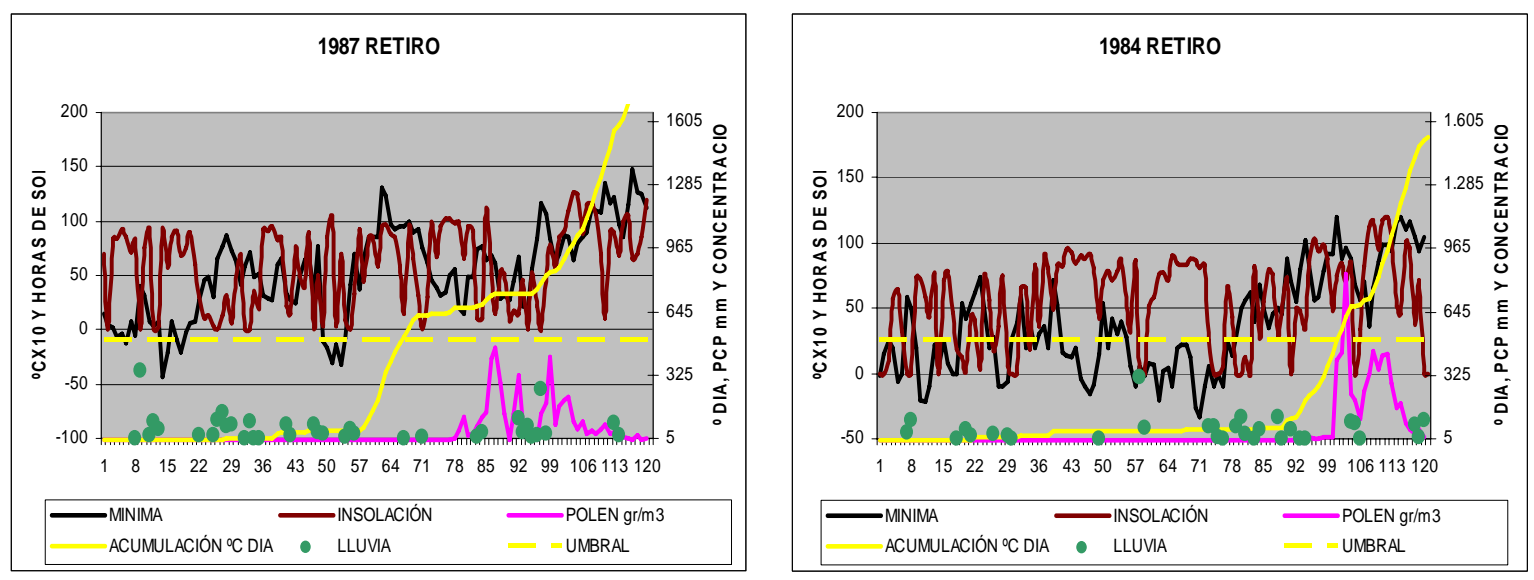

Figura 6.1. Representación gráfica para los años 1987 y 1984 de la evolución de las variables meteorológicas en El Retiro y de la concentración del polen de plátano en Madrid General Pardiñas. El umbral del predictor PAC es $50{ }^{\circ} \mathrm{C}$. El año 1987 aparece el polen el día juliano 79 y el año 1984 el día 95. (El año 1984 es el registro más tardío en la aparición del polen).

También se ha hecho un seguimiento visual del desarrollo de las flores del Plátano para evaluar un "diagnóstico" botánico que sirva en la predicción. La vía es de gran interés y abre puertas a una apasionante colaboración con los botánicos en el desarrollo de la fenología.

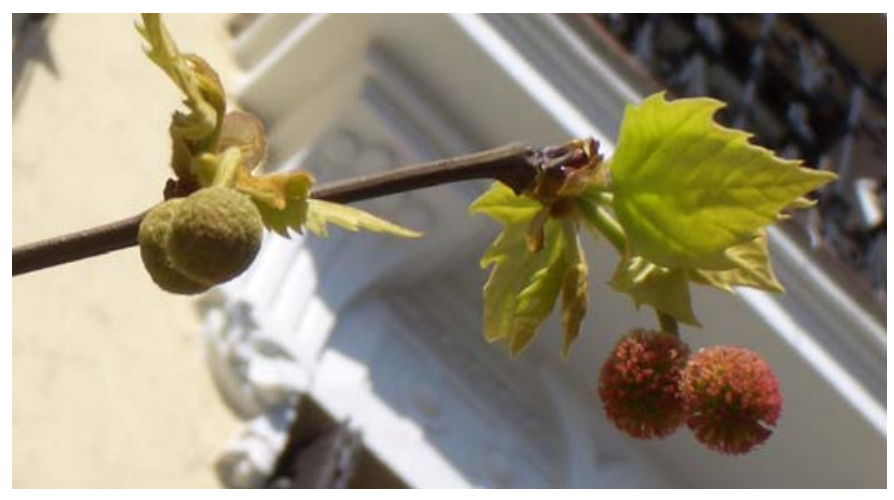

Figura 6.2. Estado de las inflorescencias el día 15 de marzo de 2008, en los árboles del paseo Reina Cristina (Madrid, Retiro). Inflorescencias masculinas verde-amarillentas a punto de emitir el polen e inflorescencias femeninas rojiza y de mayor tamaño.

Un primer resultado de este estudio ha sido darnos cuenta de los errores difundidos por los libros de botánica que sitúan, en reiteradas y modernas ediciones, la polinización del plátano a primeros de mayo en Madrid, mes y medio más tarde que lo que se observa actualmente.

Aunque el ajuste en la tendencia de la fecha de aparición del polen no es muy significativo, la tendencia es negativa, esto es, cada vez ocurre más pronto. Con esta tendencia, en el año 1960 el plátano florecía el 30 de marzo (día 90) y el año 2008 lo haría el día 77 (17 de marzo). Dentro de 20 años lo hará el día 70 (10 de marzo). Las fechas de abril o mayo que aparecen en los libros de botánica como aparición de las flores del plátano se deben remontar, según esta tendencia a, a 80 años antes de la serie 
Subiza. O sea, a principios del siglo XX los plátanos debían florecer sobre el 20 de abril.
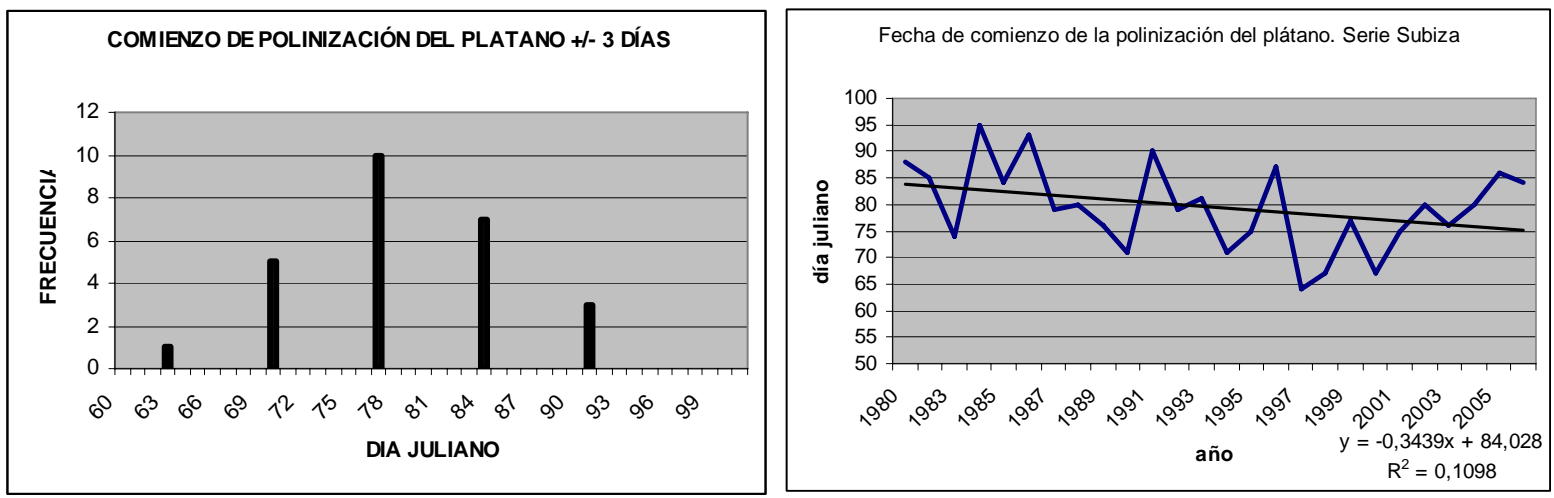

Figura 6.3. a) En el eje $\mathrm{x}$ los días julianos y en el eje y el número de años en que la polinización comenzó con $+/-3$ días. Los datos se han obtenido de la serie de observación de General Pardiñas (barrio de Salamanca o serie Subiza)) desde 1980 hasta 2007. b) evolución de la fecha de aparición del polen.

\subsection{APLICACIÓN A LOS AÑOS 2008 Y 2009}

El comportamiento climatológico de estos años en El Retiro, comparado con el período 1960-1990 fue como sigue:

\begin{tabular}{|r|l|l|l|}
\hline & \multicolumn{1}{|c|}{ Enero } & \multicolumn{1}{|c|}{ Febrero } & \multicolumn{1}{c|}{ Marzo } \\
\hline $\begin{array}{r}2008 \text { T } \\
\text { P }\end{array}$ & $\begin{array}{l}\text { Cálido } \\
\text { normal }\end{array}$ & $\begin{array}{l}\text { Extremadamente cálido } \\
\text { seco }\end{array}$ & $\begin{array}{l}\text { Muy cálido } \\
\text { Muy seco }\end{array}$ \\
\hline $\begin{array}{r}2009 \text { T } \\
\text { P }\end{array}$ & $\begin{array}{l}\text { Frío } \\
\text { normal }\end{array}$ & $\begin{array}{l}\text { Normal } \\
\text { normal }\end{array}$ & $\begin{array}{l}\text { Muy cálido } \\
\text { normal }\end{array}$ \\
\hline
\end{tabular}

Tabla 6.1. Carácter climático de los meses de invierno. Fuente AEMET. T es la Temperatura y P la Precipitación.

Los dos años, el polen aparece el mismo día, día juliano 75. Tienen en común un mes de marzo muy cálido.

\subsubsection{Desarrollo de la predicción en el año 2008}

El polen aparece el día juliano 75 en la estación medidora de General Pardiñas, este día es el mismo en que el PAC del Retiro alcanza el valor $50^{\circ}$. La superación del umbral. Fue prevista, por primera vez, el día 71 aunque la predicción del día siguiente, reduce el valor y elimina la alarma. 


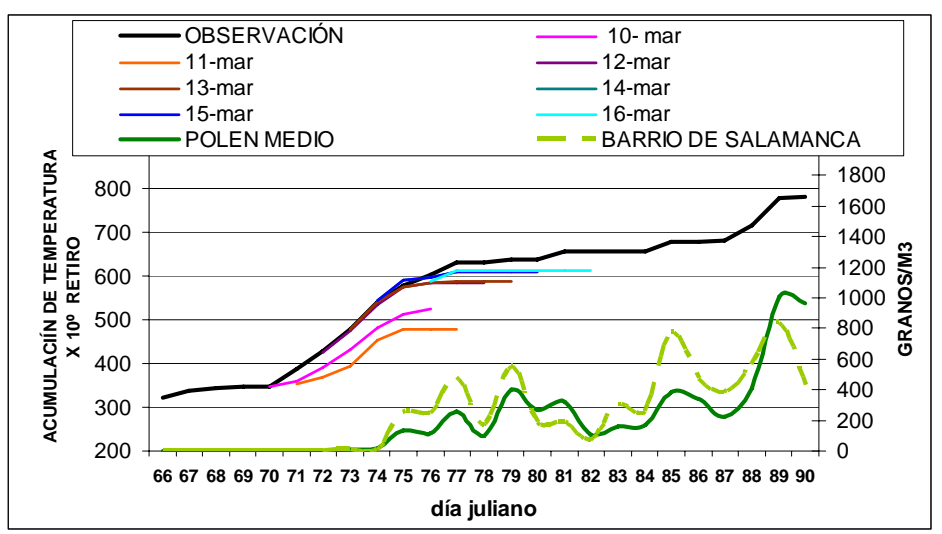

Figura 6.4. Comportamiento del PAC observado y de las predicciones en torno a las fecha de aparición del polen.

La dispersión de las predicciones es debida a la imprecisión del pronóstico de las temperaturas mínimas. Se prevé una intrusión polar que detendrá la acumulación de calor y hay incertidumbre en el momento en que esto va a ocurrir.

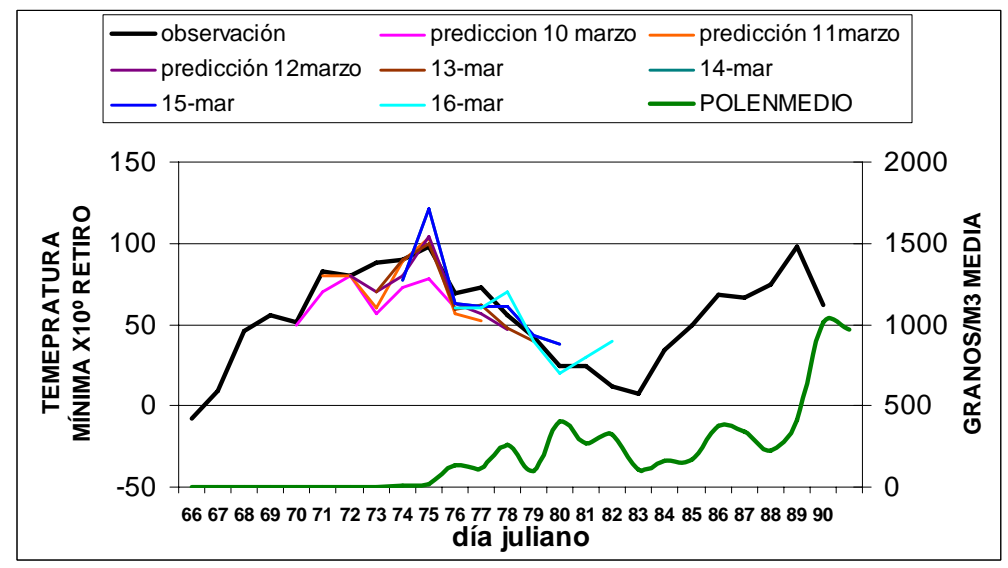

Figura 6.5. Evolución de las temperaturas mínimas, la concentración del polen y las predicciones a 7 días.

\subsubsection{Desarrollo de la predicción en el año 2009}

El polen aparece por primera vez el día juliano 75 (15 de marzo) en la estación medidora de Getafe. Este día es el mismo en que el PAC del Retiro alcanza el valor $50^{\circ}$. La superación del umbral. Fue prevista, por primera vez, el día 9 de marzo y todas las predicciones siguientes corroboran el día 15 como fecha de inicio.

A diferencia del año 2008, el índice PAC tiene un progresivo y lineal ascenso que no se detendrá prácticamente aunque se reduce la pendiente. Como consecuencia, la predicción es más consistente y por lo tanto más "fiable". 


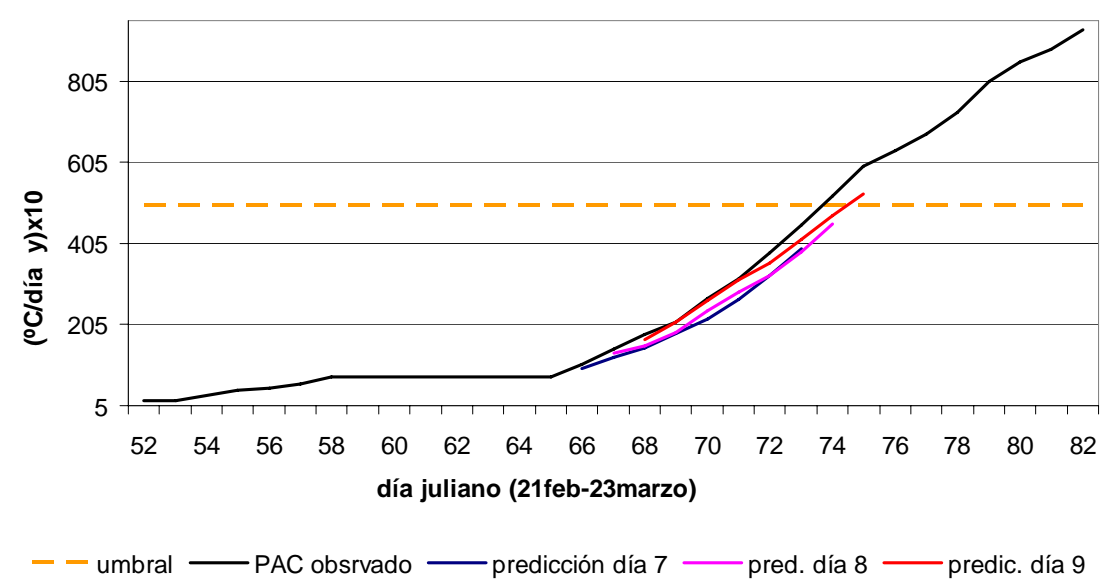

Figura 6.6. Evolución del índice PAC, la concentración del polen y las predicciones a 7 días los días previos al pronóstico de superación del umbral.

\subsection{ConCLuSIÓN}

Desde el punto de vista de la evaluación de las predicciones, el método ha funcionado satisfactoriamente. En los dos años des experimento, 2008 y 2009, el umbral del índice PAC se supera en la estación del Retiro por primera vez siete días antes de la aparición del polen de Plátano en algún punto de la Comunidad de Madrid.

El polen aparece en situaciones estables y soleadas ("veranillos") que se prolongan durante el mes de Marzo. Las intrusiones frías retardan la aparición del polen. Si la aparición del polen está cercana a una intrusión de aire polar, como es el caso del año 2008, la "fiabilidad" de las predicciones puede verse afectada negativamente. Por el contrario, si el pronóstico es de continuación del "veranillo" de marzo, la calidad de la predicción aumenta.

Desde el punto de vista técnico, la elaboración y difusión de un producto de predicción en la Agencia Meteorológica de Madrid, es sencilla y viable.

Humana y socialmente, cabe destacar la colaboración interdisciplinar entre meteorólogos, botánicos y sanitarios en busca de bienestar social. Se abre una puerta hacia el estudio de la fenología desde una perspectiva práctica y avanzada en el uso de herramientas científicas.

\subsection{Propuesta de futuros desarrollos}

Lógicamente, la mejora del producto de predicción está supeditada a la continuación del intercambio de datos entre AEMET y la red PALINOCAM.

En AEMET se cuenta con otros métodos de predicción además de la técnica EPS utilizada. Método de análogos y predicción mediante filtros de Kalman, estos últimos proporcionada por la Delegación en Sevilla. 
Existen otros productos en la Delegación de Madrid para la predicción de temperaturas extremas para 15 días, que podrían ser aprovechados e investigados. Este producto sería de gran interés en el caso de años con "veranillos" continuados en el mes de marzo ya que la predicción es muy "consistente" en estas circunstancias.

La predicción estacional/semanal del ECMWF podría servirnos para anticiparnos en más de dos semanas cuando las condiciones sean de persistencia de la situación meteorológica. 


\title{
7. DESCRIPCIÓN DEL MÉTODO DE PRONÓSTICO DE TEMPERATURAS MÁXIMAS Y MÍNIMAS
}

\author{
Inmaculada Cadenas. AEMET
}

\subsection{INTRODUCCIÓN AL SISTEMA DE PREDICCIÓN POR CONJUNTOS (EPS)}

Con el tiempo los modelos numéricos globales de predicción meteorológica (modelos) mejoraron sustancialmente, fundamentalmente en el corto plazo (hasta $\mathrm{D}+2$ ) y el medio plazo cercano $(\mathrm{D}+3$ hasta $\mathrm{D}+5)$. Se ha observado un aumento gradual del periodo de validez de la predicción, debido sobre todo a una mejor descripción de las condiciones iniciales (mejora en los datos en sí mismos y su asimilación) y sucesivas mejoras en el modelo de predicción del Centro Europeo.

A pesar de la cada vez mayor calidad de las predicciones meteorológica, los modelos globales de alta resolución no consiguen predicciones fiables más allá de unos pocos días. Se considera que la predictibilidad es el alcance hasta el que se puede usar un modelo.

Lorenz añadió un problema más afirmando que el más pequeño error en la especificación de cualquier variable meteorológica (viento, presión, temperatura,..) en cualquier lugar del mundo se amplificará, al cabo de un cierto número de días, dando lugar a una predicción sin valor alguno.

En otras palabras, la atmósfera es un SISTEMA CAÓTICO. Estos sistemas dependen, entonces, de forma sensible de las condiciones iniciales. De acuerdo con Lorenz, el límite teórico para el que una predicción es válida es de dos o tres semanas (predicciones más allá de este periodo no aportan nada a la climatología).

Puesto que no nos podemos fiar totalmente del modelo operativo para elaborar la predicción de medio plazo, en este punto nos podemos preguntar:

No se puede hacera nada acerca de la PREDICIBILIDAD, lo que sí se puede hacer es, entre otras cosas, intentar prever la fiabilidad del modelo. Así el uso de solo un modelo y una única pasada da lugar a una predicción DETERMINISTA.

Cuando se consideran otras salidas de modelos, la predicción surge de un consenso de esas fuentes de información; aunque, la predicción puede ser determinista o puede entrar en juego el concepto de predicción PROBABILISTICA.

\subsubsection{Descripción del EPS (en el ECMWF)}

La estrategia del EPS, se basa en la suposición de que los errores de predicción se deben principalmente a errores del análisis de partida. La forma de tener en cuenta los errores del análisis (análisis de Control) es considerar perturbaciones pequeñas en diferentes regiones del espacio. A partir de estas perturbaciones se origina un conjunto de análisis perturbados y a partir de estos, un conjunto de predicciones. 
De todas las perturbaciones que se pueden aplicar al análisis de Control, solamente unas pocas, son las que más rápidamente crecen desde un punto de vista dinámico.

Estas perturbaciones son las que nos interesan, por las siguientes razones:

- los errores de predicción proceden, en buena parte, de estas perturbaciones;

- son fácilmente identificables mediante métodos matemáticos;

- es un número manejable, varias decenas, que permite a los centros operativos de predicción muestrear bastante bien el estado inicial de la atmósfera.

Para un determinado periodo de tiempo en el que el modelo presenta un comportamiento lineal, las perturbaciones de crecimiento máximo pueden obtenerse con facilidad a partir de Vectores Singulares (VS) de un operador lineal. Las perturbaciones que interesan son aquellas en las que los errores del análisis que presentan un mayor crecimiento dando como resultado grandes errores de predicción.

\section{Propiedades de los VS:}

- los VS definen las direcciones de máxima inestabilidad del espacio de fases de la atmósfera, que están asociadas con el máximo crecimiento de las perturbaciones;

- dependen del llamado intervalo de tiempo de optimización T (periodo de tiempo durante el cual se considera una evolución lineal de las perturbaciones y en el que, por tanto, el modelo A tiene validez; suele estar comprendido entre 36 y 48 horas) y de la definición de norma la perturbación;

- los VS de mayor crecimiento, para $\mathrm{T}=48$ horas, tienen factores de amplificación entre 10 y 20 ;

- tienden a estar localizados y concentrados en las principales regiones de cizalladura vertical de viento (W del Atlántico y Pacífico).

Estos VS están muy localizados, por lo que se les aplica una rotación en el espacio de las fases para dar lugar a N/2 campos con una distribución espacial más uniforme. También son escalados para que tengan un tamaño comparable al de los errores locales del análisis. Para controlar el cambio de escala se utiliza un factor constante, definido como el cociente máximo entre la amplitud de la perturbación y el error del análisis. El resultado son las llamadas PERTURBACIONES INICIALES. Hay que tener en cuenta que estas se calculan y aplican en todo el globo, si bien son fundamentalmente las generadas en el hemisferio norte las que más afectan a Europa.

De todos los VS se seleccionan $\mathrm{N} / 2$ ( $\mathrm{N}$ es el número de análisis y predicciones perturbados que se pretenden construir), con los siguientes criterios:

- los primeros VS son siempre seleccionados;

- no se permite que una zona geográfica esté sobre representada por VS. Para ello un VS será seleccionado si la mitad de la energía total está localizada fuera de las regiones representadas por VS ya seleccionados.

Las diferentes condiciones iniciales o análisis perturbados se obtienen a partir del análisis de Control (NO perturbado), sumando y restando las N/2 perturbaciones iniciales.

Con un modelo de menor resolución que el operativo (el EPS1 T399L62) e integrando los $\mathrm{N}$ análisis perturbados se obtienen $\mathrm{N}$ predicciones (50 miembros del EPS). Con las 
condiciones iniciales sin perturbar (las mismas del modelo operativo) se obtiene el CONTROL.

Además tenemos la predicción del modelo operativo (T799L95), Se dispone por tanto de $\mathrm{N}+2$ predicciones.

\section{Marzo 2008:}

\section{T799 L95: MODELO OPERATIVO}

$0,25^{\circ} \times 0,25^{\circ}$ lat/long grid (unos $\mathbf{2 5} \mathbf{~ k m}$ )

T399 L62: (EPS1) MODELO EPS (10 días) resolución de 50 km, $0,5^{\circ} \times 0,5^{\circ}$ lat $/$ long grid

T255 L62: (EPS2) MODELO EPS (15 días) resolución de unos 80 km, $1,5^{\circ} \times 1,5^{\circ}$ lat/long grid

A lo largo de 2009 se pondrá operativo el modelo T1279 con una resolución de 16 km.

\subsubsection{El EPS en España}

Al principio, en el Centro Nacional de Predicción se recibían por fax los "sellos" para el D+7 y los diagramas de "penachos" para tres ciudades de la Península Ibérica (La Coruña, Madrid y Barcelona). En mayo de 1995 se comienzan a recibir los gráficos de probabilidad (desde el $\mathrm{D}+1$ al $\mathrm{D}+10$ ) de anomalías cálidas y frías en $850 \mathrm{hPa}$, precipitación y velocidad del viento a $10 \mathrm{~m}$. Los predictores hacían uso de estos campos en sí mismos y como indicadores de la fiabilidad del modelo operativo. La probabilidad de anomalías de temperatura en $850 \mathrm{hPa}$ resultaron ser muy útiles en la predicción de olas de calor y de frío.

En abril de 1996 se empieza a recibir los "cluster" medios de Z500 y Z1000.

\section{DESCRIPCIÓN CLUSTER}

Tomando como punto de partida las $\mathrm{n}=\mathrm{N}+1$ predicciones del EPS, es decir $\mathrm{n}$ grupos, el principio del algoritmo del cluster consiste en unir en cada paso los dos grupos más próximos o similares entre sí, mediante un distancia genérica.

Primer paso: Los dos miembros que presentan la distancia mínima constituyen el primer grupo. En esta fase tendremos $n-1$ grupos: el primer grupo y los $n-2$ miembros restantes que conforman grupos individuales.

Segundo paso y sucesivos: Se trata de aplicar sistemáticamente el paso anterior, reduciendo, en cada paso, en una unidad el número de grupos.

Fase final del proceso: Si no se impone ninguna condición el proceso finaliza cuando se hayan agrupado todos los miembros en un único grupo (media del conjunto).

Si lo que interesa es la obtención de varios grupos que den una idea de las diferentes situaciones meteorológicas que se presentan. 


\subsection{TEMPERATURAS MÁXIMAS Y MÍNIMAS A PARTIR DEL EPS}

El primero en abordar el problema de utilizar la técnica del EPS a la obtención de campos meteorológicos en superficie fue Francisco Sánchez Martín. A partir del año 1997 (1/5/1997) al cambiar la situación del Servicio de Aplicaciones Climatológicas y convertirse en el Servicio de Aplicaciones Meteorológicas, en ese momento se incorpora Juan Antonio Navarro, aportando los conocimientos estadísticos necesarios. A partir de 1997 se incorpora al proyecto Inmaculada Cadenas Cortina y más tarde Alberto Fernández... (todas estas personas pertenecientes al Servicio de Aplicaciones Meteorológicas).

Puesto que existen diferencias sustanciales entre la orografía real de España y la proporcionada por el modelo (aun cuando mejora día a día) el método elegido fue el de solicitar al ECMWF el campo de T2m (Temperatura del termómetro seco a $2 \mathrm{~m}$ ) (operativo, control, 50 EPS) interpolado horizontalmente en los puntos en los que existen estaciones que proporcionan datos mediante SYNOP. Se obtienen, por tanto, 51 predicciones para cada alcance de la predicción. Se estudiaron varias posibilidades: solo el operativo, solo el Control, la media, mediana y moda de los EPS, la media de 50 EPS + CONTROL + OPERATIVO...

La variable que proporciona menor error cuadrático medio es la media de los (EPS).

Con los datos observados de los últimos 30 días se resta a la predicción el bias o error medio cometido. Al utilizar los datos observados de temperaturas mínimas (00Z) y máximas (12Z) se obtenían los datos de temperaturas máximas y mínimas. Al cambiar el modelo $i$ ? se pasó a trabajar con 40 alcances (00Z, 06Z, 12Z, 18Z), lo que ha permitido cambiar la hora de la mínima (actualmente se trabaja con la 06Z).

Entre 1999 y 2001 se consideró cambiar la el campo de variable T2m (167), por los campos de temperaturas mínimas (201) y máximas (202). Este cambio complicaba sustancialmente el cálculo y apenas proporcionaba mejoras. En algunos casos empeoró. También se consideró la opción de utilizar menos días para calcular el error medio, pero el número de 31 días se consideró objetivamente para tener en cuenta los posibles errores en los SYNOPS y que existan huecos. En muchos casos basta con 20 días, siempre y cuando se tengan los datos observados y sean buenos. En muchos casos los datos proporcionados tienen errores.

En el año 2003 se pusieron operativas la predicción de las temperaturas (T2m) para las 4 horas que proporciona el modelo T399L62 (00Z, 06Z, 12Z, 18Z), que se añaden a las predicciones de temperaturas extremas. Al añadirse más temperaturas nos encontremos con la posibilidad de que algunas de las temperaturas horarias fuera menor que la mínima o mayor que la máxima, por lo que en el nuevo filtro se tuvo en cuenta esta posibilidad. Asimismo se añadieron más estaciones (304), y se tuvo en cuenta la posibilidad de que si fallase la estación manual se sustituyesen los datos por la automática situada en el mismo punto.

Para seguir explicando el proceso utilizaremos la estación 08221 Madrid/Barajas. 
Los dos EPSgramas que aparecen a la continuación (Fig. 7.1 y Fig. 7.2) corresponden a los dos modelos EPS. Se ha solicitado exactamente el punto en el que está la estación 08221 ,

\section{$40^{\circ} 16^{\prime} 17^{\prime}$ ' $\mathrm{N}, 3^{\circ} 19^{\prime} 26^{\text {' }} \mathrm{W}, 582$ metros de altura}

El primer Epsgrama corresponde al modelo T399 (EPS) y el modelo operativo T799 con los alcances de 4 horas cada día. El Epsgrama proporciona las variables: total cobertura nubosa, total precipitación, velocidad del viento a $10 \mathrm{~m}$, y la temperatura calculada a la altura del la orografía del punto.

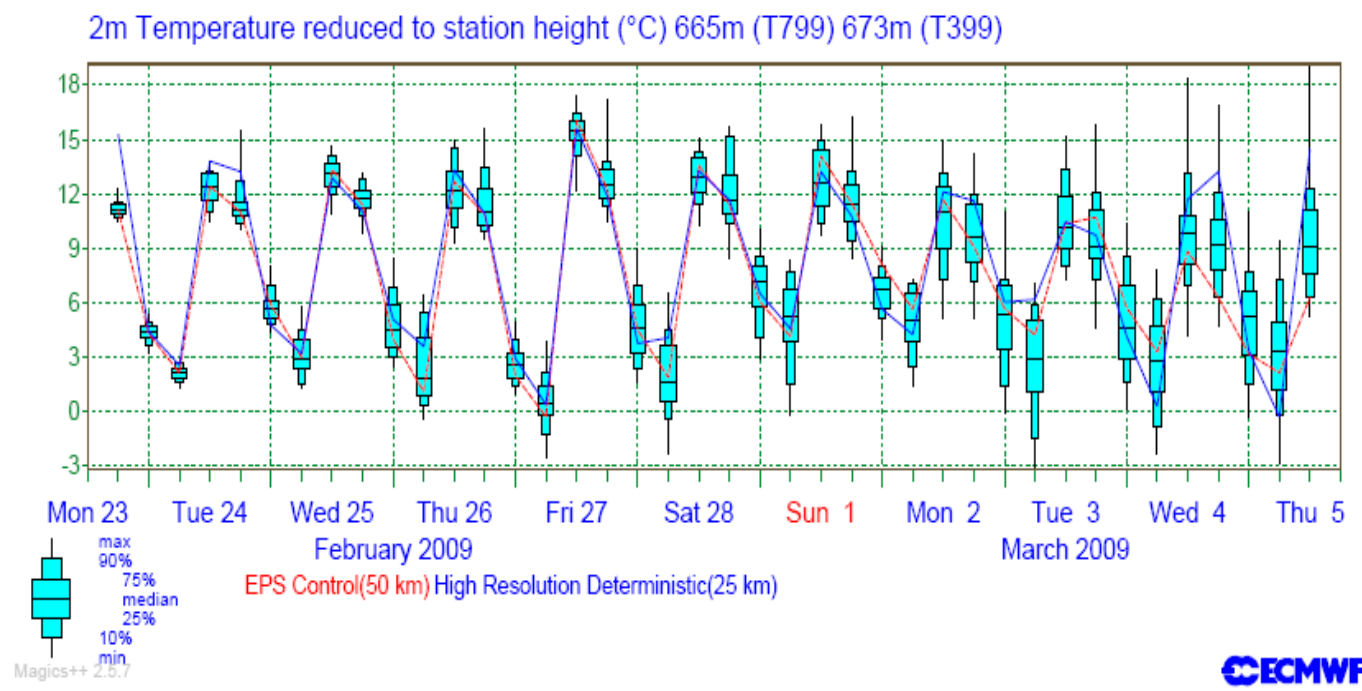

Fig. 7.1. EPSgrama de temperaturas de Madrid a 10 días. Fuente CEPPM.

En el segundo EPSgrama sólo hay una salida del modelo por día y sólo se usa el modelo EPS T255, en cambio aunque el modelo es de peor calidad se obtienen predicciones hasta un alcance de 10 días.

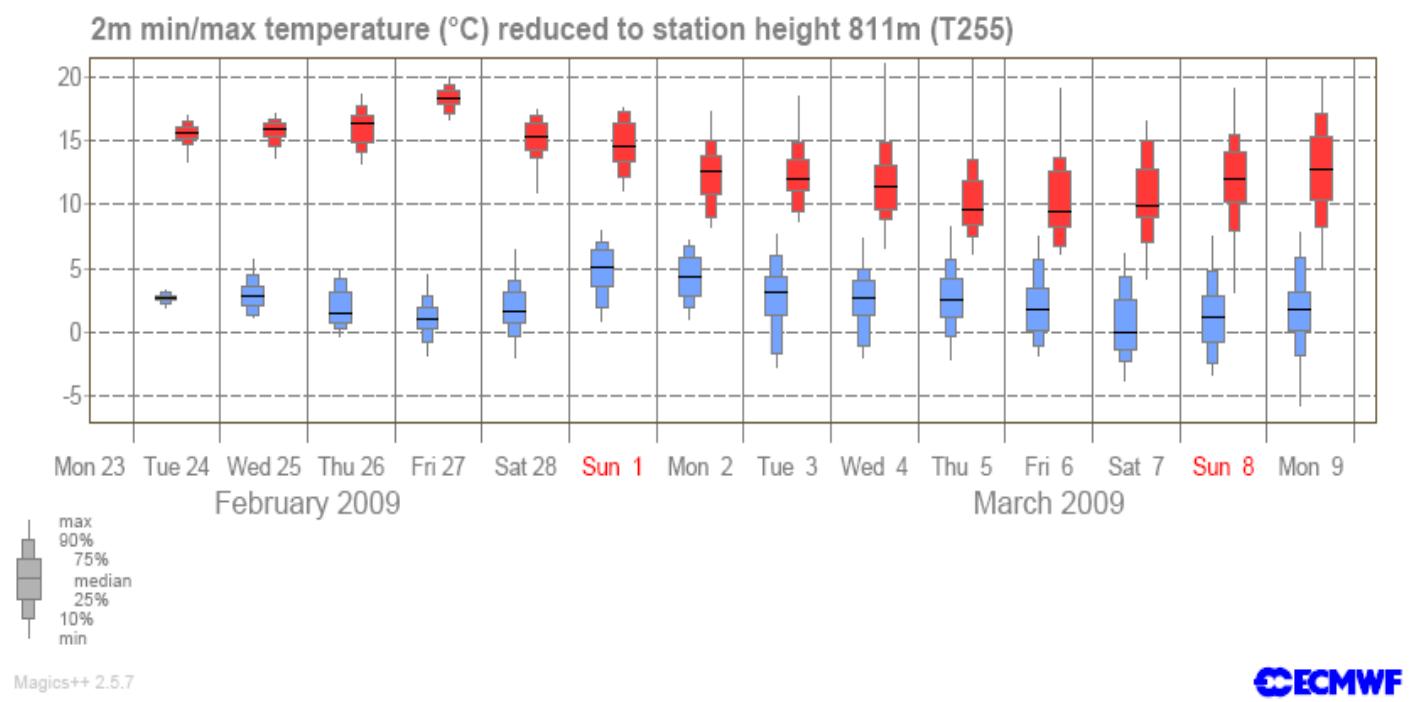

Fig. 7.2. EPSgrama de temperaturas máximas y mínimas de Madrid a 15 días. Fuente CEPPM. 
En la salida de temperatura se ve exactamente las diferencias de altura (OROGRAFÍA) de los 3 modelos respecto al punto real: $\mathbf{6 5 5} \mathbf{m}$ el modelo operativo, $673 \mathbf{m}$ el EPS1, y $811 \mathrm{~m}$ el EPS2, mientras que la altura de Barajas es de 582 metros.

Estas diferencias son las que se intentan compensar con el filtro. La salida a la petición diaria al Centro Europeo (sólo para Madrid-Barajas, ya que se solicitan 315 puntos correspondientes a estaciones) se puede ver en el Anexo 2. Esta da como resultado 40 alcances y para cada uno de ellos 52 datos de temperaturas Celsius en décimas de grado $(\mathrm{t} 2 \mathrm{~m} \times 10)$. (La salida directa sería en Kelvin). La primera fila corresponde al modelo operativo, la segunda al control (modelo EPS con las condiciones iniciales del operativo). De la 3 a la 52, cada uno de los casos del EPS. En cada caso 40 alcances.

Puesto que en el CE se ejecuta primero el operativo, el modelo EPS no se ejecuta hasta pasado cierto tiempo, así que cuando se recibe el fichero (aproximadamente a las $2 \mathrm{Z}$ del día siguiente) las dos primeras columnas (18Z y 00Z) ya se han producido, y no se tienen en cuenta.

Inicialmente el modelo EPS proporcionaba sólo 20 alcances y se trabajaba con las temperaturas de las $00 \mathrm{Z}$ para las mínimas y de las $12 \mathrm{Z}$ para las máximas (en realidad serían más apropiadas las de las $18 Z$, pero no se alcanzaría el décimo día, por eso se utilizan las temperaturas de las 12Z).

Para ilustrar el resto trabajaremos exclusivamente con los datos de las 06Z, que son las que se utilizaran para calcular las temperaturas mínimas Al eliminar el resto de los alcances no quedamos con una matriz de datos de 52 modelos x 10 días de temperaturas a las $06 z$ horas que debemos convertir en temperaturas mínimas.

Para manejar esta cantidad de información se utilizan (para cada alcance) 6 parámetros:

$\begin{array}{lcccccccccc}\text { DÍAS } & \mathbf{2 4} & \mathbf{2 5} & \mathbf{2 6} & \mathbf{2 7} & \mathbf{2 8} & \mathbf{1} & \mathbf{2} & \mathbf{3} & \mathbf{4} & \mathbf{5} \\ \text { OPERATIVO } & 1,10 & 2,00 & 1,70 & 0,50 & 3,50 & 4,20 & 3,10 & 5,00 & -1,10 & -0,20 \\ \text { CONTROL } & 0,90 & 1,20 & -0,10 & -1,20 & 0,60 & 3,60 & 4,00 & 2,70 & 2,00 & 0,40 \\ \text { MEDIA } & 0,94 & 1,38 & 1,30 & -0,19 & 0,69 & 3,68 & 3,63 & 1,33 & 1,31 & 1,80 \\ \text { MEDIANA } & 1,00 & 1,20 & 1,10 & -0,40 & 0,25 & 3,60 & 3,60 & 1,80 & 1,75 & 1,65 \\ \text { MODA } & 1,00 & 1,00 & 0,00 & -1,00 & 0,00 & 3,00 & 4,00 & 2,00 & 2,00 & -1,00 \\ \text { MCTR } & 0,94 & 1,38 & 1,27 & -0,21 & 0,68 & 3,67 & 3,64 & 1,35 & 1,33 & 1,77\end{array}$

El OPERATIVO Y el CONTROL son los resultados de ambos modelos, mientras que la media, mediana y moda se refieren a los 50 miembros del EPS.

Y además se utilizan 31 días anteriores (20090114-20090223) de manera que se calcula el error cometido (medio, cuadrático medio y absoluto medio para los 6 parámetros y 10 días de predicción), entre las temperaturas a las $06 \mathrm{Z}$ y las temperaturas mínima para los 31 días anteriores.

$\begin{array}{rllllllllll}\text { EM OPER } & -0,356 & -0,842 & -0,522 & -0,564 & -0,917 & -1,368 & -1,485 & -1,597 & -1,642 & -0,893 \\ \text { CTRL } & -0,974 & -1,153 & -1,151 & -0,914 & -0,960 & -0,965 & -1,936 & -1,675 & -2,497 & -3,153 \\ \text { MEDI } & -0,987 & -1,211 & -1,127 & -1,189 & -1,501 & -1,459 & -1,857 & -2,016 & -1,946 & -1,750 \\ \text { MDNA } & -0,983 & -1,208 & -1,099 & -1,064 & -1,464 & -1,387 & -1,888 & -2,128 & -2,119 & -1,835 \\ \text { MODA } & -1,018 & -1,208 & -1,084 & -0,961 & -1,609 & -1,268 & -1,797 & -2,859 & -2,961 & -2,687 \\ \text { MCTR } & -0,987 & -1,210 & -1,127 & -1,183 & -1,491 & -1,449 & -1,859 & -2,010 & -1,957 & -1,778\end{array}$ 


$\begin{array}{cllllllllll}\text { ECM OPER } & 1,584 & 1,702 & 1,479 & 1,598 & 1,820 & 2,931 & 3,271 & 3,936 & 3,830 & 3,347 \\ \text { CTRL } & 1,686 & 1,962 & 1,848 & 1,783 & 2,151 & 2,521 & 3,368 & 3,342 & 4,967 & 4,349 \\ \text { MEDI } & 1,715 & 1,886 & 1,737 & 1,776 & 2,186 & 2,261 & 2,934 & 3,429 & 3,576 & 3,576 \\ \text { MDNA } & 1,706 & 1,892 & 1,713 & 1,628 & 2,150 & 2,157 & 3,094 & 3,653 & 3,793 & 3,782 \\ \text { MODA } & 1,685 & 1,954 & 1,792 & 1,549 & 2,370 & 2,535 & 3,460 & 4,641 & 4,642 & 4,347 \\ \text { MCTR } & 1,715 & 1,887 & 1,738 & 1,772 & 2,176 & 2,255 & 2,936 & 3,415 & 3,590 & 3,567 \\ \text { EAM OPER } & 1,290 & 1,326 & 1,181 & 1,325 & 1,334 & 2,174 & 2,509 & 2,766 & 3,023 & 2,660 \\ \text { CTRL } & 1,359 & 1,511 & 1,535 & 1,414 & 1,417 & 1,618 & 2,542 & 2,506 & 3,852 & 3,460 \\ \text { MEDI } & 1,393 & 1,484 & 1,422 & 1,364 & 1,624 & 1,625 & 2,063 & 2,422 & 2,545 & 2,559 \\ \text { MDNA } & 1,383 & 1,484 & 1,396 & 1,286 & 1,584 & 1,549 & 2,115 & 2,616 & 2,723 & 2,785 \\ \text { MODA } & 1,331 & 1,524 & 1,435 & 1,278 & 1,734 & 1,609 & 2,391 & 3,241 & 3,581 & 3,573 \\ \text { MCTR } & 1,392 & 1,484 & 1,423 & 1,363 & 1,615 & 1,622 & 2,063 & 2,418 & 2,553 & 2,558\end{array}$

Siendo EM el error medio, ECM el error cuadrático medio y EAM el error absoluto medio de cada una de los 6 parámero que estamos considerando (en este momento todavía no se ha decidido que parámetro se usará de los 6 (OPER, CTRL, MEDI, MDNA, MODA, MCTR)

Ahora se resta a cada temperatura de cada día el error medio cometido para cada uno de los 6 parámetros, lo que da como resultado, y se calcula de nuevo el error medio, cuadrático medio y absoluto medio.

$\begin{array}{llllllllllll}\text { EM } & \text { OPER } & 0,000 & 0,000 & 0,000 & 0,000 & 0,000 & 0,000 & 0,000 & 0,000 & 0,000 & 0,000 \\ \text { CTRL } & 0,000 & 0,000 & 0,000 & 0,000 & 0,000 & 0,000 & 0,000 & 0,000 & 0,000 & 0,000 \\ \text { MEDI } & 0,000 & 0,000 & 0,000 & 0,000 & 0,000 & 0,000 & 0,000 & 0,000 & 0,000 & 0,000 \\ \text { MDNA } & 0,000 & 0,000 & 0,000 & 0,000 & 0,000 & 0,000 & 0,000 & 0,000 & 0,000 & 0,000 \\ \text { MODA } & 0,000 & 0,000 & 0,000 & 0,000 & 0,000 & 0,000 & 0,000 & 0,000 & 0,000 & 0,000 \\ \text { MCTR } & 0,000 & 0,000 & 0,000 & 0,000 & 0,000 & 0,000 & 0,000 & 0,000 & 0,000 & 0,000 \\ \text { ECM OPER } & 1,543 & 1,480 & 1,384 & 1,495 & 1,572 & 2,593 & 2,915 & 3,598 & 3,460 & 3,225 \\ \text { CTRL } & 1,376 & 1,587 & 1,446 & 1,531 & 1,924 & 2,329 & 2,756 & 2,892 & 4,294 & 2,996 \\ \text { MEDI } & 1,403 & 1,446 & 1,323 & 1,319 & 1,589 & 1,727 & 2,271 & 2,773 & 3,000 & 3,118 \\ \text { MDNA } & 1,394 & 1,456 & 1,314 & 1,232 & 1,574 & 1,652 & 2,451 & 2,969 & 3,145 & 3,308 \\ \text { MODA } & 1,342 & 1,536 & 1,427 & 1,215 & 1,741 & 2,195 & 2,956 & 3,656 & 3,575 & 3,418 \\ \text { MCTR } & 1,402 & 1,448 & 1,323 & 1,319 & 1,585 & 1,728 & 2,272 & 2,761 & 3,010 & 3,093 \\ \text { EAM OPER } & 1,242 & 1,186 & 1,080 & 1,275 & 1,111 & 1,958 & 2,348 & 2,621 & 2,592 & 2,448 \\ \text { CTRL } & 1,119 & 1,221 & 1,177 & 1,319 & 1,381 & 1,672 & 2,131 & 2,180 & 3,319 & 2,330 \\ \text { MEDI } & 1,125 & 1,149 & 1,036 & 1,069 & 1,256 & 1,358 & 1,709 & 2,060 & 2,121 & 2,282 \\ \text { MDNA } & 1,115 & 1,150 & 1,020 & 1,023 & 1,183 & 1,287 & 1,800 & 2,091 & 2,251 & 2,419 \\ \text { MODA } & 1,065 & 1,172 & 1,182 & 1,050 & 1,295 & 1,505 & 2,130 & 2,682 & 2,574 & 2,615 \\ \text { MCTR } & 1,124 & 1,149 & 1,037 & 1,069 & 1,248 & 1,358 & 1,708 & 2,048 & 2,124 & 2,270\end{array}$

De esta forma se obtiene el error medio cometido al calcular las temperaturas mínimas mediante las temperaturas a las $06 \mathrm{Z}$.

Ahora es el momento de elegir el parámetro que se usará para calcular las temperaturas. Se trata simplemente de aquel que tenga el menor error cuadrático medio. 
En la figura 7,3 siguiente se han considerado el error cuadrático medio de cada parámetro para cada día:

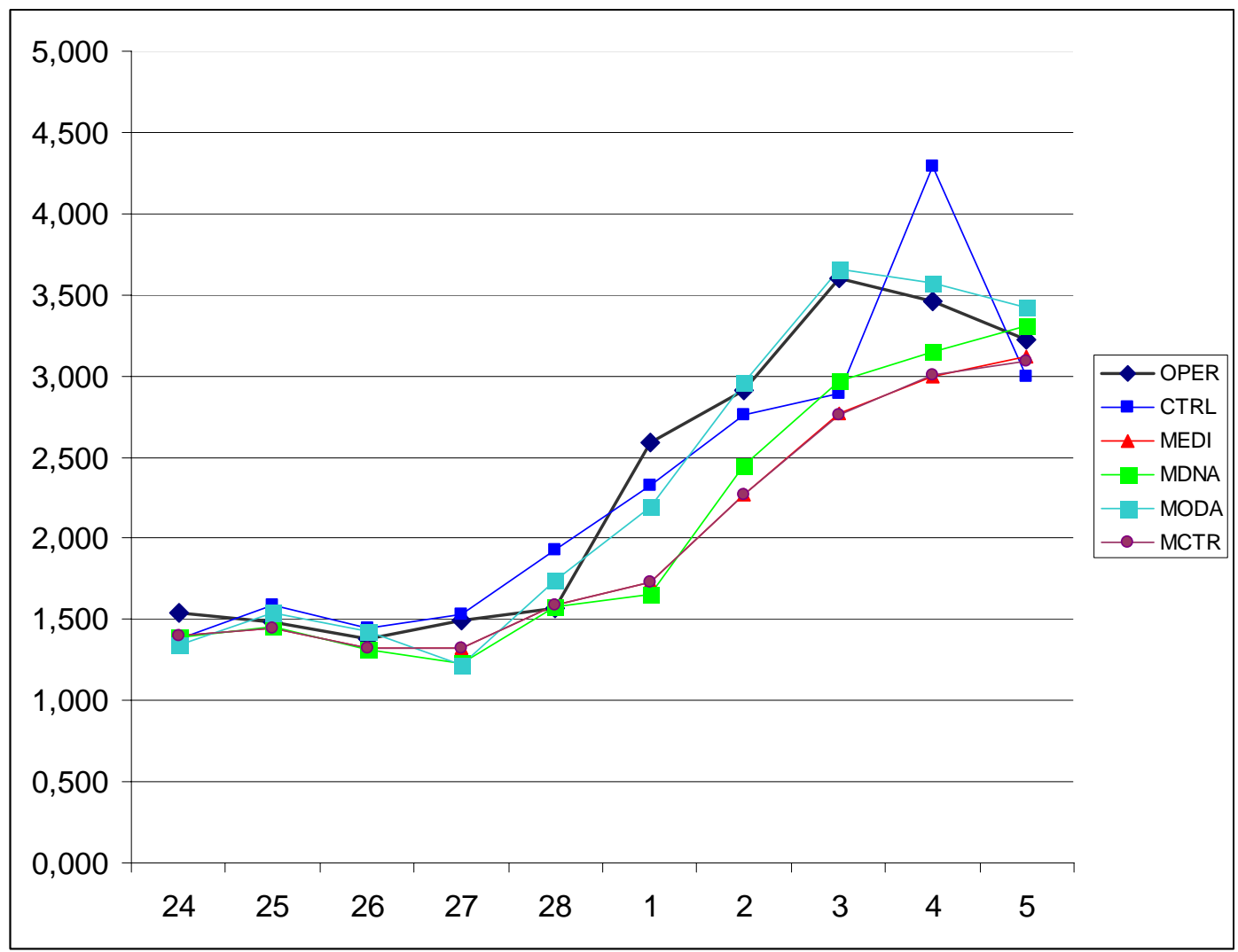

Figura 7.3. Error cuadrático medio calculado para el operativo, control, media mediana y moda de los 50 EPS y media de los EPS+control.

En los primeros días no existen diferencias entre los distintos parámetros pero a partir del 4 día se ve que tanto el operativo como el control cometen mayor error, y los menores errores corresponden a la media y la mediana.

Este es un solo caso, un solo día, una sola estación. Al calcular y observar estos valores durante días se elige la media de los EPS como parámetro ya que es el parámetro que comete menor error cuadrático medio.

SE SUPONE QUE ESTE ES UN ERROR SISTEMATICO, ES DECIR QUE ESTE ERROR (O BIAS), ENGLOBA TANTO EL ERROR DE LA PREDICCION, EL ERROR COMETIDO AL UTILIZAR LAS TEMPERATURAS DE LAS 06Z PARA CALCULAR LAS MINIMAS COMO LA INTERPOLACIÓN VERTICAL U OROGRAFIA, QUE NO TIENE EN CUENTA EL MODELO.

Al restar el error medio (entre las temperaturas dadas por el CE a las 06Z y las temperaturas mínimas reales) se obtienen las temperaturas mínimas. El mismo proceso se sigue con las temperaturas previstas a las $12 \mathrm{z}$ y las temperaturas máximas pasadas para obtener las máximas previstas. 
Teniendo como resultado, estas temperaturas

TEMPERATURAS MÍNIMAS

PREVISTAS A 2 m DESDE EL

20090224 HASTA EL 20090305

Media miembros EPS

DÍAS

$\begin{array}{llllllllll}24 & 25 & 26 & 27 & 28 & 01 & 02 & 03 & 04 & 05\end{array}$

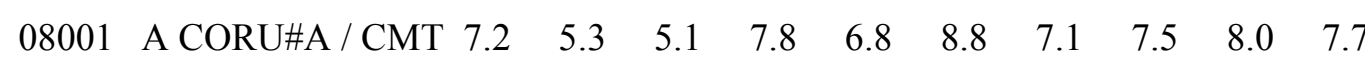

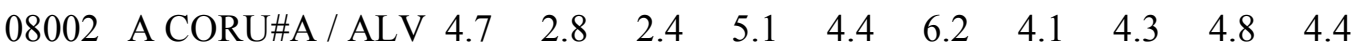

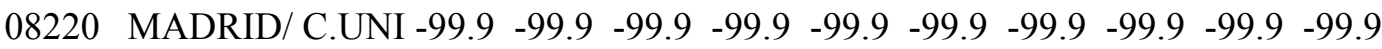

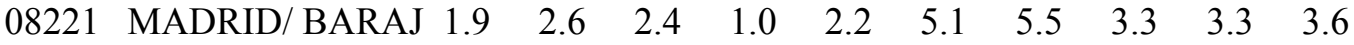

TEMPERATURAS MÁXIMAS

PREVISTAS A 2 m DESDE EL

20090224 HASTA EL 20090305

Media miembros EPS

DÍAS

$================================================$

$\begin{array}{llllllllllll}08001 & \text { A CORU\#A/CMT } & 17.3 & 17.8 & 17.7 & 18.8 & 17.2 & 14.3 & 13.8 & 14.0 & 13.5 & 13.4\end{array}$

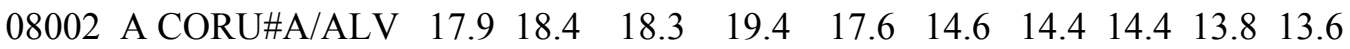

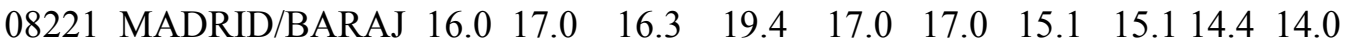

En total se trabaja con 305 estaciones, sin embargo, en los casos que no se tienen los datos de temperaturas pasadas, no se puede calcular la temperaturas con filtro y es en estos casos los resultados son -99.9, como se puede ver para la estación 08220 Madrid/ Ciudad Universitaria. Los observatorios donde menos lagunas en temperaturas se observan, son los situados en aeropuertos, razón por la que los resultados son mejores.

\section{REFERENCIAS BIBLIOGRÁFICAS}

N. ${ }^{\circ}$ 33. Sistema de Predicción por Conjuntos (EPS: Ensemble Prediction System). B. Elvira y A. Martín. 


\title{
8. EVALUACIÓN DEL MÉTODO PARA OTROS OBSERVATORIOS DE LA COMUNIDAD DE MADRID Y PARA CÓRDOBA
}

\author{
Inmaculada Cadenas y José Luis Camacho. AEMET
}

Con el objetivo de validar este método en otros puntos de la Comunidad de Madrid o en otros lugares de características climáticas diferentes, evaluar en lugares puntuales la estabilidad de éste método se eligieron las ciudades de Alcalá de Henares, Alcobendas, Aranjuez y Getafe en la Comunidad Autónoma de Madrid y Córdoba en la Comunidad Autónoma de Andalucía. En principio se utilizó el umbral de 30 granos $/ \mathrm{m}^{3}$, para considerar el inicio de la estación polínica. En cambio el umbral del PAC está sujeto a ajuste estación por estación, determinado por el promedio de acumulación de grados en las fechas de inicio de la temporada polínica. Se verá a lo largo de este apartado como es necesario cambiar este umbral de acuerdo a la estación considerada y a la serie de datos meteorológicos asociados.

\subsection{ESTACIONES PRÓXIMAS A MADRID}

En el apartado 6, se pudo comprobar como las fechas de floración del plátano dependían en gran medida de las condiciones locales, pudiendo haber diferencias significativas de hasta una semana en observatorios que estaban a pocos kilómetros uno del otro. El primer trabajo a realizar es validar o poner en cuestión el umbral del PAC considerado de 50 grados utilizado en las series de la ciudad de Madrid en el periodo 1994-2008, comenzando la evaluación de los pronósticos del inicio de la temporada de polen de plátano con el umbral de PAC mencionado que se encontró como adecuado, con la serie de polen de Getafe asociada a los datos meteorológicos de Getafe Base Aérea, y permitiendo un error de $+/-2$ días se obtiene la tabla 8.1.

Se puede apreciar que existe una alta probabilidad de detección y ningún caso de detección tardía utilizando una estación meteorológica situada en la misma localidad. A continuación se procedió a estudiar el comportamiento del modelo para predecir el inicio de la temporada en Alcobendas utilizando la serie meteorológica de MadridBarajas. En este caso, el umbral de PAC adecuado se calculó en 71 grados. En la serie de pólenes hubo dudas sobre algunos datos de 1996 y 2004 por lo que se rechazaron estos años. En este caso la probabilidad de detección (POD) fue de 0,55, el coeficiente de falsas alarmas (FAR) fue de 0,27 y el índice de retrasos (LWR) de 0,18. Esta estación tiene un problema estadístico con la serie de polen y es que sus valores son significativamente más pequeños que los del resto. En un año de poca producción de polen o si se han realizado podas en los árboles, la cantidad diaria recogida a duras penas sobrepasa en algún momento el umbral considerado como crítico para que un segmento significativo de los alérgicos muestren síntomas como ocurrió en el año 2006 en los que se superó el umbral de 30 granos $/ \mathrm{m}^{3}$ el día 2 de abril y solo ese día y el día 4 , con un registro de 57 granos $/ \mathrm{m}^{3}$ se alcanzaron cantidades por encima. En todo caso, ello reduce el problema médico para las personas alérgicas a este tipo de polen en esa localidad. 


\begin{tabular}{|l|l|l|l|l|l|l|}
\hline AÑO & $\begin{array}{l}\text { JULIANO } \\
\text { PAC (50) }\end{array}$ & $\begin{array}{l}\text { JULIANO } \\
\text { granos(30) }\end{array}$ & DIF Días & $\begin{array}{l}\text { ACIERTOS Falsa } \\
\pm 2\end{array}$ & $\begin{array}{l}\text { Retraso } \\
\text { Alarma }\end{array}$ \\
\hline 1994 & 74 & 76 & 2 & 1 & 0 & 0 \\
\hline 1995 & 79 & 77 & -2 & 1 & 0 & 0 \\
\hline 1996 & 90 & 89 & -1 & 1 & 0 & 0 \\
\hline 1997 & 63 & 67 & 4 & 0 & 1 & 0 \\
\hline 1998 & 66 & 73 & 7 & 0 & 1 & 0 \\
\hline 1999 & 77 & 79 & 2 & 1 & 0 & 0 \\
\hline 2000 & 65 & 67 & 2 & 1 & 0 & 0 \\
\hline 2001 & 81 & 80 & -1 & 1 & 0 & 0 \\
\hline 2002 & 82 & 82 & 0 & 1 & 0 & 0 \\
\hline 2003 & 72 & 82 & 10 & 0 & 1 & 0 \\
\hline 2004 & 79 & 81 & 2 & 1 & 0 & 0 \\
\hline 2005 & 80 & 90 & 10 & 0 & 1 & 0 \\
\hline 2006 & 86 & 85 & -1 & 1 & 0 & 0 \\
\hline 2007 & 77 & 76 & -1 & 1 & 0 & 0 \\
\hline 2008 & 70 & 73 & 3 & 0 & 1 & 0 \\
\hline \hline TOTAL= 15 áños & & & & 10 & 5 & 0 \\
\hline Prob de detección & & & POD & & 0,71 & \\
\hline Falsa Alarma & & & FAR & & 0,29 & \\
\hline Predice tarde & & & Miss (\%) & & 0,00 & \\
\hline
\end{tabular}

Tabla 8.1. Evaluación del pronóstico de día de inicio de la estación polínica del plátano en Getafe a partir de los promedios de acumulación de calor de Getafe-Base Aérea. Se permite error de $+/-2$ días. Series temporales entre 1994 y 2008. Sombreadas en azul las falsas alarmas.

Finalmente trataremos el caso de Alcalá de Henares. En este caso, se encuentran dos problemas. El primero atañe a la serie de datos de polen ya que el captador se encuentra en medio de un grupo de plátanos. El resultado sobre los datos desde el punto de vista estadístico es singular ya que la media de valores diarios entre marzo y abril en el periodo considerado para Alcalá es de 354 granos doblando los registros de Aranjuez y Facultad de Farmacia, captadores ubicados ambos en zonas con abundantes plátanos de sombra. El máximo diario registrado es de 12917 granos $/ \mathrm{m}^{3}$ frente a los 3757 de Aranjuez y los 4936 de Facultad de Farmacia.

El segundo problema se refiere a que no se dispone de datos continuos meteorológicos en tiempo real en Alcalá por lo que, para ser compatible con el sistema de predicción, se han utilizado los datos de Madrid-Barajas. El umbral del PAC que se ha considerado idóneo ha sido de 50 grados. Considerando todos estos factores, no ha extrañado encontrar resultados muy modestos para el rendimiento del modelo. La probabilidad de detección ha sido de 0,36 , el coeficiente de falsas alarmas también de 0,36 y el índice de retrasos de 0,29. En algunos casos el retraso ha sido de más de 30 días.

\subsection{El Caso de ARAnJuez}

En este caso, la serie de datos de polen es muy buena y tiene la virtud de representar a una zona geográfica alejada de la capital. En la localidad existe una estación meteorológica, sin embargo tiene abundantes lagunas faltando datos de máximas, mínimas y, en ocasiones, ambas. Tampoco está dentro de las estaciones consideradas 
como principales en la actualidad por lo que no se dan datos de predicción en el esquema actual, si bien esto es posible de realizar en un futuro próximo.

Por todo ello se intentó realizar un ajuste lineal mediante las series de extremas tanto de Toledo como de Torrejón de Ardoz de las que si se disponía tanto de datos de observación como de predicción. Tanto en la serie de máximas, como de mínimas el ajuste es mejor en la serie de Toledo, que en la de Torrejón de Ardoz con coeficientes de correlación para Toledo de 0,91 para las mínimas y de 0,99 para las máximas. Por ello se decidió usar la serie de Toledo para Aranjuez, no sólo por que en el análisis da mejores resultados, sino por que también proporciona mejores predicciones.

Usando los datos polínicos de Aranjuez y los datos de máximas y mínimas de Toledo, y obteniéndose un ajuste para el umbral del PAC de 88 grados, se obtuvieron los resultados: siguientes: probabilidad de detección de 0,36 , coeficientes de falsas alarmas de 0,21 e índice de retrasos de 0,43. Se da el caso de que la probabilidad de dar el pronóstico de inicio de la temporada con un retraso superior a 2 días es superior a la probabilidad de acertar dentro de ese margen.

A la vista de estos resultados se intentó un relleno de lagunas en la serie de Aranjuez En aquellos casos en los que era posible y eliminando los meses de Mayo a Diciembre se hicieron regresiones lineales entre los datos de máximas y mínimas de Aranjuez y Toledo sustituyéndose los huecos por los datos modelados. No hay datos suficientes en 2000 ni en 2005. Con las series así obtenidas y un valor de umbral del PAC de $88^{\circ}$ se obtuvo los siguientes resultados que se muestran en la tabla 8.2: En este caso la probabilidad de detección fue de 0,33, el coeficiente de falsas alarmas de $0.44 \mathrm{y}$ el retraso de 0,22 . Por tanto no se mejoró en la probabilidad de detección y el modelo daba una elevada tasa de falsas alarmas pronosticando demasiado pronto el inicio de la temporada de polinización.

\begin{tabular}{|l|l|l|l|l|l|}
\hline AÑO & Dif días & $\begin{array}{l}\text { ACIERTOS } \\
\pm 2\end{array}$ & $\begin{array}{l}\text { Falsa } \\
\text { Alarma }\end{array}$ & Retraso & $\begin{array}{l}\text { Numero } \\
\text { de días } \\
\text { ellenados }\end{array}$ \\
\hline 1997 & 0 & 1 & 0 & 0 & 6 \\
\hline 1998 & 1 & 1 & 0 & 0 & 2 \\
\hline 1999 & -8 & 0 & 1 & 0 & \\
\hline 2001 & 3 & 0 & 0 & 1 & \\
\hline 2002 & 2 & 1 & 0 & 0 & 5 \\
\hline 2003 & -5 & 0 & 1 & 0 & 19 \\
\hline 2004 & 15 & 0 & 0 & 1 & 6 \\
\hline 2006 & 4 & 0 & 0 & 1 & 2 \\
\hline 2007 & 27 & 0 & 0 & 1 & 16 \\
\hline Totales & & $\mathbf{3}$ & $\mathbf{2}$ & $\mathbf{4}$ & \\
\hline
\end{tabular}

Tabla 8.2. Evaluación del pronóstico de día de inicio de la estación polínica del plátano en Aranjuez a partir de los promedios de acumulación de calor de la serie "rellenada" de Aranjuez. Se permite error de $+/-2$ días. Series temporales entre 1997 y 2007. Sombreadas en azul las falsas alarmas. 


\subsection{CAMbios en UMbral: CóRdoba}

A continuación se exponen los resultados del estudio realizado en un ámbito geográfico diferenciado de la Comunidad de Madrid. En este caso se utilizaron los datos de registros diarios de polen de la Universidad de Córdoba, cedidos para este estudio, y los registros meteorológicos del Aeropuerto de Córdoba. El periodo estudiado abarca dese 1993 a 2007. Utilizando el mismo umbral de 30 granos $/ \mathrm{m}^{3}$ de polen diario, se determinó un umbral para el PAC de 137 grados, bastante por encima del calculado en Madrid. Este dato refleja el hecho de que en Córdoba es preciso una cantidad de calor mayor que en Madrid antes de que comience el periodo de polinización. No obstante, las fechas de inicio están ligeramente adelantadas respecto a Madrid comenzando la temporada en promedio alrededor del 11 de marzo en vez del 21 de marzo como se ha obtenido en Madrid-General Pardiñas.

Una vez ajustado el umbral del PAC, los resultados del modelo se exponen en la tabla 8.3.

\begin{tabular}{|c|c|c|c|c|c|c|}
\hline \multirow{3}{*}{$\begin{array}{l}\mathbf{A N \tilde { O }} \\
1993\end{array}$} & \multicolumn{5}{|c|}{ JULIANOJULIANODIF ACIERTOSFalsa } & \multirow{2}{*}{ Retraso } \\
\hline & PA & granos30 & Día & $\mathbf{s} \pm 2$ & & \\
\hline & 74 & 76 & 2 & 1 & 0 & 0 \\
\hline 1994 & 69 & 70 & 1 & 1 & 0 & 0 \\
\hline 1995 & 71 & 68 & -3 & 0 & 1 & 0 \\
\hline 1996 & 83 & 83 & 0 & 1 & 0 & 0 \\
\hline 1997 & 59 & 57 & -2 & 1 & 0 & 0 \\
\hline 1998 & 64 & 62 & -2 & 1 & 0 & 0 \\
\hline 1999 & 74 & 75 & 1 & 1 & 0 & 0 \\
\hline 2000 & 62 & 59 & -3 & 0 & 1 & 0 \\
\hline 2001 & 70 & 70 & 0 & 1 & 0 & 0 \\
\hline 2002 & 70 & 70 & 0 & 1 & 0 & 0 \\
\hline 2003 & 71 & 72 & 1 & 1 & 0 & 0 \\
\hline 2004 & 74 & 69 & -5 & 0 & 1 & 0 \\
\hline 2005 & 82 & 80 & -2 & 1 & 0 & 0 \\
\hline 2006 & 82 & 84 & 2 & 1 & 0 & 0 \\
\hline 2007 & 57 & 62 & 5 & 0 & 0 & 1 \\
\hline $\begin{array}{l}\text { TOTA } \\
\text { años= }\end{array}$ & & & & 11 & 3 & 1 \\
\hline
\end{tabular}

Tabla 8.3. Evaluación del pronóstico de día de inicio de la estación polínica del plátano en Córdoba a partir de los promedios de acumulación de calor de la serie meteorológica de "Córdoba-Aeropuerto". Se permite error de +/- 2 días. Series temporales entre 1993 y 2007. Los casos de falsas alarmas se presentan en azul. El único caso de retraso esta marcado en naranja oscuro.

Los resultados estadísticos para estos 15 años fueron los siguientes:

Prob. detección

Coeficiente Falsas Alarmas

Retraso
$\begin{array}{ll}P O D & 0,73\end{array}$

FAR $\quad 0,20$

LWR $\quad 0,07$ 


\section{CONCLUSIONES Y PROPUESTA DE ESQUEMA DE OPERACIÓN}

\section{José Luis Camacho, Darío Cano y Patricia Cervigón}

Como conclusiones de este trabajo podemos citar las siguientes:

- Existe relación estadística demostrada entre la acumulación de calor desde el 1 de enero en observatorios próximos al captador de polen y la fecha de inicio de la temporada de polinización del plátano definida mediante criterios médicos y estadísticos.

- $\quad$ El desarrollo de futuros productos debe de focalizarse en aquellos que puedan integrarse dentro de los sistemas de vigilancia de riesgos ambientales en salud, uno de cuyos objetivos fundamentales es dar difusión e informar a la población, pacientes, sistema asistencial y medios de comunicación de la información útil para la prevención y mejor manejo del asma y alergias respitratorias.

- Desde el punto de vista aerobiológico, el conocimeinto previo del inicio de la polinización, supone un complemento muy importante a la información polínica diaria que se ofrece desde la Red Palinocam con la previsión de niveles medios de polen.

- Desde el punto de vista de la evaluación de las predicciones, el método ha funcionado satisfactoriamente. En los dos años des experimento, 2008 y 2009, el umbral del índice PAC se supera en la estación del Retiro por primera vez siete días antes de la aparición del polen de Plátano en algún punto de la Comunidad de Madrid.

- Desde el punto de vista técnico, la elaboración y difusión de un producto de predicción en la Agencia Meteorológica de Madrid, es sencilla y viable.

- Humana y socialmente, cabe destacar la colaboración interdisciplinar entre meteorólogos, botánicos y sanitarios en busca de bienestar social. Se abre una puerta hacia el estudio de la fenología desde una perspectiva práctica y avanzada en el uso de herramientas científicas. La mejora del producto de predicción está supeditada a la continuación del intercambio de datos entre AEMET y la Consejería de Sanidad, en virtud al Convenio suscrito entre ambas instituciones, para facilitar datos meterorológicos y aerobiológicos entre los servicios y/o departamentos implicados. 


\section{ANEXO 1}

Climatología. Tabla promedio 1980-2007 acumulación PAC para Madrid Retiro. Apoyo al pronóstico

\begin{tabular}{|c|c|c|c|c|}
\hline Code & Count & Average & Median & $\begin{array}{l}\text { Standard } \\
\text { Deviation }\end{array}$ \\
\hline \multirow{2}{*}{\multicolumn{5}{|c|}{ - - - - - - - - - - - - - - - - - - - - - - - - - - - - - - - - - - - - - - - - - - - - - - - - - - - - - - - - - - - - - - - - - - - - - - - - - - - - - - - - - - - }} \\
\hline & & & & \\
\hline 1 & 27 & 0,592593 & 0,0 & 2,70696 \\
\hline 2 & 27 & 0,740741 & 0,0 & 2,78171 \\
\hline 3 & 27 & 0,962963 & 0,0 & 2,95455 \\
\hline 4 & 27 & 1,05556 & 0,0 & 3,08325 \\
\hline 5 & 27 & 1,05556 & 0,0 & 3,08325 \\
\hline 6 & 27 & 1,2963 & 0,0 & 3,21732 \\
\hline 7 & 27 & 1,2963 & 0,0 & 3,21732 \\
\hline 8 & 27 & 1,2963 & 0,0 & 3,21732 \\
\hline 9 & 27 & 1,62963 & 0,0 & 3,52898 \\
\hline 10 & 27 & 2,22222 & 0,0 & 5,56834 \\
\hline 11 & 27 & 2,5 & 0,0 & 5,63983 \\
\hline 12 & 27 & 2,64815 & 0,0 & 5,8257 \\
\hline 13 & 27 & 2,64815 & 0,0 & 5,8257 \\
\hline 14 & 27 & 2,64815 & 0,0 & 5,8257 \\
\hline 15 & 27 & 2,64815 & 0,0 & 5,8257 \\
\hline 16 & 27 & 2,87037 & 0,0 & 5,98169 \\
\hline 17 & 27 & 2,87037 & 0,0 & 5,98169 \\
\hline 18 & 27 & 2,88889 & 0,0 & 5,97323 \\
\hline 19 & 27 & 2,88889 & 0,0 & 5,97323 \\
\hline 20 & 27 & 3,53704 & 0,0 & 6,48063 \\
\hline 21 & 27 & 4,14815 & 0,0 & 7,43021 \\
\hline 22 & 27 & 5,18519 & 0,0 & 9,23845 \\
\hline 23 & 27 & 5,22222 & 0,0 & 9,22093 \\
\hline 24 & 27 & 6,2963 & 0,0 & 11,1314 \\
\hline 25 & 27 & 6,98148 & 0,0 & 11,2408 \\
\hline 26 & 27 & 8,0 & 1,0 & 12,0256 \\
\hline 27 & 27 & 11,7778 & 1,0 & 18,0519 \\
\hline 28 & 27 & 12,5 & 3,0 & 19,0591 \\
\hline 29 & 27 & 13,1296 & 4,0 & 18,9024 \\
\hline 30 & 27 & 14,3889 & 4,0 & 19,8011 \\
\hline 31 & 27 & 14,8148 & 4,0 & 20,4423 \\
\hline 32 & 27 & 15,3889 & 5,0 & 20,8051 \\
\hline 33 & 27 & 16,3889 & 9,5 & 21,3894 \\
\hline 34 & 27 & 17,7963 & 10,5 & 23,3861 \\
\hline 35 & 27 & 20,1667 & 12,5 & 27,0466 \\
\hline 36 & 27 & 24,4259 & 16,0 & 33,4195 \\
\hline 37 & 27 & 27,4259 & 16,0 & 38,8265 \\
\hline 38 & 27 & 30,5185 & 16,0 & 41,1537 \\
\hline 39 & 27 & 32,9074 & 17,0 & 41,8438 \\
\hline 40 & 27 & 34,5926 & 24,0 & 41,8052 \\
\hline 41 & 27 & 35,0556 & 24,5 & 41,7744 \\
\hline 42 & 27 & 37,6667 & 29,5 & 42,6779 \\
\hline 43 & 27 & 40,463 & 35,0 & 43,9538 \\
\hline 44 & 27 & 44,0926 & 37,5 & 44,1815 \\
\hline 45 & 27 & 48,5 & 50,0 & 44,0893 \\
\hline 46 & 27 & 52,6667 & 50,0 & 46,4288 \\
\hline 47 & 27 & 55,7407 & 50,0 & 49,0662 \\
\hline 48 & 27 & 59,537 & 50,0 & 53,8184 \\
\hline 49 & 27 & 62,1667 & 55,0 & 57,4915 \\
\hline 50 & 27 & 65,7407 & 60,0 & 60,7714 \\
\hline 51 & 27 & 70,1296 & 63,0 & 63,4351 \\
\hline 52 & 27 & 75,5556 & 63,0 & 66,4758 \\
\hline 53 & 27 & 80,6111 & 63,0 & 70,1792 \\
\hline 54 & 27 & 85,6111 & 82,5 & 73,9072 \\
\hline 55 & 27 & 90,537 & 82,5 & 78,7235 \\
\hline 56 & 27 & 94,3519 & 82,5 & 82,9238 \\
\hline 57 & 27 & 98,1111 & 82,5 & 86,272 \\
\hline 58 & 27 & 104,87 & 87,5 & 94,5486 \\
\hline 59 & 27 & 113,0 & 96,5 & 101,162 \\
\hline 60 & 27 & 121,87 & 103,5 & 108,365 \\
\hline 61 & 27 & 129,926 & 109,0 & 115,612 \\
\hline 62 & 27 & 143,037 & 113,0 & 124,059 \\
\hline 63 & 27 & 155,537 & 123,5 & 133,164 \\
\hline
\end{tabular}




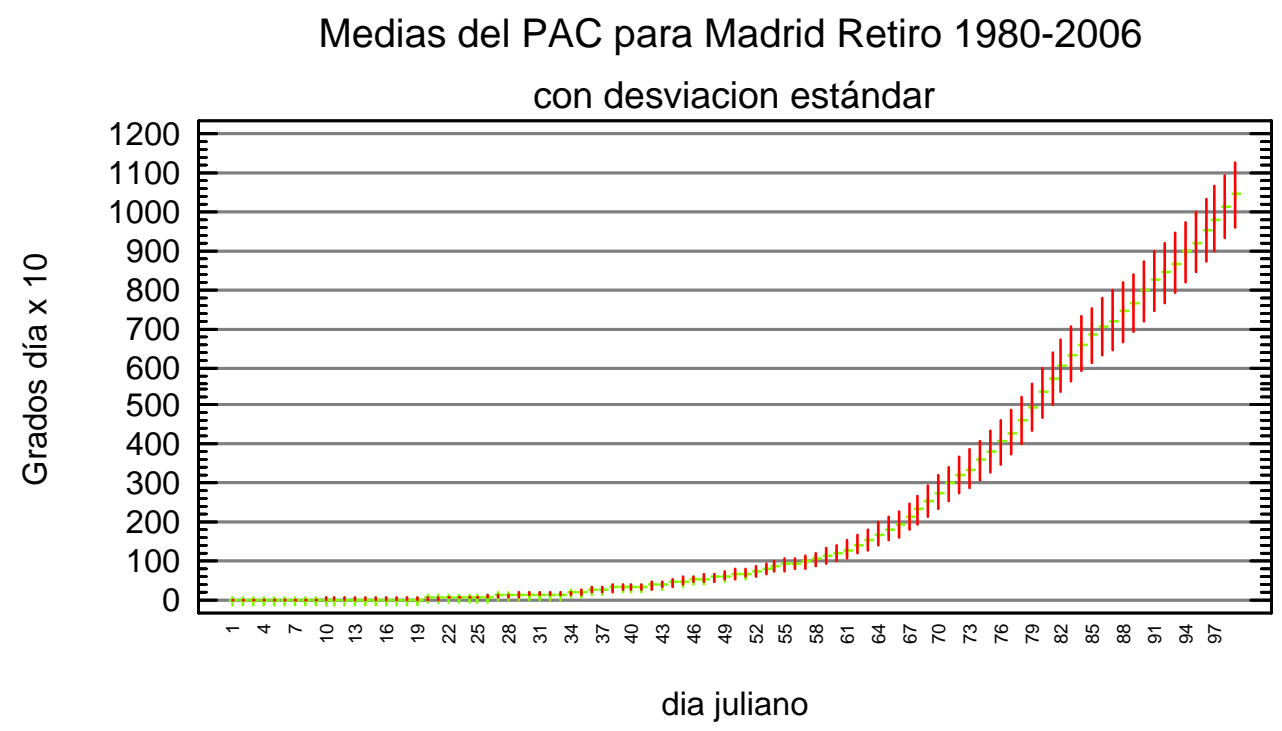

Figura 1. Valor promedio del PAC para Madrid Retiro en el periodo de tiempo 1980-2006 en cada día juliano desde el 1 de enero hasta finales de abril (curva verde) y valores de la desviación estándar (barra roja). 


\section{ANEXO 2}

Salida a la petición diaria al Centro Europeo (sólo para Madrid-Barajas, ya que se solicitan 315 puntos correspondientes a estaciones)

$\mathrm{PAR}=167 \mathrm{DATE}=2009022312 \mathrm{NSTA}=315 \quad 2$ metre temperature

CLNR 1111111111111111111111111111111111111111111111111111 $0822140.46-3.55$

$14434111381185320120130531712910522 \quad 51541344435131121794213010451$ $311121085650989631-1111112036-2146$

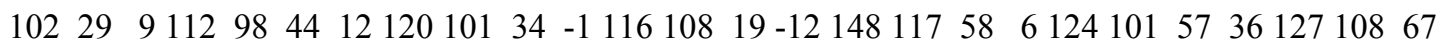
$\begin{array}{llllllllllllll}40 & 97 & 74 & 43 & 27 & 87 & 93 & 39 & 20 & 74 & 49 & 11 & 4 & 50\end{array}$

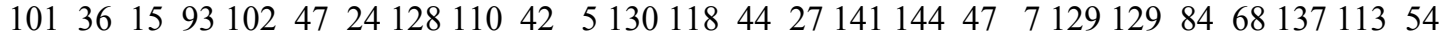
$\begin{array}{llllllllllllll}27 & 105 & 89 & 44 & -9 & 89 & 77 & 39 & 8 & 66 & 59 & 25 & 26 & 78\end{array}$

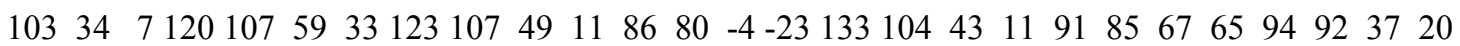
$\begin{array}{lllllllllllll}71 & 73 & 30 & 7 & 87 & 72 & 27 & 18 & 84 & 76 & 35 & 21 & 69\end{array}$

$109341011710341 \quad 10132109371911811628 \quad 2139113 \quad 16-1611711775 \quad 312611276$ $\begin{array}{llllllllllllll}42 & 96 & 72 & 47 & 22 & 86 & 74 & 62 & 23 & 74 & 68 & 36 & 29 & 102\end{array}$

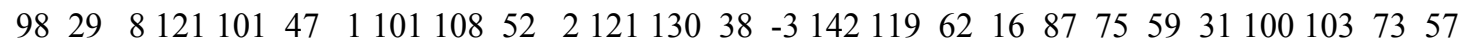
$\begin{array}{llllllllllllll}71 & 77 & -1 & -29 & 85 & 74 & 26 & -15 & 115 & 106 & 69 & 58 & 86\end{array}$

$11035161179435 \quad 8110113452511412638331501186016116103585712310255$ $401109958401161198962889148 \quad 17 \quad 37$

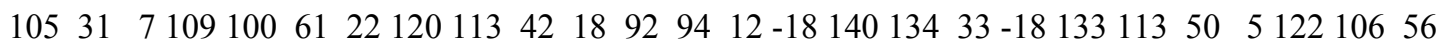
$\begin{array}{llllllllllllll}32 & 108 & 94 & 33 & 18 & 103 & 93 & 62 & 25 & 80 & 84 & 36 & 42 & 97\end{array}$

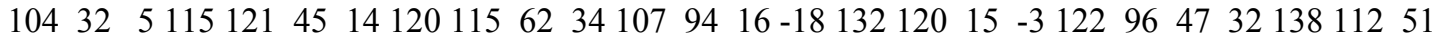
$\begin{array}{llllllllllllll}27 & 71 & 66 & 17 & -8 & 67 & 68 & 29 & 0 & 93 & 87 & 21 & -10 & 97\end{array}$

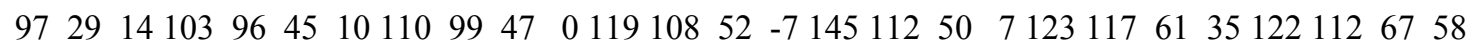
$\begin{array}{llllllllllllll}117 & 76 & 38 & 27 & 103 & 89 & 11 & -20 & 98 & 109 & 26 & -10 & 130\end{array}$

$9926 \quad 61201015411125101 \quad 45 \quad-113713047 \quad 516112441 \quad 18124104544784745740$ $\begin{array}{llllllllllllll}56 & 42 & 14 & 9 & 61 & 56 & 9 & -12 & 88 & 81 & 46 & 11 & 87\end{array}$

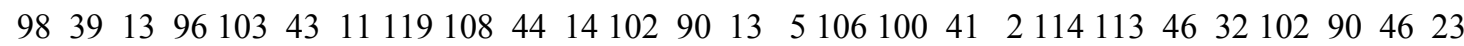
$11110445 \quad 44858552 \quad 38969642 \quad 1060$

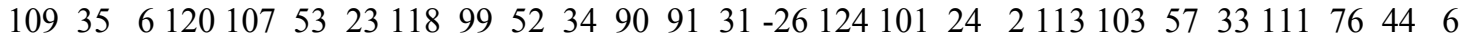
$\begin{array}{lllllllllllll}73 & 74 & 2 & -19 & 97 & 89 & 23 & -4 & 82 & 76 & 51 & 32 & 63\end{array}$

$10731 \quad 111029942 \quad 3121107 \quad 5513134126 \quad 36 \quad 7142125693011210558 \quad 35114105 \quad 56$ $2212412263 \quad 30129141793417015396 \quad 64179$

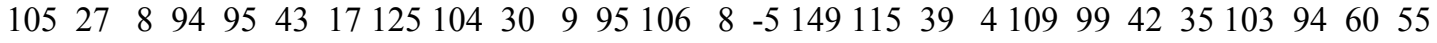

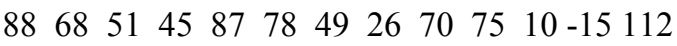

$108321212110056221231104020105103 \quad 27-1313811965 \quad 371078755 \quad 591018828$ $\begin{array}{lllllllllllllll}9 & 79 & 63 & 22 & 30 & 62 & 77 & 59 & 58 & 70 & 46 & 17 & 15 & 64\end{array}$

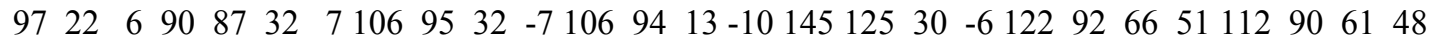
$1021026123116 \quad 6344 \quad 406962 \quad 1 \quad-8104$

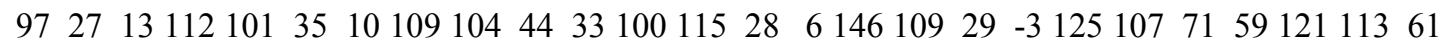

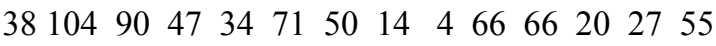

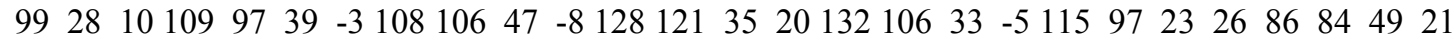
$\begin{array}{llllllllllllll}91 & 92 & 53 & 18 & 83 & 73 & 18 & -28 & 85 & 95 & -1 & -36 & 107\end{array}$

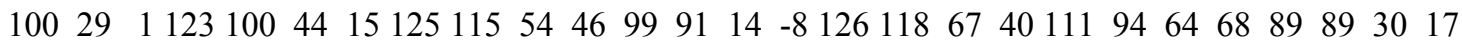
$\begin{array}{lllllllllllll}56 & 72 & -12 & -36 & 89 & 74 & 35 & 34 & 56 & 51 & 35 & 20 & 56\end{array}$

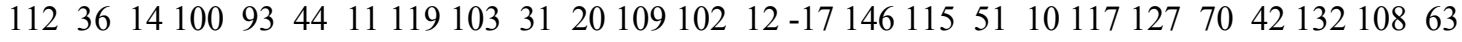
$\begin{array}{llllllllllllll}50 & 106 & 80 & 59 & 48 & 76 & 83 & 18 & -22 & 60 & 63 & 35 & 41 & 78\end{array}$

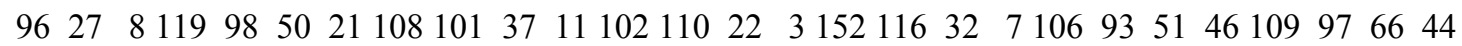
$\begin{array}{lllllllllllll}98 & 81 & 56 & 45 & 85 & 77 & 23 & -1 & 85 & 74 & 35 & 26 & 69\end{array}$

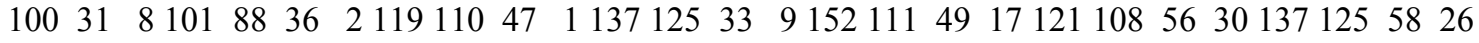
$1181165338108102763780703528 \quad 80$

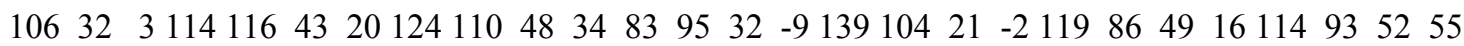
$10397523811411473 \quad 428683 \quad 605897$

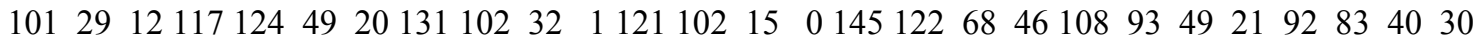
$\begin{array}{lllllllllllll}87 & 83 & 37 & 27 & 85 & 70 & 46 & 30 & 54 & 56 & 24 & 14 & 46\end{array}$ 
$101231112510138 \quad 3113102 \quad 39-1112113124 \quad 615010634 \quad 312510749299497 \quad 70$ $6010894625210110647 \quad-1104904516 \quad 63$

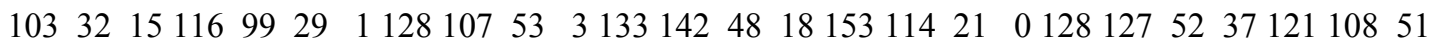
$\begin{array}{llllllll}5310098 & 66 & 191149043 & 189485 & 5949 & 78\end{array}$

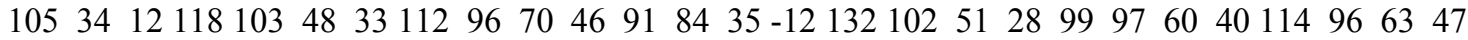
$\begin{array}{llllllllllllll}83 & 73 & 4 & -10 & 92 & 70 & 67 & 34 & 61 & 37 & 12 & 6 & 73\end{array}$

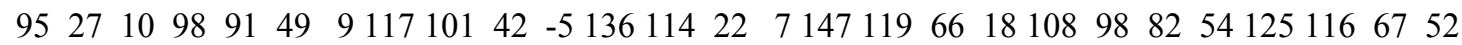
$\begin{array}{lllllllllllll}51 & 32 & 20 & 15 & 66 & 55 & 18 & 10 & 54 & 54 & -6 & -22 & 78\end{array}$

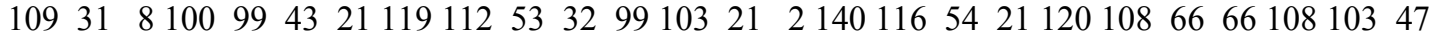

$\begin{array}{llllllllllllll}38 & 108 & 101 & 39 & 14 & 97 & 71 & 9 & -11 & 67 & 71 & -4 & -24 & 93\end{array}$

$10732 \quad 12117964433119105432592 \quad 8916 \quad-513595 \quad 14-14139118 \quad 31 \quad 1132102 \quad 5443$

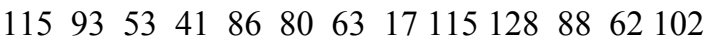

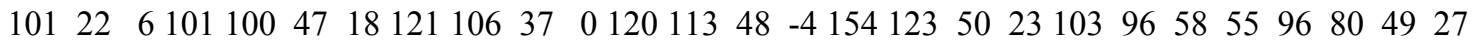
$\begin{array}{lllllllllllll}40 & 58 & -4 & -35 & 75 & 58 & 13 & -3 & 85 & 73 & 37 & 28 & 140\end{array}$

$10627 \quad 41131124127115105615211010925 \quad 2144126 \quad 6738115128794012311141$

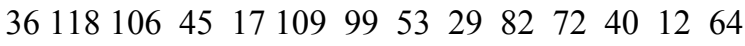

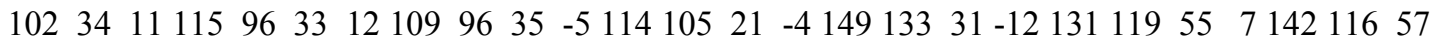
$\begin{array}{llllllllllllll}36 & 96 & 87 & 50 & 23 & 100 & 86 & 24 & 13 & 97 & 94 & 56 & 42 & 75\end{array}$

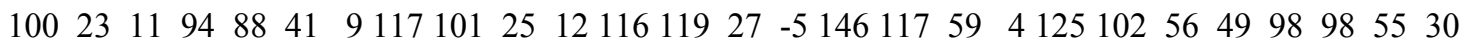
80813917105964741137117596395

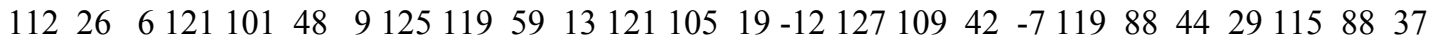
$\begin{array}{lllllllllllllll}36 & 59 & 62 & 21 & -26 & 83 & 74 & 4 & -15 & 87 & 86 & 48 & 10 & 102\end{array}$

$104351010892361611690 \quad 35 \quad-1108102 \quad 24-1713311942 \quad 26102 \quad 97 \quad 66 \quad 63 \quad 88 \quad 83 \quad 6056$ $10410671 \quad 1912211144207855 \quad 6 \quad-2 \quad 53$

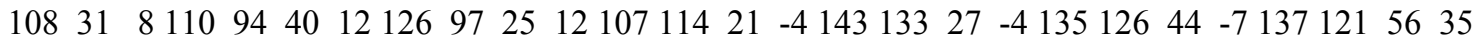
$\begin{array}{lllllllllllll}132 & 92 & 55 & 20 & 103 & 78 & 26 & 19 & 51 & 49 & 6 & -10 & 48\end{array}$

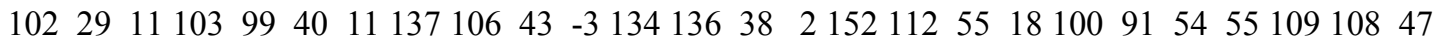
$\begin{array}{llllllllllllll}49 & 91 & 82 & 22 & 5 & 62 & 53 & -4 & -12 & 75 & 65 & 26 & 10 & 60\end{array}$

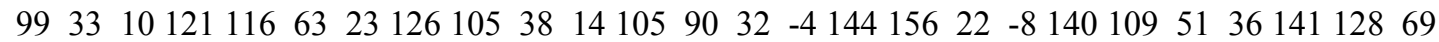
291271269557127104755811172504650

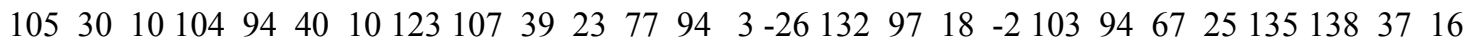
$\begin{array}{llllllllllllll}99 & 67 & 4 & -19 & 96 & 96 & 44 & 23 & 95 & 82 & 23 & -5 & 74\end{array}$

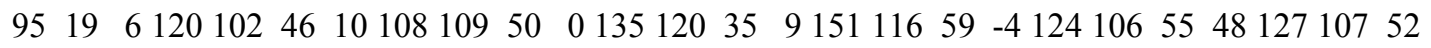
$\begin{array}{llllllllllllll}33 & 77 & 41 & 17 & 4 & 70 & 61 & -6 & -26 & 62 & 60 & 50 & 40 & 55\end{array}$

$1042810107994413108102 \quad 40 \quad-4120112 \quad 43-20150106 \quad 17 \quad-211410652 \quad 269988 \quad 36 \quad 9$ $\begin{array}{lllllllllllll}74 & 64 & 20 & 14 & 63 & 67 & 19 & 18 & 60 & 38 & 8 & 4 & 73\end{array}$

$10629710010146131341094032109111442714611640 \quad-11109340371119957$ 38110112623513111560331501048981111

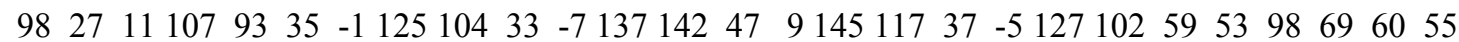
$\begin{array}{llllllllllllll}64 & 53 & 24 & 14 & 69 & 70 & 3 & -38 & 73 & 77 & 30 & -11 & 102\end{array}$

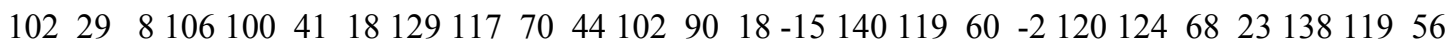
$\begin{array}{llllllllllllll}50 & 88 & 64 & 40 & 19 & 62 & 33 & -6 & -5 & 27 & 44 & 10 & 18 & 90\end{array}$

$10531 \quad 1510496 \quad 42 \quad 2100 \quad 87 \quad 34 \quad 6 \quad 6112109 \quad 5-10139112 \quad 25-10137134923614412585$

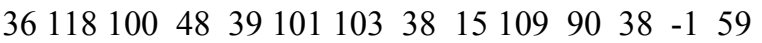

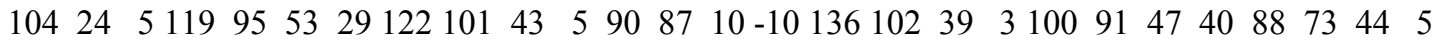
$\begin{array}{lllllllllllll}67 & 64 & 22 & -3 & 67 & 66 & 19 & 23 & 36 & 32 & 15 & 6 & 43\end{array}$

$10123 \quad 8117104562311310050 \quad 5119104 \quad 31 \quad-7134116 \quad 17-17135136412313711465$ $\begin{array}{lllllllllllllll}48 & 55 & 62 & -9 & -38 & 76 & 79 & 60 & 57 & 59 & 32 & 2 & -7 & 62\end{array}$

$\begin{array}{lllllllllllllllllllllllllll}103 & 39 & 9 & 108 & 93 & 38 & 7 & 123 & 95 & 36 & -4 & 128 & 101 & 37 & 10 & 137 & 114 & 41 & -4 & 99 & 103 & 61 & -3 & 118 & 109 & 59 & 33\end{array}$ $\begin{array}{llllllllllllll}96 & 81 & -2 & -31 & 80 & 74 & 17 & -5 & 123 & 105 & 42 & 22 & 76\end{array}$

$10429 \quad 8120117421911410856459491261411210824 \quad-5108101513011311368$ $\begin{array}{llllllllllllll}57 & 94 & 94 & 36 & -9 & 76 & 73 & 8 & 3 & 92 & 66 & 17 & -12 & 50\end{array}$

$1002914110100 \quad 38 \quad 0124106 \quad 48 \quad-3120110 \quad 19 \quad-515012173 \quad 411099367 \quad 5093 \quad 68 \quad 4121$ $\begin{array}{llllllllllllll}56 & 51 & -2 & -32 & 69 & 61 & -8 & -35 & 78 & 77 & 41 & 19 & 70\end{array}$ 


\title{
ANEXO 3
}

\section{EJEMPLOS DE GRÁFICAS}

Para cada estación de la RED PALINOCAM y para el periodo 1994-2008 se incluye una hoja con tres gráficas:

1. Serie de datos diarios de concentración media de polen de plátano (granos de polen $/ \mathrm{m}^{3}$ de aire)

2. Polen total anual de plátano (PTA) y promedio del periodo 1994-2008

3. Estación polínica de plátano, días de inicio, pico y final

Estaciones de la RED PALINOCAM (en amarillo las que se representan)

\author{
Alcalá de Henares \\ Alcobendas \\ Aranjuez \\ Coslada \\ Ciudad Universitaria \\ Getafe \\ Leganés \\ Barrio de Salamanca \\ Collado-Villalba
}




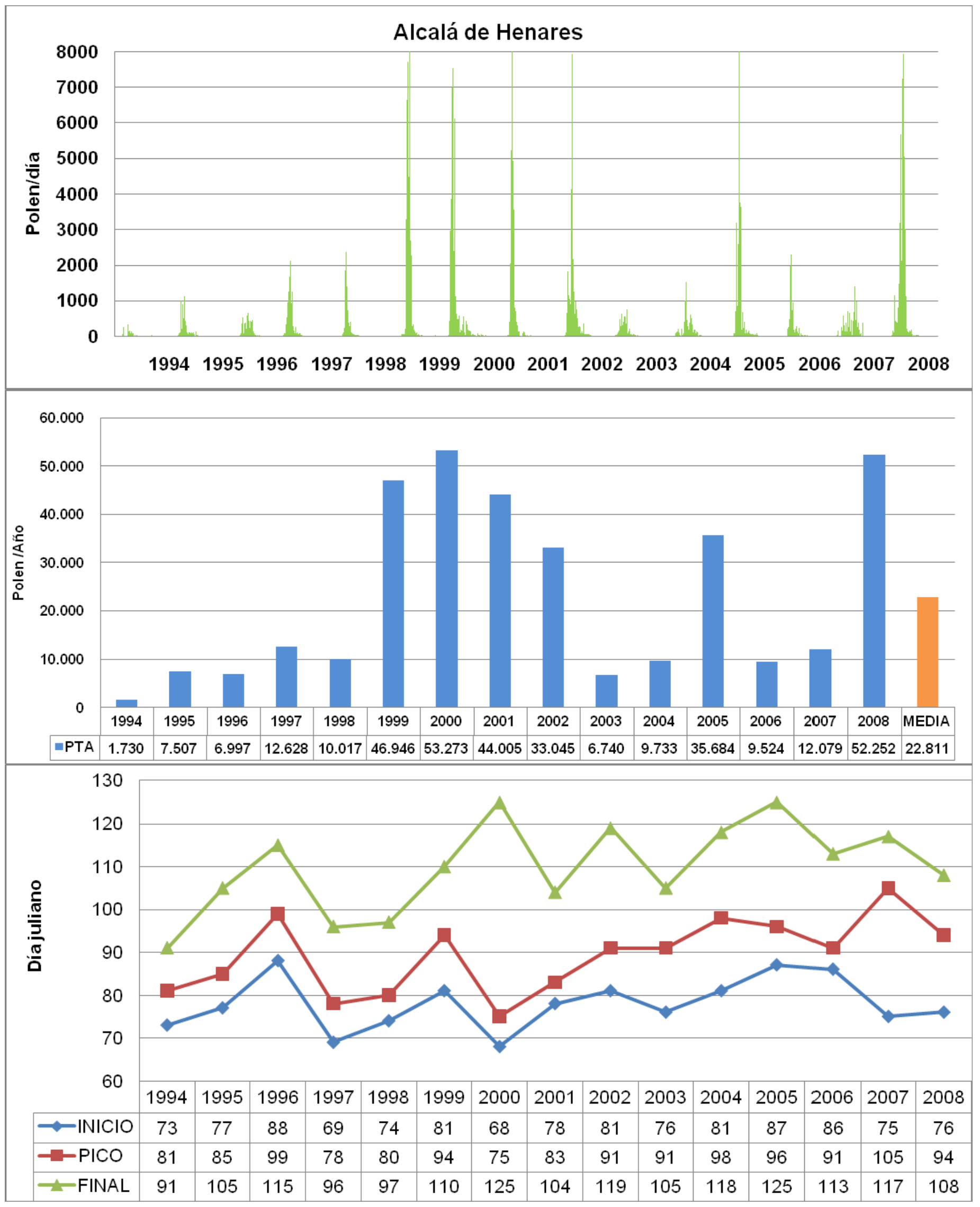




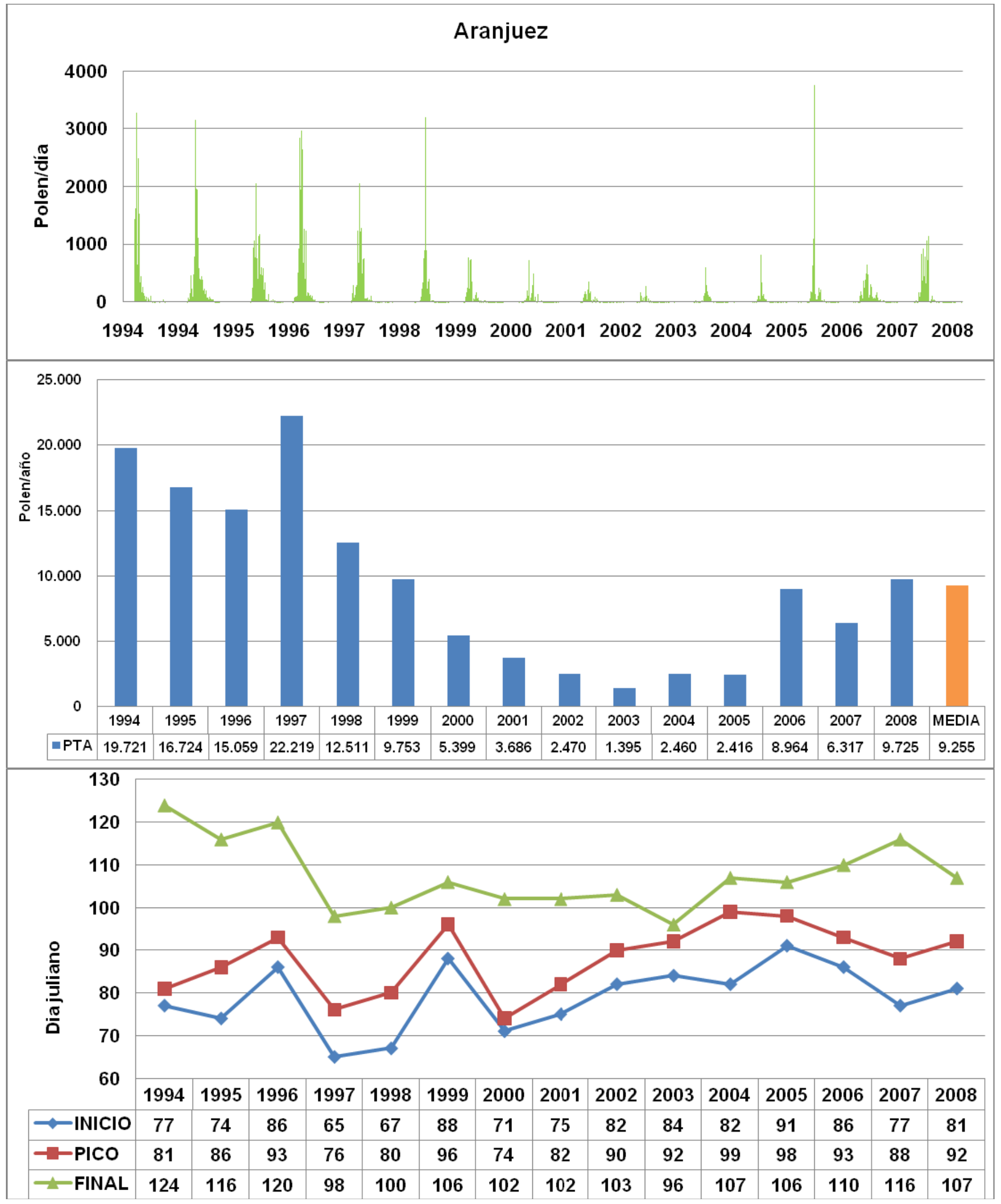




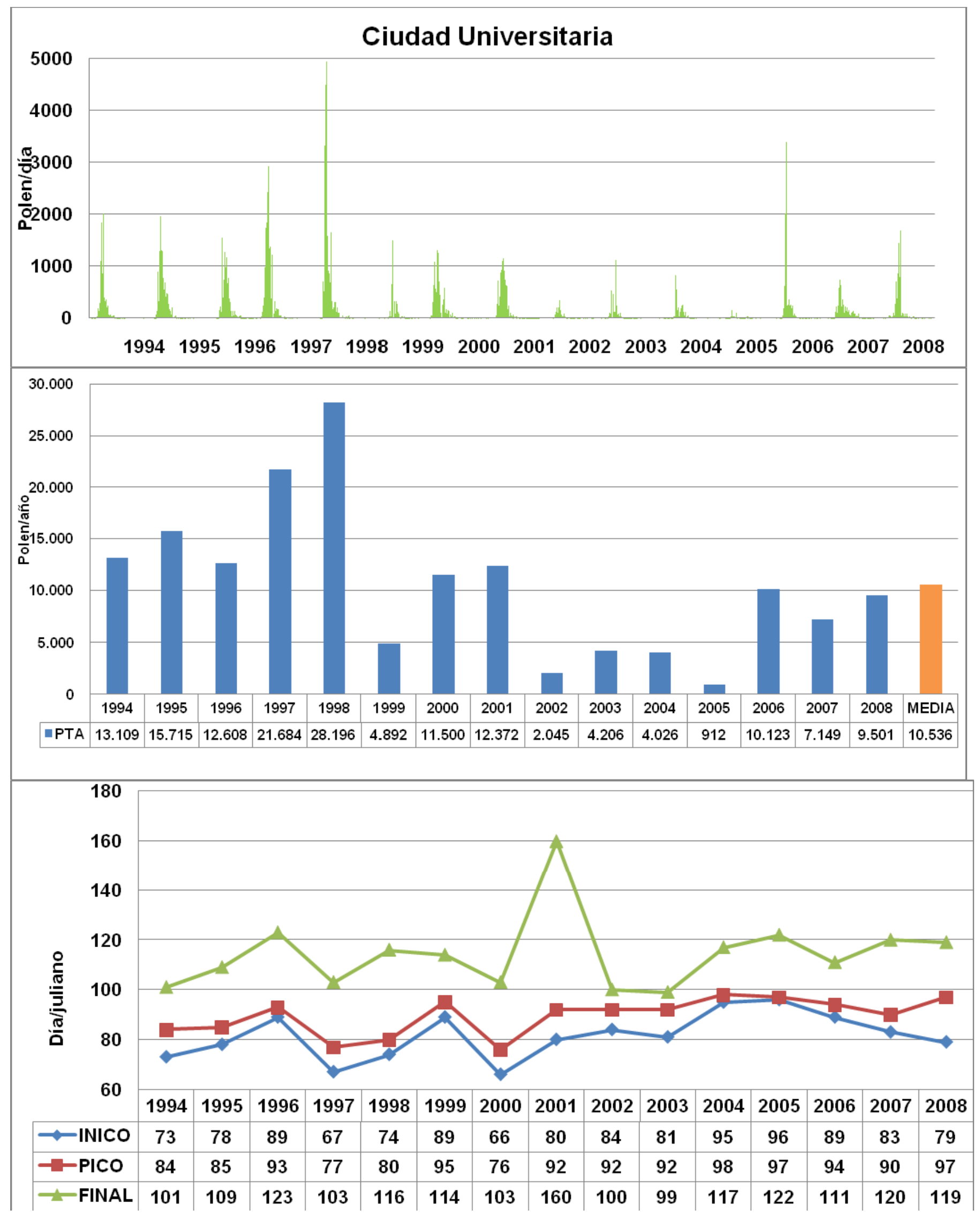

